\title{
Hydrogen as a Transportation Fuel: \\ Costs and Benefits
}

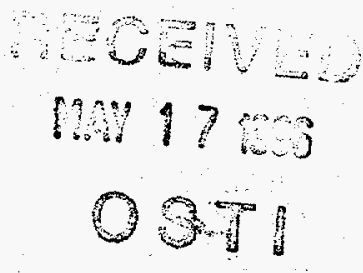

\author{
Gene D. Berry
}

\section{March 1996}

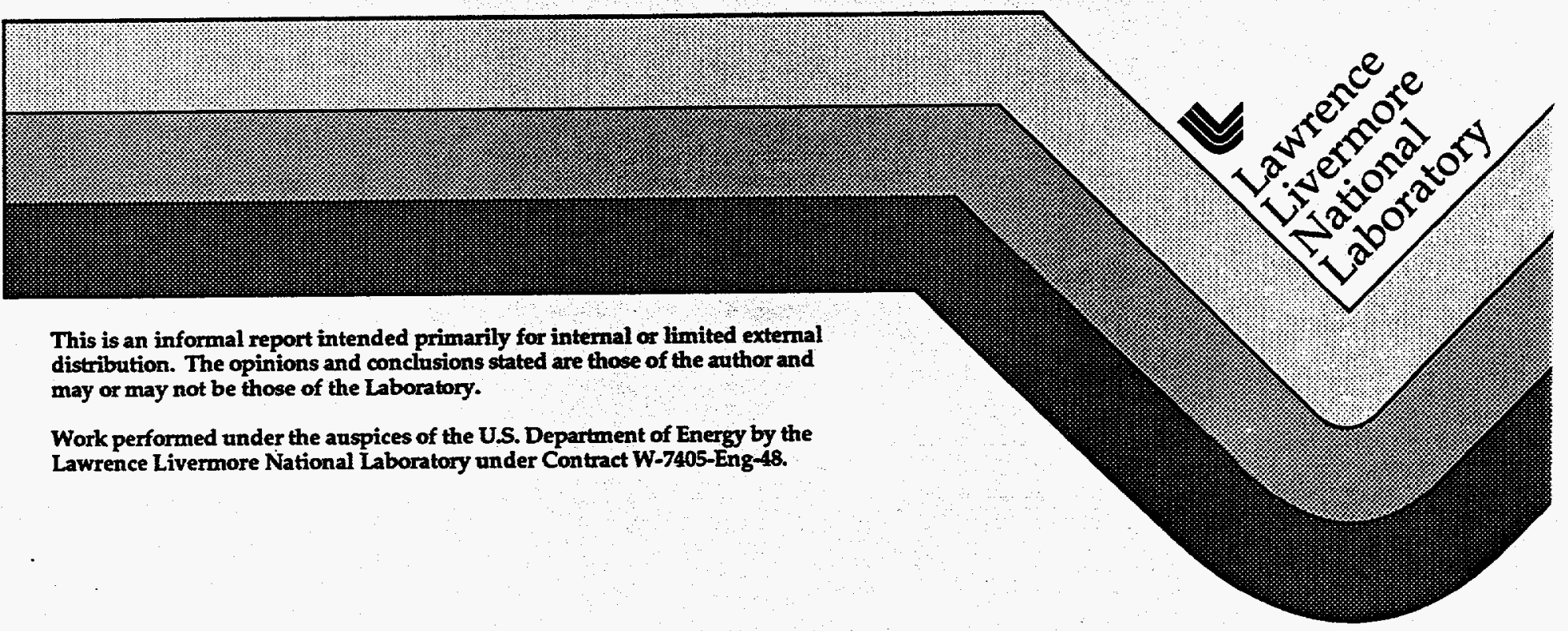




\section{DISCLAMMER}

This document was prepared as an account of work sponsored by an a $\mathrm{v}$ of the United States Government. Neither the United States Government nor the University of California nor any eir employees, makes any warranty, express or implied, or assumes any legal liability or responsibility for the :aracy, completeness, or usefulness of any information, apparatus, product, or process disclosed, or represents thia its use would not infringe privately owned rights. Reference herein to any specific commercial product, process, or service by trade name, trademark, manufacturer, or otherwise, does not necessarily constitute or imply its endorsement, recommendation, or favoring by the United States Government or the University of California. The views and opinions of authors expressed herein do not necessarily state or reflect those of the United States Government or the University of California, and shall not be used for advertising or product endorsement purposes.

This report has been reproduced directly from the best available copy.

Available to DOE and DOE contractors from the Office of Scientific and Technical Information P.O. Box 62, Oak Ridge, TN 37831

Prices available from (615) 576-8401, FTS 626-8401

Available to the public from the National Technical Information Service

U.S. Department of Commerce

5285 Port Royal Rd.

Springfield, VA 22161 


\section{DISCLAMMER}

Portions of this document may be illegible in electronic image products. Images are produced from the best available original document. 


\section{Contents}

Executive Summary

Page

Background

I. Introduction 9

A. Goals and Issues

1. Issues for Hydrogen-fueled Vehicles 10

a. Competing Alternative Fuels and Vehicles 10

b. Hydrogen-powered Vehicles $\quad 11$

c. Vehicle Efficiency and Onboard Storage Determine Hydrogen's Value 13

d. Vehicles Influence Infrastructure Scale, Shape, and Feasibility 13

2. Infrastructure Considerations for Alternative Fuels 14

3. Infrastructure Considerations for Hydrogen 16

a. Infrastructure Is the Bottleneck $\quad 16$

b. Options Beyond Today's Conventional Fuel Infrastructures 16

c. Unique Infrastructure Can Distinguish Hydrogen from Other Fuels 17

d. Comparing Infrastructures: Scale, Market Size, and Economic Risk) 17

4. A Plausible Beginning: Start Small and Deliver a Feasible

Equivalent Zero Emission Vehicle $\quad 19$

B. Approach and Methodology 20

1. Model Description and Methodology for This Study 20

2. Examination of Cost, Efficiency, and Ful- Cycle Emissions for a Range of Pathways

3. Conservative Economic and Technical Assumptions and Units Methodology

II. Delivered Hydrogen Costs 23

A. Centralized Infrastructure $\quad 23$

1. Production $\quad 23$

2. Transmission and Distribution of Hydrogen 24

a. Hydrogen Delivered by Truck 24

b. Mobile Hydrogen Storage System Costs 25

c. Transport Equipment and Operating Costs of Hydrogen Delivery by Truck

d. Energy Cost of Hydrogen Storage $\quad 26$

e. Compression and Liquefaction Costs 26

f. Total Cost of Hydrogen Delivery by Truck $\quad 27$

3. Centralized Production of Hydrogen Carriers $\quad 27$

a. Methanol Synthesis $\quad 28$

b. Methanol Decomposition $\quad 28$

c. Ammonia Synthesis $\quad 29$

d. Ammonia Decomposition 29 
B. Decentralized Infrastructure $\quad 30$

1. On-Site Hydrogen Production 30

2. Hydrogen Pathways and Refueling Scenarios for Stations, Fleets, and Individual Vehicles

3. Delivered Hydrogen Cost Estimates for Stations, Fleets, and Homes

III. Energy and Emissions for Vehicles using Hydrogen from Natural Gas

A. Primary and Process Energy Requirements for Hydrogen Production, Delivery, and Storage

B. Greenhouse Gas Emission Comparison of Hydrogen and Other Fuels for Hybrid Vehicles

C Tailpipe and Fuel-Cycle Emissions from Hydrogen and Other Alternative Fuel Vehicles

IV. Electricity-Generation Mix Changes and Impacts on Pathway Emissions

A. Three Scenarios of Greenhouse-Gas Emissions for Hydrogen Pathways in $\mathbf{2 0 3 0}$

B. Three Scenarios of Air Pollutant Emissions for Hydrogen

Pathways in $\mathbf{2 0 3 0}$

V. Benefits and Evaluation of a Transition to Hydrogen Vehicles

A. Charting a Transition to Hydrogen Vehicles

B. Benefits of Transitions to Hydrogen and Other Advanced Vehicles

1. Reduced Oil Use

2. Air-Pollutant and Greenhouse Gas Emission Reductions

C Maximum Credible Oil Use and Emissions-Reduction Benefits of Hydrogen Vehicles

D. Additional Potential Benefits of Hydrogen Vehicles

VI. Conclusions

A. Efficiency and Economics $\quad 47$

B. Urban Air Pollution 48

C. Greenhouse-Gas Emissions $\quad 48$

D. Other Benefits of Hydrogen Vehicles 48

E. General Conclusions 49

1. Hydrogen Is Affordable 49

2. Renewable Electricity Makes the Case Stronger 49

3. Onboard Storage Benefits 50 
VII. Recommendations and a Transition Scenario

A. Need for Technology Development and Validation

B. Need for System Studies

C. A Proposed Transition Scenario

$\begin{array}{ll}\text { Acknowledgments } & 54\end{array}$

$\begin{array}{ll}\text { References } & 55\end{array}$

Appendix A: Meeting National Energy Policy Goals with Hydrogen Energy

Appendix B: Technical and Economic Summaries of Hydrogen Pathways

Liquid Hydrogen Station Parameters $\quad 62$

Liquid Hydrogen Small Station Parameters $\quad 62$

Liquid Hydrogen Fleet Refueling Parameters 63

Compressed Gas Station Parameters $\quad 63$

Compressed Gas Small Station Parameters 64

Compressed Gas Fleet Refueling Parameters 64

Pathway 1: Central Steam-Reforming/ $\mathrm{LH}_{2}$ Delivery , 65

Pathway 2: On-site Station Steam-Reforming/Compressed $\mathbf{H}_{2}$

Pathway 3: On-site Station Methanol Decomposition/Compressed $\mathrm{H}_{2} \quad 67$

Pathway 4: On-site Station Ammonia Decomposition/Compressed $\mathrm{H}_{2} \quad 68$

Pathway 5: On-site Station Alkaline Electrolysis/Compressed H2 69

Pathway 6: On-site Station Polymer Membrane Electrolysis/Compressed $\mathbf{H}_{2} \quad 70$

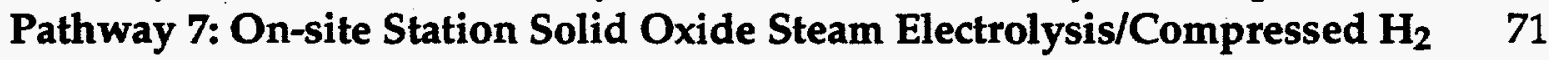
Pathway 8: Residential Electrolysis/(Hydride Compressor)/Low Pressure $\quad 72$

$\begin{array}{ll}\text { Appendix C: Figures and Captions } & 73\end{array}$ 


\section{Executive Summary}

Hydrogen fuel and vehicles are assessed and compared to other alternative fuels and vehicles. The cost, efficiency, and emissions of hydrogen storage, delivery, and use in hybrid-electric vehicles (HEVs) are estimated. Hydrogen made thermochemically from natural gas and electrolytically from a range of electricity mixes is examined. Hydrogen produced at central plants and delivered by truck is compared to hydrogen produced on-site at filling stations, fleet refueling centers, and residences. The impacts of hydrogen HEVs, fueled using these pathways, are compared to ultra-low emissions gasoline internal-combustion-engine vehicles (ICEVs), advanced batterypowered electric vehicles (BPEVs), and HEVs using gasoline or natural gas.

High-efficiency vehicles make hydrogen fuel affordable. Our conservative cost estimates (e.g., $20 \%$ discount rate, $\$ 0.05 / \mathrm{kWh}$ off-peak electricity) indicate that many hydrogen production and delivery options are affordable with efficient hydrogen vehicles. Depending upon production and distribution method, hydrogen will cost $\$ 30-50 / \mathrm{GJ}$ at filling stations or $4.5-7.5$ cents $/ \mathrm{mile}$ in an 80-mpg hydrogen vehicle. Hydrogen fuel appears affordable even at very small scales ( $\$ 70 / \mathrm{GJ}$ or 10 cents/mile for single-vehicle electrolysis).

Efficient vehicles create an economically plausible transition to hydrogen vehicles using any or all of the hydrogen production and delivery pathways we examined. Cost differences among production and delivery pathways will amount to only $\$ 120-\$ 360 / \mathrm{yr}$ in efficient ( $\sim 80$-mpg-equivalent) hydrogen vehicles, negligible in comparison to vehicle lifecycle costs (45 cents/mile or $\$ 5400 / y r)$. Such small cost differences allow a transition strategy for hydrogen vehicles to go beyond fuel cost to include broader, more comprehensive criteria and long-term vision.

Efficient fossil-fueled vehicles with advanced emission controls will weaken the urban air pollution case for hydrogen, making other benefits crucial. Although using hydrogen fuel has end-use advantages (efficiency, emissions), these will be marginal if efficient fossil-fuel vehicles are built well below the ULEV standards. It appears the rationale for hydrogen vehicles will have to expand beyond fuel cost and tailpipe emissions, focusing on the full range of benefits available from hydrogen-fueled vehicles. Realization of benefits that are indirect, synergistic, or conditional will be crucial to a robust rationale for hydrogen vehicles.

The largest and most unique benefit from hydrogen vehicles is the potential to create a large flexible electricity demand, enhancing the economic efficiency of the utility sector and permitting large-scale implementation and integration of renewable resources by 2030. The strongest and most strategic advantages of hydrogen come from its ability, unique among alternative fuels, to be made electrolytically from water when and where needed, at 
almost any scale. Electrolytic hydrogen for 200 million cars would create a large, flexible electricity demand ( $30 \%$ of electricity production). This demand would enable utilities to convert excess electricity or capacity into a useful high-value product-hydrogen fuel-and thus to increase the revenue per power plant and add to the projected $\$ 200$ billion/yr electric utility market. This flexible demand would permit renewable energy sources to contribute more feasibly to the nation's electricity mix, gaining the environmental benefits of renewable electricity while circumventing the disadvantages of intermittent and fluctuating renewable energy sources.

A robust case for hydrogen fuel requires a plausible beginning and a transition that ultimately delivers all the benefits of using hydrogen fuel in vehicles. The essentials for such a transition exist based upon high-efficiency hydrogen vehicles ( $80 \mathrm{mpg}$ equivalent). When first introduced, hydrogen vehicles will be an improvement over BPEVs produced to meet zeroemission vehicle (ZEV) regulations. The chicken-and-egg dilemma facing vehicle manufacturers and fuel suppliers can be resolved through production of small-scale hydrogen generation and storage equipment, manufactured at rates in coordination with hydrogen vehicle production rates. On-site fuel production can guarantee fuel availability for fleets and perhaps homes. Later, when vehicle numbers can support filling stations, refueling costs will be comparable to gasoline fueling costs today, using hydrogen generated from natural gas or off-peak electricity, and ultimately using renewable or nuclear sources (fission or eventually fusion). Both renewable electricity and fuel cells can develop in parallel with the transition to hydrogen fuel and to advanced hydrogen technologies over the 30 years needed for developing a significant fraction (30-50\%) of the 200-million-vehicle passenger car fleet that is fueled by hydrogen. 


\section{Background}

Although the concept of hydrogen as a vehicle fuel is virtually unknown to the general public, hydrogen use is widespread and well established. In the future hydrogen can be a clean, flexible, and ubiquitous synthetic fuel. As one of the most basic and important industrial chemical commodities, hydrogen is crucial to many chemical processes supporting modern industrialized society. It is a necessity in the production of ammonia, urea, methanol, higher alcohols, and hydrochloric acid. Hydrogen is critical in the reduction of metals and in the processing of petroleum, plastics, and food oils. Hydrogen can be efficiently used by catalytic or flame combustion or in fuel cells to produce transportation energy, electricity, work, heat, and high-purity steam or water.

Hydrogen fuel best meets the most recent consensus on energy policy goals for the nation. The Energy Policy Act of 1992 established goals for energy research and development. In 1995 these goals were echoed by President Clinton's Sustainable Energy Strategy. Hydrogen fuel, vehicles, and production technology can best achieve these goals, far more comprehensively and with greater flexibility and consistency than other options. (See Appendix A).

The technologies required to produce, store, and use hydrogen have been proven technically feasible and can be highly efficient, but they have not yet been mass produced in sufficient quantity to achieve overall costs as low as the direct costs of today's fossil-fueled energy systems. The case for hydrogenbased energy systems will strengthen, however, as the security, trade imbalance, pollution, health, and environmental costs incurred by protecting, extracting, shipping, storing, and burning fossil fuels rise with time.

The strongest case for hydrogen as an energy carrier is in high-value markets with large public benefits from replacing fossil-based systems. Hydrogen vehicles represent, by far, the most economically feasible use of hydrogen with the greatest benefits. The highest-value mass market is personal transportation, particularly buses and light-duty vehicles, where fuel is a small fraction of total life-cycle costs $(-10 \%)$.

Hydrogen-fueled buses, cars, and light trucks would capture the large and widespread public benefits that flow from replacing gasoline vehicles. These benefits include the reduction of oil imports and associated environmental pollution, the elimination of automotive air pollution, which will improve urban air quality, and the elimination of fuel cycle and greenhouse gas emissions if hydrogen is made from nuclear or renewable energy sources.

These benefits are very attractive, but other alternative fuel/vehicle options can deliver some of these benefits as well. A robust rationale for hydrogen vehicles must take competing alternative-fuel and vehicle technologies into 
account. This study assesses hydrogen-fueled vehicles and compares them to conventional gasoline internal combustion engine vehicles (ICEVs), hybrid electric vehicles (HEVs) fueled by gasoline or natural gas, and battery-powered electric vehicles (BPEVs). The results of these comparisons, combined with a monetary valuation of the benefits, show the hydrogen pathways, technologies, and policy priorities that will make the strongest case for hydrogen fuel and vehicles and enable the formulation of a sound transition strategy to hydrogen-fueled vehicles.

It will require until 2005 to introduce advanced/altemative-fuel vehicles, and an additional 30 years to complete a transition. This is the context in which comparisons should be made. A gasoline-powered passenger car fleet achieving 30-mpg average fuel efficiency and meeting Ultra-Low Emission Vehicle (ULEV) standards represents the baseline for comparison. Oil use and emissions reductions are the major criteria for comparison. When comparing hydrogen vehicles by these criteria, it is important that the cost, energy efficiency, and emissions associated with the full range of hydrogen production and distribution pathways be considered over this time period. 


\section{Introduction}

\section{A. Goals and Issues}

Hydrogen possesses the greatest diversity of production, storage, and utilization methods of any fuel. This diversity creates strategic versatility in achieving the scale, overall efficiency, environmental quality, and economic objectives necessary to justify a transition to hydrogen vehicles. Unparalleled flexibility, however, means a large number of tradeoffs are involved when choosing a particular hydrogen energy pathway from production to end use. Understanding the relative desirability of various production, distribution, and end-use options requires wider knowledge and broader exploration of alternative technologies and market structures than for fossil fuels. This is especially true from a strategic perspective because significant technological, market, and regulatory developments can be expected over the next 20 to 30 years. The tradeoffs involved in a particular pathway generally take the form of a balance between hydrogen's two dominant characteristics:

(1) Many potential benefits. Hydrogen fuel combines unparalleled supply flexibility, energy security, end-use efficiency, cleanliness, and versatility with unmatched potential for sustainability (using renewable electricity from wind, hydro, or solar energy), safety (using metal hydride storage), and widespread use of fluctuating or intermittent sustainable energy resources.

(2) A spectrum of costs to achieve those benefits. Thermochemical hydrogen (from fossil or biomass sources) is typically lower cost, capturing the end-use benefits of using hydrogen fuel. Electrolytic hydrogen is more expensive but also eliminates hydrogen transmission and distribution difficulties, enabling easy decentralization and sustainability (when using renewable electricity).

There are a wide variety of potential pathways and attendant rationales for hydrogen reflecting different balances among these benefits and costs. The less expensive routes to hydrogen generally lack some of the advantages that provide a strong rationale for hydrogen vehicles over other alternative fuel/vehicle combinations. Pathways that capture all of hydrogen's potential benefits as a fuel usually require greater investment.

With these factors in mind, we have examined an extended range of production/storage/delivery pathways for hydrogen vehicles, even if fuel costs are somewhat higher than for other options, to assess a wide range of possibilities in the search for the strongest overall rationale for hydrogen vehicles. In addition to hydrogen delivery by truck, we consider on-site hydrogen production using electricity, natural gas, methanol, and ammonia. We also consider the possibility of hydrogen production at very small scales, down to the individual vehicle level. 


\section{Issues for Hydrogen-fueled Vehicles}

Before examining hydrogen production/storage/delivery pathways, we discuss the issues surrounding vehicles and infrastructure, and rationales for hydrogen fuel, to provide context for the various costs and emissions estimates and comparisons, and their implications for a sound transition strategy.

\section{a. Competing Alternative Fuels and Vehicles}

No fuel, including hydrogen, is the clear alternative to gasoline on the basis of all relevant criteria. Even when a consensus is reached that current gasoline-powered vehicles are no longer the best option, a new debate emerges among the alternative fuels and the vehicles competing to replace gasoline. Figure 1 is a schematic representation of how hydrogen vehicles relate to the infrastructure and environment. A rationale is composed of a balance among (1) the costs of hydrogen fuel, infrastructure, and onboard storage to provide a vehicle of sufficient value to consumers, (2) the public benefits (emissions, energy security, improved economic efficiency of potential fuel suppliers, environmental impact, sustainability), and (3) alternative fuel transition criteria, such as a smooth, flexible transition (involving fuel infrastructure scale and shape, and assured fuel availability). These three components of a rationale, in turn, depend on a range of technical, economic, and policy factors and are interconnected. Various alternative-fuel/vehicle choices can each be compelling under a different set of priorities and reasons for moving away from the problems of gasoline. A rationale for each alternative-fuel vehicle depends upon priorities, future vehicle technology, and market demands.

The rationale for hydrogen vehicles is most compelling when increased priority is given to the public benefits of alternative-fuel vehicles, and moderate vehicle range is demanded. Hydrogen is a high cost-but high value-fuel. Hydrogen can be more sustainable, cleaner, and more efficiently utilized than natural gas or methanol; but among alternative fuels, only batteries are heavier and more expensive than the on-board storage systems for hydrogen. The best niche for hydrogen fuel exists for vehicles with range and performance similar to today's vehicles (200-400 miles). If range or performance requirements are relaxed, battery-powered electric vehicles (BPEVs) begin to compete with hydrogen vehicles, both on consumer cost and policy criteria (energy security, urban air pollution, and sustainability). For vehicles with very long range ( $>400$ miles), hydrogen compares unfavorably to higher-energy-density fuels such as natural gas and methanol. (Hydrogen will have significantly higher storage costs, weights, and volumes, in addition to fuel cost.) Consequently, a major premise of hydrogen vehicles is that consumers will require and be satisfied with a $200-400$ mile range. 


\section{b. Hydrogen-Powered Vehicles}

Not all classes of hydrogen vehicles can fill hydrogen's niche better than other alternatives. There are three major ways to employ hydrogen in vehicles. (1) Hydrogen can be burned in internal combustion engine vehicles (ICEVs) essentially as gasoline vehicles operate today. (2) Alternatively, electricity can be generated onboard in a fuel cell electric vehicle (FCEV) at very high efficiency. (3) The third option is a hydrogen-fueled hybrid-electric vehicle (HEV), which burns hydrogen only at peak efficiency in a small internal combustion engine to generate electricity when needed. Each option will be briefly examined and compared to alternatives to find the most suitable option upon which to base a transition strategy (and infrastructure requirements).

Option 1: Conventional Internal Combustion Engine Vehicles. Burning hydrogen in today's internal combustion cars is too costly, bulky, and heavy, because the vehicle efficiency is too low and too much hydrogen is required for a moderate range. Simple calculation shows that a 30 -mpg-equivalent hydrogen car would require $10 \mathrm{~kg}$ of hydrogen to travel 300 miles. If the hydrogen were stored (relatively compactly) as a liquid (density $=0.0708$ $\mathrm{kg} /$ liter), it would have a volume of 37 gallons. The multilayered insulation cryogenic tank would take up at least another 13 gallons, yielding a 50-gallon external volume fuel tank. Hydrogen storage as a gas would take even more space (175 gallons at $3600 \mathrm{psi}$ ). Hydrogen can be compactly stored in metal hydrides, but the lightest and cheapest hydride $\left(\mathrm{MgH}_{2}\right)$ would weigh more than $130 \mathrm{~kg}$ with at least $70 \mathrm{~kg}$ of auxiliary equipment. These problems could be reduced by a factor of 3 (to manageable levels) by reducing the range between fill-ups to 100 miles, which would require $3.3 \mathrm{~kg}$ of hydrogen. Optimistic estimates are that hydrogen at a small or medium-size fuel station would cost $\$ 20-25 / G^{1}$ ( $\$ 2.50-\$ 3.13$ per gallon gasoline equivalent), resulting in a 100-mile fill-up costing $\$ 8-\$ 10$. This is very expensive in comparison to similar-range BPEVs, especially with advanced lightweight batteries. Finally, the low efficiency of conventional ICEVs would make hydrogen vehicles inferior to high-energy-efficiency BPEVs on lifecycle emissions and environmental grounds.

Option 2: Fuel Cell Electric Vehicles. The bulky fuel tank problem and the high costs of both tank and fuel could be solved through the high fuel efficiency of FCEVs. Replacing today's 15\% efficient (over the driving cycle) internal combustion engine with a 50\% efficient fuel cell gains a factor of 3 in fuel economy and range. The resulting $-90-\mathrm{mpg}$-equivalent hydrogen car could afford hydrogen costs of $\$ 3.75 /$ gallon energy equivalent ( $\$ 30 / \mathrm{G})$ and still equal today's fuel costs (4.2 cents/mile). Unfortunately the cost of the fuel cell to make all this feasible is currently too high. Fuel cells were originally developed for the U.S. space program and are principally used in military and submarine applications, where cost is not a leading concern. Experimental proton exchange membrane (PEM) fuel cells have advanced to achieve power 
densities ( $1 \mathrm{~kW} /$ liter and $0.7 \mathrm{~kW} / \mathrm{kg}$ ) suitable for automobiles, ${ }^{2}$ but automotive-size fuel cells are still expensive. Cost projections are on the order of $\$ 250 / \mathrm{kW}$ in mass production. ${ }^{3}$ Today's mass-produced gasoline engine and drivetrain costs are much lower $(\$ 20 / \mathrm{kW}) .4$

Option 3: A Proposed Hydrogen Hybrid-Electric Vehicle. A hybrid-electric vehicle avoids the high cost of fuel cells but still achieves very high fuel-towheels efficiency $(40 \%)$. Aceves and Smith have recently described a conceptual design for a practical hydrogen-fueled HEV with adequate range ${ }^{5}$ (Fig. 2.) This vehicle weighs about $1300 \mathrm{~kg}$ and is designed to accelerate from 0 to $96 \mathrm{~km} / \mathrm{h}(60 \mathrm{miles} / \mathrm{h})$ in 10 seconds. It would burn hydrogen in a small optimized internal combustion engine $(40 \mathrm{~kW})$ to run a generator charging an electrical storage system that in turn powers an electric motor to drive the wheels. The engine runs intermittently at a constant speed and maximum efficiency $(\sim 45 \%)$ with enough power to climb long hills at $96 \mathrm{~km} / \mathrm{hr}$. The electrical storage system ( $1 \mathrm{kWh}$ of flywheels, batteries, or ultra-capacitors) is optimized for acceleration and stores enough energy for 7-8 miles of normal driving, recharging enroute when necessary. The car carries about $3.75 \mathrm{~kg}$ of hydrogen, enough for a 480-km (300-mile) range. Using a chassis with low aerodynamic drag, rolling resistance, and cross-sectional area similar to the demonstrated GM Impact III (soon to be sold as the GM EVI), the vehicle has the gasoline energy equivalent mileage of $95 \mathrm{mpg}$. If redesigned for five passengers, $80 \mathrm{mpg}$ is achieved. Ford displayed a remarkably similar concept car, the Synergy 2010, exploring hybrid vehicle technologies, such as flywheels, regenerative braking, and lightweight materials (aluminum), at the North American International Auto Show on January 6-15, 1996. The Synergy 2010 was quoted as seating six people with "triple the fuel efficiency of a typical family sedan" (approximately $80 \mathrm{mpg}$ ). ${ }^{6}$

Of the three major types of hydrogen vehicles, FCEVs are the ideal technical choice for hydrogen-powered vehicles, and fuel cells should eventually replace the hydrogen combustion engine-generator in HEVs. Fuel cell vehicles operate at the highest efficiencies, producing zero emissions. However, until fuel cells are low cost, the piston-engine hybrid vehicle can be the near-term forerunner of the fuel-cell-powered vehicle, providing a mass market and developing the infrastructure for FCEVs earlier than otherwise possible.

Since HEVs can fill the niche for hydrogen vehicles without awaiting the development of cost-effective fuel cells, the baseline hydrogen vehicle used in our analysis is a five-passenger hybrid-electric vehicle, with peak power electrical storage for acceleration: It achieves $80-\mathrm{mpg}$ equivalent energy efficiency on the combined federal driving cycle, with a range of 300 miles. Stored onboard are $3.75 \mathrm{~kg}$ of hydrogen (125 kWh or $0.45 \mathrm{GJ}$ on a lower heating value basis); however, increasing the onboard hydrogen to $4.75 \mathrm{~kg}$ would provide a 380 -mile range, thus meeting the goals of the Partnership for 
a New Generation of Vehicles (PNGV) for fuel efficiency and range. Figure 3 displays the volumes, weights, and energy requirements of various onboard hydrogen storage systems. Figure 4 shows fueling costs as a function of gasoline-energy-equivalent mileage. These figures demonstrate the feasibility of onboard storage and the importance of fuel efficiency in hydrogen vehicles. High fuel efficiency is necessary to reduce fuel costs and the size, weight, and cost of on-board hydrogen storage to reasonable levels. High fuel efficiency is probably the single most important factor in creating a hydrogen vehicle with sufficient consumer value and appeal.

\section{c. Vehicle Efficiency and Onboard Storage Determine Hydrogen's Value}

A product's value usually depends upon how well it is used. In the case of hydrogen fuel, the value of a transition to hydrogen vehicles and the relative advantages of various hydrogen pathways revolve around how well and easily vehicles can use hydrogen. This depends upon onboard storage in addition to fuel efficiency. Using hydrogen efficiently in vehicles enhances the value of hydrogen pathways, delivery infrastructures, and onboard storage systems. Onboard hydrogen storage systems, in turn, determine the ease of refueling and the delivery infrastructures that are feasible. Infrastructure choices, in turn, can influence the availability of hydrogen, the ease of a transition from gasoline, and broader benefits such as supply flexibility and synergy with existing energy infrastructures. All of these consequences flow from the choice of vehicle range and implied onboard storage. Very high vehicle range ( $>400$ miles), even with high efficiency, constrains onboard hydrogen storage choices, implied infrastructure, and efficiency.

Onboard storage is crucial, not only because of the hydrogen production/delivery pathway consequences, but also in comparing hydrogen vehicles to other alternative-fuel vehicles. Hydrogen can be stored onboard in compressed gas cylinders, cryogenic tanks, or as metal hydrides. All hydrogen storage choices involves greater bulk, weight, cost, and/or energy requirements than for other alternative fuels (e.g., natural gas or methanol). Compressed hydrogen is somewhat more expensive, and three times more bulky, than compressed natural gas. Liquefying hydrogen can increase hydrogen storage density but raises questions of the cost, dormancy, and energy efficiency of liquid hydrogen $\left(\mathrm{LH}_{2}\right)$. Fortunately, the diversity of hydrogen storage technologies that are practical in high-efficiency vehicles can enhance hydrogen vehicles in other ways. For example, hydrogen stored in metal hydrides is probably safer than gasoline or any other alternative fuel, especially compressed gaseous fuels such as natural gas and propane.

\section{d. Vehicles Influence Infrastructure Scale, Shape and Feasibility}

In addition to fuel cost and efficiency, onboard storage choices can strongly influence the feasibility of starting a transition to hydrogen vehicles and can perhaps even shape the evolution towards the ultimate hydrogen production and delivery infrastructure. Early on, a few dispersed hydrogen vehicles 
necessitate small-scale fuel production, storage, and refueling facilities. Offpeak electrolysis with low-pressure hydrogen storage can achieve this easily with vehicles that use hydrides for storage. Hydride storage supports the broadest range of hydrogen production/delivery options, especially at small scales, with the clear advantage of safety and low energy requirements. Compressed gas storage offers a transition to filling stations with fast refueling. It also has the potential for blending natural gas and hydrogen, at the filling station or in the current pipeline system, thus providing greater economic and engineering flexibility in balancing air quality benefits against fuel cost and onboard storage system cost, volume, and weight. Liquid hydrogen filling stations could support a transition to a centralized fuel delivery system similar to gasoline today and support the most feasible option for onboard hydrogen storage in heavy-duty vehicles, such as trucks, trains, and aircraft.

In conclusion, a consideration of issues facing hydrogen vehicles shows that a robust rationale exists for high-efficiency hydrogen vehicles. This rationale is based on hydrogen pathways that deliver public benefits and value to hydrogen vehicle owners. Both can be enhanced, and in some cases determined, by strategic consideration of fuel efficiency, vehicle range, onboard storage, and infrastructure. High efficiency, sufficient vehicle range (200-400 miles), and an assured fuel supply infrastructure are necessary for consumer acceptance. The likelihood of an assured fuel supply infrastructure depends, in turn, on the vehicle's fuel efficiency, range, and onboard hydrogen storage. This circular and reinforcing link between vehicles and infrastructure can strengthen the rationale for hydrogen vehicles and forms the heart of infrastructure considerations for alternative fuels.

\section{Infrastructure Considerations for Alternative Fuels}

There are three important infrastructure considerations in making a transition from gasoline to an alternative fuel:

(1) An alternative fuel infrastructure will not develop without an end-use demand (e.g., vehicles). The converse is also true, leading to a classic chickenandegg dilemma faced by all prospective technological advances, especially commodities such as vehicles and fuels. Competition with established fuel/vehicle combinations will be difficult without economies of scale.

(2) Alternative fuels and vehicles should be long-term solutions, compatible worldwide and globally competitive: flexible in the face of technological advancements, supply limitations, or changing environmental and economic priorities. The risks of stranded assets and perhaps obsolete alternative fuel and vehicle industries must be minimized.

(3) Potential large-scale synergies may exist between an alternative fuel and the current energy and industrial infrastructure. 
Hydrogen vehicles are uniquely suited to replace gasoline vehicles in light of these considerations.

Hydrogen can overcome infrastructure and economy-of-scale barriers through small-scale production for small fleets or even individual vehicles. The supply versatility and small-scale production economics possible with hydrogen enable a low-risk exploration of the possibilities for an efficient, clean, and cost-effective alternative fuel before making the tremendous investments required for 200 million alternative-fuel vehicles and necessary infrastructure. No other alternative fuel can be manufactured as easily as hydrogen. Hydrogen can be produced affordably, and ultimately renewably, from all the same sources as other alternative fuels but, unlike the others, can also be made using only electricity and water, dramatically reducing environmental and resource impacts.

As the ultimate fuel, hydrogen, once established, will provide a single transition to a stable alternative fuel, protecting long-term development and investment in alternative-fuel vehicles and infrastructure. As the most versatile fuel, it still allows for continuing innovation in production, storage, and end-use technologies, maintaining competitiveness and accelerating development. Hydrogen vehicles do not preclude any primary energy source, storage, or utilization technology (e.g., combustion engines, fuel cells, catalytic combustion). Hydrogen storage options have flexibility (cryogenic liquid, compressed gas, metal hydride, chemical carrier, glass microspheres) not available using other fuels.

A single fuel transition from gasoline would circumvent the economic dislocation and infrastructure duplication arising from a succession of competing alternative-fuel transitions. Methanol and natural gas vehicles run the risk of being only partial or temporary solutions to the problems of gasoline-powered vehicles because natural gas, like oil, is a finite supply. A transition to hydrogen vehicles, on the other hand, would last for the foreseeable future.

Hydrogen vehicles also offer the potential to integrate renewable electricity, and the transportation fuel market, into the utility and possibly the ammonia industry. Electrolytic hydrogen fuel for a significant fraction of the 200 million U.S. vehicles represents a very large and conveniently flexible electricity demand, enabling maximum utilization of utility generating capacity, permitting the use of intermittent or fluctuating renewables, and perhaps using excess ammonia or production capacity for seasonal hydrogen storage. 


\section{Infrastructure Considerations for Hydrogen}

\section{a. Infrastructure Is the Bottleneck}

The challenge for hydrogen vehicles revolves around production and distribution infrastructure. The scale, production, distribution methods-and primary energy sources - of a hydrogen fuel infrastructure determine the majority of the benefits of hydrogen fuel and the case for hydrogen vehicles. Infrastructure is also the strategic bottleneck limiting the transition to hydrogen as a fuel, influencing both the absolute availability of hydrogen fuel and the cost and value of hydrogen energy when first introduced.

Hydrogen's low energy density underscores the importance of infrastructure. Hydrogen as a liquid or gaseous fuel has only 25 to $30 \%$ the energy density of gasoline and natural gas respectively. This makes the energy, capital, and operating costs of hydrogen transport and distribution important cost drivers - in some cases more important than production costs. Currently, for example, liquefaction, transport, and storage costs exceed $50 \%$ of the total costs for liquid hydrogen delivered by truck. ${ }^{1}$ Under this kind of cost structure, production methods influence hydrogen prices, not only through direct production costs but also, more importantly, through the infrastructure costs accompanying a chosen production method and scale.

Although affordable hydrogen is important, fuel cost will not limit the transition to hydrogen vehicles for cars achieving between 70 and $100 \mathrm{mpg}$ energy equivalent mileage. Conservatively high delivered-hydrogen costs of $\$ 40 /$ G (equivalent to $\$ 4.80$ per gallon of gasoline) correspond to only $4.2-6.8$ cents/mile in such vehicles (see Fig. 4). Hydrogen production also does not appear to be a limiting factor. In 1993 U.S. intentional gaseous hydrogen production was 15.8 million $\mathrm{kg} /$ day, ${ }^{7}$ enough to theoretically fuel $\sim 40$ million vehicles similar in fuel efficiency to those described earlier.

Delivery and distribution infrastructure, not production capacity, limit the transition to hydrogen fuel. Today, nearly all hydrogen is used at the point of production, in ammonia manufacture or petroleum refining. Only 0.39 million $\mathrm{kg} /$ day of hydrogen $(2.5 \%)$ are delivered through 270 miles of pipelines in the United States. Less than half that amount $(0.16$ million $\mathrm{kg}$ /day) is liquefied and therefore available for widespread distribution, representing the majority of world liquid $\mathrm{LH}_{2}$ capacity. Combined, the hydrogen delivered by pipeline and as a liquid could theoretically fuel 1.5 million vehicles. Assuming $30 \%$ of the merchant hydrogen market could be diverted for fuel, this would be enough to comfortably support the first five years of pilot production (100,000 hydrogen cars per year), but ultimately more infrastructure would be needed to fuel more than $1 \%$ of the U.S. fleet of $\sim 200$ million cars in 2050. 


\section{b. Options Beyond Today's Conventional Fuel Infrastructures}

It should not be taken for granted that the hydrogen transition is best facilitated by expanding today's hydrogen delivery infrastructure to fuel 140200 million vehicles. Today's infrastructure is either high-cost and energyintensive ( $\mathrm{LH}_{2}$ delivery by truck), serving niche markets, or else very largescale (pipelines), requiring that a transition to mass-market hydrogen vehicles have already occurred.

There are infrastructure options that take much greater advantage of hydrogen's strengths. Hydrogen can be made anywhere from widely available resources, permitting the option of a decentralized infrastructure that employs mass-produced equipment to produce, store, and deliver hydrogen at or near the point of use. On-site hydrogen production (by electrolysis or by steam-reforming natural gas) for home, fleet, and filling station refueling would eliminate transmission and distribution requirements of a conventional large-scale infrastructure.

\section{c. Unique Infrastructure Can Distinguish Hydrogen from Other Fuels}

Both vehicle and infrastructure considerations point to the conclusion that hydrogen vehicles will likely make the most sense when distinguished by offering benefits that other alternative-fuel/vehicle combinations cannot (i.e., clean vehicles with adequate range and performance; onboard storage safety advantages; a single, smooth, flexible, and ultimate fuel transition; and new markets for the existing energy infrastructure that encourage intermittent sustainable energy use in the future). Hydrogen vehicles and compatible delivery infrastructures that emphasize these unique advantages allow a broad, robust rationale based on the benefits gained by using hydrogen in exchange for its high but affordable cost. Hydrogen vehicles (and delivery infrastructures) that offer no benefits beyond other alternative-fuel/vehicle options (e.g., natural-gas vehicles) run the risk of being moderately cleaner vehicles that are not worth the additional cost.

Hydrogen can be distinguished by an adaptable infrastructure. The myriad production, storage, and use methods for hydrogen provide unparalleled strategic versatility for meeting changes in economic, efficiency, environmental quality, and other objectives. The next few decades could see more competitive electricity markets, improved electrolysis and fuel cell materials and technologies, advances in renewable energy production, rising fossil fuel prices, increasingly stringent air quality standards, clear evidence of global climate change, and incentives to reduce carbon dioxide emissions. Any or all of these developments would radically alter the desired structure of a hydrogen fuel infrastructure. Tradeoffs among various options need to be articulated and understood in developing a transition strategy.

\section{d. Comparing Infrastructures: Scale, Market Size, and Economic Risk}

Table 1 qualitatively compares hydrogen and energy distribution technologies in terms of market size, economic flexibility, safety, and construction lead 
times. ${ }^{8,9}$ The chief point to note is that off-peak electrolysis seems the best choice to begin, and perhaps to complete, the transition to hydrogen-fueled vehicles. Increasing U.S. electricity production $25 \%$ above the 3.2 trillion $\mathrm{kWh}$ projected for $2010^{10}$ would provide enough electricity to produce and deliver more than 13.6 billion $\mathrm{kg}$ of hydrogen. This could support up to 100 million hydrogen vehicles, while offering relatively small initial investment requirements, economic flexibility, and safe distribution. Any necessary changes to the existing electricity infrastructure could be performed quickly as needed. Hydrogen transport by rail, truck, or pipeline is potentially lower cost because hydrogen can be made by cheaper methods than electrolysis, but hydrogen transport per se is limited by minimum market size requirements

Table 1. Hydrogen energy transport by pipeline, rail, and truck is compared with electricity distribution and local production. Local production with offpeak electricity from the grid can produce enough hydrogen for up to 100 million hydrogen vehicles, with high relative safety, economic flexibility, and short lead times, thus providing the infrastructure for a smooth transition to hydrogen vehicles. Data for the large pipeline are cited in Ref. 8. Other hydrogen transport technologies are from Ref. 9. Railcars are assumed to carry 23,000 gallons of $\mathrm{LH}_{2}$. Tanker trucks are assumed to carry 13,000 gallons of $\mathrm{LH}_{2}$.

\begin{tabular}{|c|c|c|c|c|}
\hline $\begin{array}{l}\text { Infrastructure } \\
\text { Technology }\end{array}$ & $\begin{array}{l}\text { Vehicles } \\
\text { supported }\end{array}$ & $\begin{array}{l}\text { Economic } \\
\text { Flexibility }\end{array}$ & $\begin{array}{l}\text { Safety } \\
\text { Risk }\end{array}$ & $\begin{array}{l}\text { Lead } \\
\text { Times }\end{array}$ \\
\hline $\begin{array}{l}\text { Large pipeline } \\
(1.7 \mathrm{~m}, 24 \mathrm{GW})\end{array}$ & 40 million & low & medium & long \\
\hline Rail (60-car train) & 900,000 & medium & medium & medium \\
\hline $\begin{array}{l}\text { Small pipeline } \\
(100,000 \mathrm{~kg} / \text { day })\end{array}$ & 250,000 & low & medium & medium \\
\hline $\begin{array}{l}\text { Tanker truck } \\
\text { (1 truck) }\end{array}$ & 8500 & high & high & short \\
\hline $\begin{array}{l}\text { On-site electrolysis } \\
\text { (energy distribution } \\
\text { as electricity) }\end{array}$ & $\begin{array}{l}\text { from one car to } \\
100 \text { million }^{b}\end{array}$ & high & low & short \\
\hline
\end{tabular}

aVehicles travel an average 12,000 miles/yr, using $3.75 \mathrm{~kg} \mathrm{H}_{2}$ in a $40 \%$ efficient hydrogen-powered electric drivetrain to achieve a range of 300 miles. Number of hydrogen vehicles served assumes hydrogen transport systems are fully dedicated.

bUsing an additional $25 \%$ of 3.2 trillion kWh annual U.S. electricity production projected for 2010. Assumes $68 \%$ efficient off-peak electrolysis and an additional $10 \%$ storage energy requirements (based on the lower heating value of hydrogen produced and stored). 
and economic flexibility. In addition, fuel costs do not appear to be major issues for high mileage (70-100 mpg) vehicles (see Fig. 4), and the cost savings for centralized large-scale hydrogen production is offset by transmission, storage, and distribution costs.

Beginning the hydrogen transition not with hydrogen transmission per se but by transmitting off-peak electricity using the existing infrastructure means that investment in a new large-scale hydrogen delivery infrastructure (eventually 100-200 times its current size) need be made only if and when economically justified. Understanding the prospects for an economically sound large-scale infrastructure requires an analysis of the cost of alternatives: on-site hydrogen production using energy transmitted by high-voltage power lines or using natural gas transported by pipelines, with the centrally produced hydrogen delivered by truck.

\section{A Plausible Beginning: Start Small and Deliver a Feasible Equivalent Zero Emission Vehicle}

A transition to hydrogen could begin by starting small and by selling complete systems rather than individual components. Efficient hydrogen-powered HEVs coupled with small-scale hydrogen production and/or storage are among the most promising systems. On-site hydrogen production systems for individual homes, fleets, or fuel stations avoid the high distribution and storage cost of hydrogen by eliminating transport and large-scale storage. Investment risks are reduced as well. Manufacturers of hydrogen production equipment could quickly gain economies of scale and market certainty by mass-producing residential, fleet, and fuel-station-sized systems in numbers coordinated with automobile manufacturers and fleet operators. Vehicle manufacturers would in turn be guaranteed a fuel supply and a clean vehicle with greater range and performance than the battery-powered zero-emission vehicles (ZEVs) that are mandated to be sold in California in quantities of roughly 300,000 vehicles/yr by 2003.11 The importance of alternative-fuelvehicle range and performance has been highlighted by the delayed implementation of the ZEV mandate in California, pushing back mass production at least two years. 12 Hydrogen vehicles can easily perform well beyond the ultimate performance capabilities of BPEVs. Capital investment to begin the transition could be provided in part by utilities and/or by methanol and ammonia suppliers, who would gain a solid, new mass market for interruptible, off-peak electricity and/or excess production. 


\section{B. Approach and Methodology}

\section{Model Description and Methodology for the Study}

This study addresses a broad range of factors influencing the costs and benefits of a transition to hydrogen vehicles. A consistent set of technical, economic, and market assumptions is necessary throughout, while still maintaining the flexibility to explore the impact of alternative assumptions, hydrogen pathways, competing gasoline and alternative-fuel vehicles, changes in electric-generation mix, emissions, and other factors, especially over the 40-year timeframe of a transition from conventional gasoline vehicles.

Consequently, the costs, energy use, emissions, and other information for each hydrogen production, storage, and delivery option-as well as assumptions about vehicle fuel efficiency, transportation demand, alternative-fuel-vehicle market penetration, electric-generation mixes, and various other data assembled during this study-were incorporated into a relational database computer model, allowing scenario construction and sensitivity analysis. The result is consideration of a representative set of hydrogen pathways over a wide range of assumptions.

The software used to construct the database, pathway analyses, and scenarios is commercially available (STELLA II from High Performance Systems Inc. of Hanover, $\mathrm{NH}$ ) and employs a graphical interface. This enables simple visualization, conceptualization, and interconnection of technical, economic, or market variables. Importantly, the value of each factor and its relationship to other factors are easily modified, allowing exploration of strategic parameter spaces such as production and storage scale, efficiency, discount rate, equipment lifetimes, vehicle fuel efficiency, and transportation demand. The model therefore allows more dynamic analysis, and data can be easily updated to include new information. For this report, the model was used in calculating costs, emissions, and energy use of hydrogen production and delivery pathways and in comparing hydrogen vehicles to other alternativefuel and gasoline vehicles, and then in extending this comparison to consider the changes that will occur over the time required for a transition, both in terms of a changing electricity mix and of vehicle population and use.

The goal for this exercise was to help determine the characteristics of hydrogen pathways and vehicles that are essential to a broad, robust rationale for hydrogen vehicles.

\section{Examination of Cost, Efficiency, and Full-Cycle Emissions for Range of Pathways}

The value of various possible transitions to hydrogen fuel depend fundamentally on the efficiency, emissions, and costs of two basic approaches: 
(1) Hydrogen production at large plants using a centralized distribution and storage infrastructure.

(2) On-site hydrogen production and storage at fuel stations, fleets, or homes.

The potential benefits of a transition to hydrogen vehicles include the virtual elimination of automotive urban air pollution, the reduction of imported oil, and a more, efficient, sustainable transportation and utility sector.

Because hydrogen vehicles will have efficient electric drivetrains, fuel cost will be less important than emissions and other infrastructure considerations. A strong argument for hydrogen vehicles is the value of a single fuel transition but with broad flexibility for responding to future changes, without multiple restructuring of the light-duty fleet and refueling infrastructure.

These realities imply that the successful hydrogen pathways must maximize hydrogen's benefits and maintain flexibility, in addition to minimizing fuel cost. Consequently this study examines a broad range of hydrogen production, distribution, storage, and delivery pathways for hydrogen HEVs in terms of fuel costs and energy efficiency, oil import reductions, full fuel-cycle emissions, and the advantage of a single, smooth, flexible, and ultimate transition to a fuel that's clean, secure, and sustainable.

\section{Conservative Economic and Technical Assumptions and Units Methodology}

Hydrogen cost estimates depend in large measure on energy or feedstock costs, capital equipment discount rates, and off-peak electrolysis schedules. Throughout, this study uses conservatively high discount rates and these electrolysis schedules and energy costs:

Electricity (off-peak)

Natural gas

Methanol

Ammonia

Discount rate

Off-peak electrolysis schedule

Filling stations

Home or commercial electrolysis

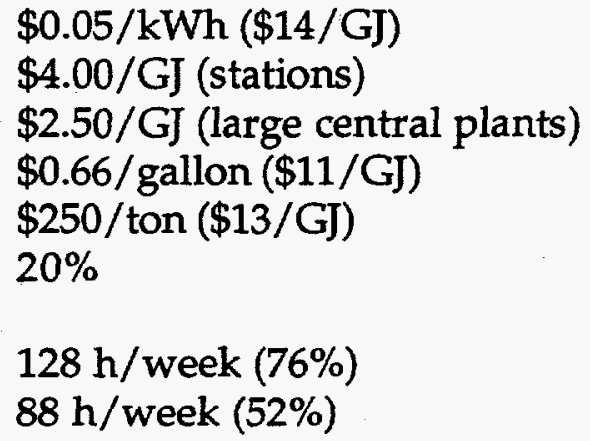

Cost estimates have been escalated to 1996 dollars. Byproduct credits, taxes, and other financial adjustments have been excluded for clarity and simplicity. Efficiency calculations use input energy divided by the output hydrogen energy (or the lower heating value [ $\mathrm{LHV}]$ of hydrogen carrier compounds) evaluated at the LHV of $33.3 \mathrm{kWh}$ or $120 \mathrm{MJ} / \mathrm{kg}$ of hydrogen. For reference, 
the LHV of a kilogram of hydrogen is nearly equal to the energy equivalent of 1 gallon of reformulated gasoline.

The volumes used for hydrogen were 2.372 grams per standard cubic foot (1 atmosphere and $68^{\circ} \mathrm{F}$ ) and 89.895 grams per normal cubic meter $\left(\mathrm{Nm}^{3}\right)$ ( 1 atmosphere and $0^{\circ} \mathrm{C}$ ). It should be noted that a normal cubic meter is $7 \%$ denser than a standard cubic foot. Ambiguity is avoided in this report by using mass units (kilograms) for hydrogen and $\$ / \mathrm{kW}$ of hydrogen energy output for capital equipment costs. When original references were in other units, any ambiguities were resolved conservatively (i.e., higher costs, lower production or storage capacity, etc.). The Compressed Gas Association's Handbook of Compressed Gases, Third Edition (1990), was used as the definitive reference for hydrogen and other substances when possible. 


\section{Delivered Hydrogen Costs}

\section{A. Centralized Infrastructure}

\section{Production}

Hydrogen can be produced electrolytically or chemically from water and an energy source (which may itself contain some hydrogen). Since electricity is much more expensive than energy from natural gas, most hydrogen today is produced thermochemically by reacting water with hydrocarbons in largescale steam methane reforming (SMR) plants. Although there are a variety of other possibilities for large-scale hydrogen production from fossil fuels (partial oxidation, coal gasification, steam-iron), they generally have efficiency, environmental, and/or emissions disadvantages for relatively small cost advantages. In addition, large quantities of hydrogen (approximately 8 million $\mathrm{kg} /$ day in 1993) (3) $^{13}$ are a byproduct of some petroleum refining operations; although production costs are low, hydrogen distribution costs diminish this advantage. The location, quantity, and price of byproduct hydrogen would probably be better suited to large-scale chemical and industrial use, in ammonia manufacture, for example. Consequently only centralized hydrogen production based on SMR is considered here. A major strength of SMR is that hydrogen from both the methane fuel and water feedstock is produced in the reaction:

$$
\mathrm{CH}_{4}(\mathrm{~g})+2 \mathrm{H}_{2} \mathrm{O}(\mathrm{l})+245 \mathrm{~kJ} / \mathrm{mol} \rightarrow \mathrm{CO}_{2}(\mathrm{~g})+4 \mathrm{H}_{2}(\mathrm{~g}) \quad
$$

The energy contained in 1 mole of methane is $802 \mathrm{~kJ}$, and the energy contained in 4 moles of hydrogen is $967 \mathrm{~kJ}$. The theoretical maximum energy efficiency (on an LHV basis) of steam reforming is $92 \%$. Large-scale steam reforming plants are quoted at $60-68 \%$ efficiency.

A typically sized SMR plant produces 100 million standard cubic feet $(237,000$ $\mathrm{kg}$ of hydrogen per day) or about $330 \mathrm{MW}$ of hydrogen energy output. For perspective, just one such plant would fuel 575,000 hydrogen cars-equal to the first five years of pilot car production. Such a plant requires a $\$ 200$ million capital investment with non-fuel operating costs (catalysts, labor, maintenance, etc.) totaling $\$ 50,000 /$ day, or $\$ 1.75 / \mathrm{GJ} .14$ Assuming plant efficiency of $68 \%$ on an LHV basis, natural gas costs of $\$ 2.50 / \mathrm{GJ}$, and industrial discount rates of $20 \%$, bulk hydrogen production costs will be $\$ 9.30 / \mathrm{GJ}$, roughly equivalent to (taxed) gasoline energy costs at $\$ 1.15 /$ gallon. More optimistic cost estimates have been developed (\$7/GJ). ${ }^{15}$ 


\section{Transmission and Distribution of Hydrogen}

Today, the costs of hydrogen storage, transmission, and distribution easily exceed hydrogen production costs of the large-scale plant just described. Liquid hydrogen delivery prices today are $\$ 30-50 / G J$. These high costs can be traced fundamentally to hydrogen's extremely low energy density and the high energy requirements for achieving energy densities suitable for transport. Hydrogen's low mass, small molecular size, and relative stability give hydrogen an extremely low liquefaction temperature $(20 \mathrm{~K})$ and a very low energy per volume as a gas or liquid (roughly one third that of natural gas or gasoline). Liquefying hydrogen is energy intensive, pipeline transport of gaseous hydrogen is less efficient than natural gas, and storage containers are large.

Today the most cost-effective ways to distribute hydrogen are by pipeline or as $\mathrm{LH}_{2}$ in trucks or trains. Hydrogen pipeline transmission costs over long distances can be low $82 / G)$ at large scales. Unfortunately pipeline construction requires a stable demand. Consequently these low transmission costs are probably achievable only as part of a large-scale infrastructure. Pipeline costs increase sharply at smaller scales, making $\mathrm{LH}_{2}$ delivery by truck more economical.

\section{a. Hydrogen Delivered by Truck}

Tanker truck transport and distribution of $\mathrm{LH}_{2}$ is practiced routinely. Truck delivery has the flexibility to adjust to shifting demand patterns and is probably well suited for hydrogen delivery to vehicle fleets in the near term. The costs of hydrogen distribution and transport by truck are high. This can be traced to a number of factors: the energy and equipment required to store the hydrogen in a usable fashion, the capital costs of mobile hydrogen storage, the energy to transport the hydrogen and its storage system, and operating costs of the truck cab and driver. The chief determinants of hydrogen distribution costs are the form of the hydrogen and the mobile storage technology employed. Cost estimates were made for four major storage technologies:

(1) Liquid hydrogen (20 K, 1-5 atm).

(2) Cryogenic compressed hydrogen ( $3600 \mathrm{psi}, 80 \mathrm{~K}$ ).

(3) High-pressure hydrogen gas in glass microspheres ( $9000 \mathrm{psi}$ ).

(4) Hydrogen stored chemically in magnesium-based hydride (released at several atmospheres, $200-250^{\circ} \mathrm{C}$ ).

Hydrogen distribution costs are determined mostly by two characteristics of storage technologies: (1) the density of stored hydrogen (both by volume and weight), which limits the amount of hydrogen that can be transported, and (2) the energy required to store the hydrogen and/or release it again for use. As shown in Table 2, the four storage systems represent a spectrum of possible tradeoffs among storage density, capital cost, and energy requirements. 
Table 2. Estimated storage densities and storage cycle energy requirements for hydrogen delivery by truck.

\begin{tabular}{|c|c|c|c|c|}
\hline Storage system & $\begin{array}{l}\text { Hydrogen } \\
\text { density } \\
\text { (kg H }{ }_{2} / \mathrm{m}^{3} \\
\text { system) } \\
\end{array}$ & $\begin{array}{l}\text { Hydrogen } \\
\text { fraction } \\
(\mathbf{k g ~ H})_{2} / \mathbf{m}^{3} \\
\text { system) }\end{array}$ & $\begin{array}{l}\text { Energy } \\
\text { requirements } \\
\text { (\% LHV of } \\
\text { stored } \mathrm{H}_{2}\end{array}$ & $\begin{array}{l}\text { Energy cost } \\
(\$ / G J)\end{array}$ \\
\hline $\begin{array}{l}\text { Liquid hydrogen } \\
\text { Cryogenic hydrogen gas } \\
\text { Glass microspheres } \\
\text { Mg-based hydrides }\end{array}$ & $\begin{array}{l}50 \\
40 \\
20 \\
40\end{array}$ & $\begin{array}{l}.20 \\
.12 \\
.10 \\
.04\end{array}$ & $\begin{array}{c}.40 \\
.25 \\
.20 \text { ( } 25 \% \text { heat }) \\
.30(100 \% \text { heat })\end{array}$ & $\begin{array}{l}5.55 \\
3.50 \\
2.10 \\
\text { N/A }\end{array}$ \\
\hline
\end{tabular}

Costs for these various cases can be roughly estimated under some simple assumptions. This has been done in Fig. 5 and the accompanying Table 3. The costs used to construct Fig. 5 are discussed briefly below.

\section{b. Mobile Hydrogen Storage System Costs}

Capital cost estimates for the various storage systems are based on discussions with $\mathrm{LH}_{2}$ equipment manufacturers and literature cost estimates for the other systems and materials. These capital cost estimates are expressed per unit of hydrogen stored and per unit of system weight in Table 3, using estimates from Ref. 9 and 16-18. An operating life of 10 years (2000-10,000 cycles) is assumed.

The cost of hydrogen storage systems in mass production is principally determined by materials cost per unit of storage. This in turn is determined by the density of hydrogen storage and the mass fraction of hydrogen that can be stored in the system. Liquid hydrogen storage is relatively dense and requires

Table 3. Approximate capital costs of mobile storage systems for hydrogen delivery trucks.

\begin{tabular}{lcccc}
\hline Storage system & $\begin{array}{l}\text { Unit cost } \\
\text { (\$ per } \mathbf{~ k g ~ o f ~} \\
\mathbf{H}_{\mathbf{2}} \text { storage) }\end{array}$ & $\begin{array}{l}\text { Hydrogen stored } \\
\left(\mathbf{k g} \text { of } \mathbf{H}_{\mathbf{2}} \text { ) }\right.\end{array}$ & $\begin{array}{l}\text { Total cost } \\
\text { (\$ per trailer) }\end{array}$ & $\begin{array}{l}\text { System cost } \\
\text { (\$ per } \mathbf{~ k g} \\
\text { of system } \\
\text { weight) }\end{array}$ \\
\hline Liquid hydrogen & 112 & 3500 & 400,000 & 23 \\
Cryogenic hydrogen gas & 480 & 2700 & $1,300,000$ & 58 \\
Glass microsphere & 70 & 1350 & 95,000 & 7 \\
Mg-based hydride & 580 & 1200 & 700,000 & 23 \\
\hline
\end{tabular}

Note: Cost estimates are from Refs. 9 and 16-18. Mg-based hydride alloys are estimated to cost $\$ 10 / \mathrm{kg}$. 
no rare or particularly expensive materials, so $\mathrm{LH}_{2}$ tanks are low cost. Cryogenic compressed gas storage offers relatively high density but generally requires expensive carbon fiber to be lightweight (since the tanks will be mobile). Magnesium-based metal hydrides could have somewhat higher materials costs depending upon alloy constituents. High-strength glass microsphere storage has great potential for low materials cost and lightweight storage but with very low storage density and with issues of durability.

\section{c. Transport Equipment and Operating Costs of Hydrogen Delivery by Truck}

A truck to transport the mobile storage system is relatively inexpensive (about $\$ 60,000),{ }^{19}$ small in comparison to the investment in hydrogen storage, except perhaps for microsphere technology. A vehicle life of 1 million miles, driven 100,000 miles per year, is assumed, as are personnel and driver costs of $\$ 100,000 / \mathrm{yr}$ for an individual truck. Fuel costs are small in comparison: $\$ 1.25 /$ gallon fuel and an average mileage of $6.0 \mathrm{mpg}^{20}$ results in fuel costs of roughly $\$ 20,000 /$ yr. Operating costs are similar to Class 8 tractor trailer trucks, which cost $\$ 0.35$ cents $/ \mathrm{mile}^{19}$ or $\$ 35,000 / \mathrm{yr}$ to operate. The non-hydrogenrelated costs for truck transport are roughly $\$ 1.50 / \mathrm{mile}$ or $\$ 150,000 / \mathrm{yr}$. These operating costs are relatively small for today's $\mathrm{LH}_{2}$ delivery trucks, which can transport $3500 \mathrm{~kg}$ of $\mathrm{H}_{2},{ }^{18}$ but they can become significant for lower density storage systems that carry only a fraction of this amount. These costs are shown in Fig. 5, which breaks down the total cost of centrally steam-reformed hydrogen delivered 250 miles by truck.

\section{d. Energy Cost of Hydrogen Storage}

The energy required to pressurize, cool, or liquefy hydrogen to adequate densities can be a significant cost. For each of the four storage systems considered, only electrical energy requirements are considered because they typically dominate energy costs. Liquefaction is the most energy-intensive, requiring at least $35 \%$ of the energy content of the $\mathrm{LH}_{2}\left(11.66 \mathrm{kWh} / \mathrm{kg} \mathrm{H} \mathrm{H}_{2}\right) .21$ Recently, smaller liquefiers ( $4000 \mathrm{~kg} /$ day) have been built that require more energy ( $13.3 \mathrm{kWh} / \mathrm{kg} \mathrm{H}$ or $40 \%$ of LHV). 22 An overall $40 \%$ energy penalty for $\mathrm{LH}_{2}$ is used to reflect transfer and filling losses. Cryogenic hydrogen gas compression and $\mathrm{LN}_{2}$ cooling are estimated to require $25 \%$ of the LHV of the stored hydrogen ( $15 \%$ for $\mathrm{LN}_{2}{ }^{21}$ cooling and $10 \%$ for compression). Electricity for hydrogen compression has been estimated to be $15 \%$ of the LHV of hydrogen stored in glass microspheres. 18 For hydride storage and glass microsphere systems, the low-grade heat costs were not considered. An electricity price of $\$ 0.05 / \mathrm{kWh}$ is used. The estimated energy costs of storage are shown in Table 2.

\section{e. Compression and Liquefaction Capital Costs}

The costs of hydrogen storage at central plants will be dominated by compressor and/or liquefier capital costs, because of high throughput (i.e., daily cycling of bulk storage before transfer to delivery trucks). Approximate 
compressor costs of $\$ 225 /\left(\mathrm{kg} \mathrm{H} \mathrm{H}_{2} \text { per day }\right)^{8}$ have been used to calculate compression costs at central loading facilities. Liquefaction plants are higher cost, even in very large plants. A small plant ( 6 tons/day) is estimated to cost $\$ 3750 /\left(\mathrm{kg} \mathrm{H} \mathrm{H}_{2}\right.$ per day), falling to $\$ 590 /\left(\mathrm{kg} \mathrm{H} \mathrm{H}_{2}\right.$ per day) at $>110$ tons $/$ day. ${ }^{23}$ Capital and operating and maintenance costs are $\$ 1.40 / \mathrm{GJ}$ for compression and $\$ 3.40 / \mathrm{GJ}$ for liquefaction at large scales.

\section{f. Total Cost of Hydrogen Delivery by Truck}

The cost breakdown of hydrogen delivery by truck is shown in Fig. 5, which displays the capital, energy, and operating costs, both for storing hydrogen and for delivering it 250 miles by truck, for each of the four hydrogen storage technologies in Tables 2 and 3. The fundamental point of Fig. 5 is that hydrogen can be delivered 250 miles by truck for roughly $\$ 20-25 / G$ from a central plant producing $\$ 9 / \mathrm{G}$ hydrogen from $\$ 2.50 / \mathrm{GJ}$ natural gas. It should be kept in mind that the technologies other than $\mathrm{LH}_{2}$ would require significant development before becoming viable options. Another important feature of hydrogen delivery shown in Fig. 5 is that storage and transport costs exceed the plant-gate production costs of steam reforming. This is principally because of intrinsic factors, either the high energy intensity of liquefaction or the relatively low amount of hydrogen that can be transported by a single truck if the hydrogen is not liquefied. The most significant conclusion from Fig. 5 is the small difference in cost $(\$ 20.00-\$ 23.50 / \mathrm{GJ})$, with a large range of technologies for vehicles of 250 -mile range.

The sensitivity of hydrogen delivery costs to delivery distance is shown in Fig. 6. All four technologies show a tradeoff between low fixed costs and high variable costs. Liquid hydrogen delivery costs are by far the least sensitive to delivery distance and therefore the most flexible. The other technologies, if they can achieve the technical and cost parameters of Tables 2 and 3, offer some potential cost savings $(\$ 5 / \mathrm{G})$ ) but only over a narrow delivery range ( $<200$ miles). Microsphere storage appears to have the greatest promise among alternatives to $\mathrm{LH}_{2}$, if low trailer cost estimates can be realized, or if the special advantages of microspheres (e.g., gas separation ability) are important. For short distances (30-50 miles) a pipeline network becomes costeffective ( $\$ 5.15 / \mathrm{GJ}$ for a 30-mile city pipeline network), 24 and could probably fill the niche of alternatives to $\mathrm{LH}_{2}$ delivery within a city.

\section{Centralized Production of Hydrogen Carriers}

One approach to overcoming the high energy costs and low density of hydrogen storage, and the impacts on delivery costs, is to transport hydrogen in higher-density chemical carriers. These carriers can then be decomposed at stations to produce hydrogen on site. Methanol and ammonia are two promising potential hydrogen carriers. Both are widely available commodities, principally produced from natural gas today, but they can be produced renewably. Methanol contains less hydrogen by weight and volume 
than ammonia but is easier to reform and store. A long-run potential advantage of ammonia is that it can be produced essentially from water, air, and renewable electricity, while renewable methanol from biomass would be much more land- and water-intensive. A disadvantage of both is health and safety risk. Methanol is toxic and can be absorbed through the skin, while ammonia, although easily detected, is an inhalation hazard. The costs and energy requirements for production and decomposition of these hydrogen carriers are briefly outlined.

\section{a. Methanol Synthesis}

If a source of carbon dioxide $\left(\mathrm{CO}_{2}\right)$ is available, the simplified overall reaction for methanol synthesis is endothermic:

$$
3 \mathrm{CH}_{4}(\mathrm{~g})+2 \mathrm{H}_{2} \mathrm{O}(\mathrm{l})+\mathrm{CO}_{2}(\mathrm{~g})+225.6 \mathrm{~kJ} \rightarrow 4 \mathrm{CH}_{3} \mathrm{OH}(\mathrm{l}) \text {. }
$$

The energy contained in 3 moles of methane is $2406 \mathrm{~kJ}$. The energy contained in 4 moles of methanol is $2564 \mathrm{~kJ}$. Therefore the maximum theoretical energy efficiency of methanol conversion from natural gas on an LHV basis is $97 \%$. If a source of $\mathrm{CO}_{2}$ is not available, then an excess of hydrogen will be produced. The simplified overall reaction in this case is also endothermic:

$$
\mathrm{CH}_{4}(\mathrm{~g})+\mathrm{H}_{2} \mathrm{O}(\mathrm{l})+118 \mathrm{~kJ} \rightarrow \mathrm{CH}_{3} \mathrm{OH}(\mathrm{l})+\mathrm{H}_{2}(\mathrm{~g}) .
$$

The theoretical maximum efficiency of converting methane energy into methanol energy for this reaction is $80 \%$. If an energy credit is given for the byproduct hydrogen, the theoretical energy efficiency increases to $95 \%$. However, large-scale (2500 tons/day) methanol plant efficiencies are reported at $57 \%$. Efficiencies in smaller modular plants (100 tons/day) drop to $48 \% .{ }^{14}$

A 2500-ton/day methanol plant is estimated to require a total capital investment of $\$ 415$ million. On a hydrogen output basis, this is $285,000 \mathrm{~kg}$ $\mathrm{H}_{2}$ /day or roughly $400 \mathrm{MW}$ of hydrogen energy. This is somewhat larger and significantly more capital-intensive than steam-reforming alone. Operating costs of methanol manufacture are estimated at $\$ 0.12 /$ gallon or $\$ 0.32 / \mathrm{kg}$ of hydrogen contained in the methanol. The resultant cost of methanol is $\$ 0.66 /$ gallon or $\$ 11.00 / \mathrm{GJ}$, somewhat more expensive than hydrogen produced by steam-reforming.

\section{b. Methanol Decomposition}

Methanol decomposition in small plants is less capital-intensive than smallscale steam reformers, in part because of lower process temperatures. These plants can probably be expected to scale down better than steam-reforming as well. The overall decomposition reaction is approximated by

$$
\mathrm{CH}_{3} \mathrm{OH}(\mathrm{l})+\mathrm{H}_{2} \mathrm{O}(\mathrm{l})+128 \mathrm{~kJ} \rightarrow \mathrm{CO}_{2}(\mathrm{~g})+3 \mathrm{H}_{2}(\mathrm{~g})
$$


The energy contained in a mole of methanol is $641 \mathrm{~kJ}$. The energy contained in 3 moles of hydrogen is $725 \mathrm{~kJ}$. Therefore the maximum theoretical energy efficiency of methanol decomposition on an LHV basis is $94 \%$. Actual decomposition units achieve $80 \%$ efficiency. The total capital investment for a $900 \mathrm{~kg} \mathrm{H} /$ day plant is estimated at $\$ 1.6$ million, with non-fuel operating and maintenance costs of $\$ 300 /$ day. Hydrogen production costs are $\$ 25 / \mathrm{GJ}$ using $\$ 11 / \mathrm{GJ}$ ( $\$ 0.66 /$ gallon) delivered methanol. ${ }^{14}$ A smaller capacity unit (180 $\mathrm{kg} \mathrm{H}_{2} /$ day) is estimated to cost $\$ 250,000$ in late- 1981 dollars 25 with operation and maintenance costs of $\$ 35,000 /$ year. Escalating these numbers to 1996 dollars with the Producer Price Index (PPI) yields a capital cost of $\$ 360,000$ with annual operating costs of $\$ 50,000 / y r$.

\section{c. Ammonia Synthesis}

Ammonia is attractive as an inexpensive carbon-free hydrogen carrier. Most ammonia synthesis plants are based on steam-reforming of natural gas. The overall process can be represented by the aggregate chemical reaction below:

$$
4 \mathrm{CH}_{4}(\mathrm{~g})+7 \mathrm{H}_{2} \mathrm{O}(\mathrm{l})+5 \mathrm{~N}_{2}+\mathrm{O}_{2}(\mathrm{~g})+237 \mathrm{~kJ} \rightarrow 4 \mathrm{CO}_{2}(\mathrm{~g})+10 \mathrm{NH}_{3}(\mathrm{~g})
$$

The energy contained in 4 moles of methane is $3208 \mathrm{~kJ}$, and the energy contained in 10 moles of ammonia is $3166 \mathrm{~kJ}$. Consequently, the theoretical maximum energy efficiency (on an LHV basis) of ammonia synthesis based on steam-reforming is $92 \%$. Ammonia synthesis plants have capital costs of $\$ 200-250$ million for a 1000 ton/day plant ${ }^{26}$ (roughly $\$ 1100 / \mathrm{kW} \mathrm{H}_{2}$ output) and achieve energy efficiencies of less than $29 \mathrm{MJ} / \mathrm{kg} \mathrm{NH} 3$ (64\% efficiency). ${ }^{27}$ Ammonia prices fluctuate significantly. Recent delivered ammonia prices have ranged from $\$ 180$ to $\$ 250 /$ ton, corresponding to $\$ 9.30-13.00 / \mathrm{GJ}$ of hydrogen contained in the ammonia.

\section{d. Ammonia Decomposition}

The process is represented by

$$
2 \mathrm{NH}_{3}(\mathrm{~g})+92 \mathrm{~kJ} \rightarrow \mathrm{N}_{2}+3 \mathrm{H}_{2} .
$$

The theoretical energy efficiency of ammonia decomposition is $88 \%$. Ammonia decomposition is not regularly done today in the ammonia industry. Energy requirements in small prototype ammonia decomposition plant designs from the early 1960s were high. Efficiencies of ammonia decomposition (input heat and ammonia divided by hydrogen energy out) were $60-65 \% .21$ There is probably some potential for improvement of this figure. A capital cost of $\$ 480,000$ is estimated 25 for a $180 \mathrm{~kg} \mathrm{H}_{2} /$ day ( $250 \mathrm{~kW} \mathrm{H}_{2}$ output) facility (escalated from $\$ 330,000$ in 1981 dollars). Using the scale dependence of the methanol decomposition units discussed previously over the same range results in an approximate capital cost of $\$ 1.9$ million at $900 \mathrm{~kg}$ 
$\mathrm{H}_{2}$ /day. Discounting at $20 \%$ over 20 years, the production cost of hydrogen from $\$ 250 /$ ton ammonia is $\$ 33 / \mathrm{GJ}$.

\section{B. Decentralized Infrastructure}

\section{On-Site Hydrogen Production}

An alternative to centralized production and truck delivery is producing hydrogen on-site at scales ranging from fuel stations $\left(900 \mathrm{~kg} \mathrm{H}_{2}\right.$ /day or 1.25 MW $\mathrm{H}_{2}$ output) to homes ( $0.4 \mathrm{~kg} \mathrm{H}$ /day or about $500 \mathrm{~W} \mathrm{H}_{2}$ output). On-site production costs are higher than for large-scale central plants, but these costs are partially offset by eliminating hydrogen transport and distribution. Two classes of small-scale on-site production technologies are considered in this report:

(1) On-site thermochemical hydrogen production from natural gas, ammonia, or methanol.

(2) Electrolysis using alkaline, polymer membrane, or solid oxide steam electrolysis.

These technologies represent a spectrum of hydrogen production options with differing technical maturity, capital intensity, energy costs, energy efficiency, supply flexibility, and synergy with the existing chemical and electrical infrastructure.

Steam reforming is the conventional method of hydrogen production, and units are commercially available today. It is capital-intensive at small scales, achieving low cost through low feedstock prices and high energy efficiency.

Decomposition of hydrogen carriers such as ammonia or methanol are less capital-intensive than steam methane reforming (at small scales) but with significantly higher feedstock prices and embodied energy requirements. One advantage of these methods is that methanol and ammonia delivery by truck is more flexible than natural gas pipelines. Another advantage of hydrogen from ammonia and/or methanol is the potential for producing these hydrogen carriers from renewable or waste resources, enabling renewable hydrogen to be easily assimilated into the filling-station infrastructure. Several methanol decomposition units are in use today. Ammonia decomposition was previously a source of hydrogen before large-scale steam methane reforming plants were built.

At small scales, electrolysis is generally less capital-intensive than thermochemical hydrogen production methods, but with correspondingly higher energy costs. Important strengths of electrolysis are very small-scale suitability, integration into the existing electricity infrastructure, and potential 
renewability. Electrolysis units have duty factors from 52 to $76 \%$ in our scenarios to allow for off-peak electrolysis as a utility load-leveling method and for capacity to meet surges in hydrogen demand. Alkaline electrolysis is proven, conventional technology, although not yet mass-produced. Polymer membrane electrolysis is advancing, and probably a near-term technological advancement would be available in time for the introduction of hydrogen vehicles in 2005 . Both technologies can achieve roughly $68 \%$ electricity-tohydrogen efficiency. Steam electrolysis using solid oxide electrolytes is advanced technology, promising the highest possible efficiencies $(\sim 90 \%)$ but requiring the most development. It could probably be available by 2010 , before hydrogen vehicles would be widespread.

\section{Hydrogen Pathways and Refueling Scenarios for Stations, Fleets, and Individual Vehicles}

The six on-site hydrogen production technologies described above and $\mathrm{LH}_{2}$ delivery by truck from a central steam-reforming plant are a representative set of hydrogen production/storage/delivery pathways, spanning a broad range of technoeconomic characteristics (energy requirements, scale economies, capital intensity, emissions) and strategic character (centralization, flexibility, and synergy with the existing energy infrastructure). The remainder of this report presents an estimate of the costs, emissions, and benefits of using these pathways to fuel high-efficiency hydrogen cars and compares them to benefits achievable with other alternatives to today's gasoline vehicles.

Hydrogen delivery costs are a strong function of scale because of the scale economies of not only production pathways but also of storage pathways. Compressors and cryogenic or compressed gas storage, in addition to hydrogen-dispensing equipment, are significant elements of delivered hydrogen cost, particularly at small scales. Four refueling scenarios were chosen to explore these cost changes, with production, storage, and delivery equipment sized accordingly, as listed below. Vehicles were assumed to refuel when a $3.75-\mathrm{kg}$ tank was $80 \%$ empty (requiring $3 \mathrm{~kg}$ of hydrogen).

(1) Filling station scale: $900 \mathrm{~kg} \mathrm{H}_{2}$ /day (300 cars/day).

(2) Small station: $180 \mathrm{~kg} \mathrm{H}_{2} /$ day (60 cars/day).

(3) Fleet: $30 \mathrm{~kg} \mathrm{H} /$ day (10 cars/day).

(4) Home refueling: $0.4 \mathrm{~kg} \mathrm{H}_{2} / 12 \mathrm{hr}$, (refueling 1 car with $3 \mathrm{~kg}$ every 8 days).

The station scenarios allow for $60 \%$ recovery of a full day's worth of hydrogen compressed gas from on-site storage in a high-pressure (8400 psi) cascade. 14 For the home refueling case, hydrogen from the electrolyzer is either produced at pressure or compressed using a small hot-water-driven hydride bed ( $30-40$ grams $\mathrm{H}_{2} / \mathrm{hr}$ capacity). The hydrogen can then be stored in a low- 
pressure tank at 500 psi (resulting in a volume of 100 gallons per kilogram of hydrogen storage capacity).

The home refueling scenario is distinct from the other scenarios in a number of ways. First, to save on capital costs, buffer storage is small and at low pressure $(500 \mathrm{psi})$. This eliminates the need for a compressor but requires hydride storage onboard the vehicle. Second, the electrolyzer is sized to meet average demand using a $50 \%$ duty cycle to allow for off-peak electricity rates. These two factors mean that, although the vehicle has a driving range of 300 miles, it will need to be "topped off" every other night, similar to EV homerecharging schemes. There is, however, some flexibility to adjust to higherthan-average home hydrogen needs. Buffer storage (I $\mathrm{kg}$ ) at home will be sufficient for an 80-mile driving range. The electrolyzer can produce $0.4 \mathrm{~kg}$ of hydrogen every 12 hours. Using off-peak electricity only, this can fuel 32 miles of driving per day (or 64 miles every two days). However, if the customer is willing to pay peak electricity prices, running the electrolyzer around the clock will produce enough hydrogen for 64 miles of driving per day (or 128 miles every two days). This is constraining but is a strategy that allows a single hydrogen-fueled vehicle to be driven in a community well before a hydrogen filling station is justified.

\section{Delivered Hydrogen Cost Estimates for Stations, Fleets, and Homes}

Our cost estimates of producing, delivering (in the case of $\mathrm{LH}_{2}$ ), storing, and dispensing hydrogen for each of the seven pathways and four scales are presented by different categories in Fig. 7-9. Relatively high energy costs (\$4.00/GJ natural gas, $\$ 11.00 / \mathrm{GJ}$ methanol, $\$ 13.00 / \mathrm{GJ}$ ammonia, and $\$ 0.05 / \mathrm{kWh}$ electricity) and discount rates $(20 \%)$ were used. Liquid hydrogen truck delivery costs were taken from Fig. 5. Detailed cost and technical assumptions used for each scenario are given in Appendix B.

Production equipment capital costs were taken from industry 14 when available. Some costs were drawn from literature sources, adjusted for inflation, and scaled approximately in some cases. Cost estimates in mass production were used in the case of solid polymer electrolysis, 28 steam electrolysis, ${ }^{29}$ and home alkaline electrolysis. 30 The electrolysis pathways operate with a duty cycle of $76 \%$ to allow off-peak electricity pricing. In general, the thermochemical production methods can be expected to have greater cost certainty but less potential for cost reductions in comparison to electrolysis technologies.

The on-site storage costs used were also conservatively chosen (see Fig. 8). Storage economics were based on compressed gas storage (for on-site production scenarios) from Ogden in her recent examination of on-site steam reforming. 8 Current industrial equipment prices could probably be reduced 
somewhat if compressors and storage tanks were manufactured in greater quantities. Hydrogen was assumed to be delivered to vehicles at $6000 \mathrm{psi}$.

Non-hydrogen-related operating costs of $\$ 720 /$ day for a 300 car/day station were assumed, to account for factors such as labor, utilities, and land. ${ }^{31}$ This equates to $\$ 2.40$ per car, which was used for smaller-scale scenarios.

Figure 7 shows delivered hydrogen cost broken down by pathway step (production, delivery, storage, and overhead). Hydrogen will cost roughly $\$ 30-50 / G J$ at filling stations refueling 300 cars/day. Costs increase to $\$ 35-60 / G J$ at $60 \mathrm{cars} /$ day, and $\$ 60-75 / \mathrm{GJ}$ at $10 \mathrm{cars} /$ day. Refueling an individual vehicle from a very small $(\sim 2 \mathrm{~kW}$ electrical) electrolyzer system costs $\$ 60-70 / \mathrm{GJ}$. Assuming an $80-\mathrm{mpg}$-equivalent hydrogen vehicle, this $\$ 30-75 / \mathrm{GJ}$ range correspond to $4.5-11$ cents/mile (see Fig. 4). Figure 7 shows that, even with high energy costs and discount rates, at stations hydrogen refueling costs are comparable with per-mile gasoline costs today.

Some conclusions about hydrogen storage costs can be drawn from Fig. 7 . Liquid storage at stations is a small $(10-20 \%)$ fraction of total costs, while compressed gas is more expensive $(15-25 \%)$. But at very small scales (10 cars/day), both systems have comparable costs. Storage costs rise far faster than production costs with decreasing scale, becoming roughly equal to production costs at 10 cars/day. Figure 7 also shows that steam electrolysis can produce hydrogen for costs comparable to the lowest-cost thermochemical methods at stations of 300 and 60 cars/day (on-site steam-reforming at 300 cars/day, and methanol decomposition at 60 cars/day). Alkaline and polymer membrane electrolysis costs are roughly equivalent to the highest-cost thermochemical methods at each scale. Liquid hydrogen delivery by truck achieves lower costs than any on-site production method down to 10 cars/day, but its greatest cost savings is actually at higher scales (60 cars/day).

Costs are disaggregated financially into capital, interest, energy, operating, and station overhead costs in Fig. 8. The most striking feature of this comparison is the increasing share for interest below the $300 \mathrm{car} /$ day station scale. Interest accounts for the majority of cost increases in delivering hydrogen at small scales. This is driven both by the high discount rate $(20 \%)$ used in these estimates and by the increasing share of costs for storage equipment, which has shorter operating life (10 years) than production equipment (20 years). Interest alone is more than repayment of the capital investments in all cases except the individual-vehicle scale, where interest is lower because consumers are assumed to use a $10 \%$ discount rate. Figure 8 also shows that, except for steam- reforming, all on-site hydrogen production pathways have a large component of energy and feedstock (including water for electrolysis) costs $(40-50 \%)$, making these pathways sensitive to changes in methanol, ammonia, or electricity prices. The energy costs of ammonia and methanol decomposition pathways are roughly comparable to electricity costs for the electrolysis pathways. 
Figure 9 gives the detailed cost breakdown of the hydrogen pathways, principally for reference in determining the largest cost driver in the categories displayed in Fig. 7 and 8. Costs are disaggregated both by pathway step and cost type. Figure 9 shows that the majority of production costs are dominated by energy, except in the case of steam-reforming, which is capitalintensive. Cost increases at smaller scales are due more to increasing capital costs of storage rather than production-related costs. For fleets (10 cars/day), hydrogen costs are $\$ 65-75 / G J$, with storage and dispensing capital costs becoming dominant. Residential electrolysis costs of $\$ 60-70 / G J$ are roughly split between capital and energy costs. Figure 9 shows that the $20 \%$ discount rate on hydrogen pathways sharply increases the cost penalties of storage at scales below 60 cars/day. Non-hydrogen-related overhead is significant (\$6$7 / G J)$, even at 300 cars per day. A major conclusion of Fig. 9 is that $\mathrm{LH}_{2}$ is a cheaper pathway for all scales than it was previously considered to be.

At smaller scales, capital equipment for production and especially storage becomes a larger share of total costs. These costs have the potential to be reduced through higher-volume production techniques. Small-scale costs may also be reduced as alternative technologies develop. One possibility is the use of magnesium-hydride stationary storage in combination with a phase change material to replace or augment compressed gas storage at a refueling facility. Alternatives to compressed gas storage are especially attractive if hydride storage is used onboard the vehicles. The cost of hydrogen storage would be roughly $\$ 3-5 / \mathrm{GJ}$ at scales as low as $35 \mathrm{~kg} \mathrm{H}_{2}$ storage. 32 Another, more speculative possibility is on-site storage using microspheres. If material costs were low, savings over compressed gas storage might be $\$ 5 / \mathrm{GJ}$ at $\$ 300 /$ cars day and $\$ 10 / G \mathrm{~J}$ at 60 cars/day, making on-site steam-reforming and steam-electrolysis station costs comparable to $\mathrm{LH}_{2}$ delivery by truck. 


\section{Energy and Emissions for Vehicles Using Hydrogen from Natural Gas}

\section{A. Primary and Process Energy Requirements for Hydrogen Production, Delivery, and Storage}

The embodied energy requirements for hydrogen fuel can be quite high. Figure 10 displays the final process (chemical or electrical) and primary (chemical including electricity production) energy requirements of hydrogen production, storage, transport, and delivery for the hydrogen pathways analyzed in Fig. 7-9. Energy requirements are broken down into (1) natural gas (or electricity) for production of hydrogen or chemical carriers; (2) fuel for $\mathrm{LH}_{2}, \mathrm{NH}_{3}$ or $\mathrm{CH}_{3} \mathrm{OH}$ truck delivery; (3) energy for chemical carrier decomposition; and (4) electricity for hydrogen storage as a liquid or highpressure gas ( $8400 \mathrm{psi})$.

Figure 10 shows net energy requirements of approximately $1.5 \mathrm{kWh}$ of energy per kWh of hydrogen delivered (LHV basis) for on-site alkaline electrolysis or steam-reforming, and compressed gas storage. The least process energy is required by steam electrolysis, only $1.2 \mathrm{kWh}$ per $\mathrm{kWh}$ of $\mathrm{H}_{2}$. Liquid hydrogen delivery by truck, methanol decomposition, and home electrolysis require roughly $2 \mathrm{kWh}$ of energy per $\mathrm{kWh}$ of $\mathrm{H}_{2}$. Ammonia decomposition is the most energy-intensive at $2.5 \mathrm{kWh}$ input energy (natural gas) per $\mathrm{kWh}$ of hydrogen. If electricity from fossil sources is used (as is most likely), then the energy-intensity picture changes. Primary energy requirements for water electrolysis rise to $4.5 \mathrm{kWh}$ per $\mathrm{kWh}$ of $\mathrm{H}_{2}$. The increase for steam electrolysis is much less. Steam-reforming and $\mathrm{LH}_{2}$ delivery increase moderately to 1.6 and $2 \mathrm{kWh}$ per $\mathrm{kWh}$ of $\mathrm{H}_{2}$ respectively. Methanol and ammonia decomposition increase to 2.1 and $3.1 \mathrm{kWh}$, respectively.

Steam-reforming (on-site) stands alone among these pathways as an energyefficient hydrogen production method. Central production and delivery of hydrogen ( $\mathrm{LH}_{2}$ trucks) or hydrogen carriers $\left(\mathrm{CH}_{3} \mathrm{OH}\right.$ and $\left.\mathrm{NH}_{3}\right)$, and their subsequent decomposition to hydrogen, are significantly more energyintensive than steam-reforming. Electrolytic hydrogen is even more energy intensive, considering the fossil energy required to produce the electricity. If, however, renewable electricity (hydro, wind, or solar) is used to produce and store hydrogen, then steam electrolysis becomes the most efficient pathway.

\section{B. Greenhouse Gas Emission Comparison of Hydrogen and Other Fuels for Hybrid Vehicles}

Greenhouse-gas-emission reductions are a major driver for both efficient vehicles and renewable fuels. Greenhouse-gas-emissions from fueling 
hydrogen vehicles are a strong function of the pathway energy requirements shown in Fig. 10 and the primary energy source. Figure 11 displays full-cycle greenhouse gas emissions (in $\mathrm{CO}_{2}$ equivalent $\mathrm{g} / \mathrm{mile}$ ) for hydrogen vehicles using fuel produced by the eight pathways and compares them to natural-gas HEVs, gasoline vehicles, and BPEVs. All electricity in this comparison is generated from natural gas. The figure shows that, if natural gas, the lowest greenhouse-gas-emitting fossil fuel, is used as the primary energy source, hydrogen vehicles do not have a clear advantage over other alternatives.

\section{Tailpipe and Fuel-Cycle Emissions from Hydrogen and Other Alternative-Fuel Vehicles}

Prototype vehicles using reformulated gasoline or natural gas have met ultralow emission vehicle standards, 33 but startup emissions, long-term catalyst effectiveness, and the cost of emission controls will limit ultimate emission reductions. For the 11 million vehicles produced in 1993 in the United States, $\$ 13.2$ billion $^{20}$ was spent on motor vehicle pollution-control devices ( $\$ 1200 /$ vehicle). This will likely rise in order to meet ULEV requirements. An inherent advantage of hydrogen vehicles is the ability to achieve essentially zero tailpipe emissions without pollution abatement devices. Tailpipe emissions from hydrogen vehicles without a catalyst can be approximately 10 times lower than ULEV standards for nitrogen oxides (NOx) and hydrocarbon emissions, 34 and 300 times lower for carbon monoxide (CO) emissions. 5 These emission levels are comparable to the equivalent ZEV standards being considered by California Air Resources Board. ${ }^{35}$

Figure 13 shows projected tailpipe emissions from HEVs fueled with hydrogen, natural gas, and gasoline. The emissions estimates for gasoline and natural gas vehicles were taken from a study performed for the Gas Research Institute in $1994^{36}$ and adjusted for the increased fuel efficiency of HEVs. Hybrid vehicles were assumed to achieve $65 \mathrm{mpg}$ using gasoline, 70-mpg equivalent using natural gas, and $80-\mathrm{mpg}$ equivalent using hydrogen. All vehicles require $0.16 \mathrm{kWh} / \mathrm{mile}$ at the wheels. The hydrogen HEV has negligible tailpipe emissions of hydrocarbons and $\mathrm{CO}$ in comparison with gasoline or natural gas-powered counterparts. Hybrid vehicles using hydrogen and natural gas with specifically formulated three-way catalysts have roughly equivalent NOx tailpipe emissions, both much lower than a gasoline hybrid. The conclusion drawn from Fig. 13 is that hydrogen provides a clear tailpipe emissions benefit over fossil fuels only in the case of CO.

In addition, there are significant emissions from fuel production for gasoline, natural gas, and hydrogen. Figure 12 shows full fuel-cycle emissions estimates for vehicles using hydrogen produced from natural gas, methanol, ammonia, or natural gas-fired electricity. These emissions are compared to gasoline and natural gas used in HEVs and gas-fired electricity recharging BPEVs. An 80mpg-equivalent vehicle using steam-reformed hydrogen can reach emissions 
levels comparable to a similar BPEV recharging from a natural-gas-fired powerplant. If hydrogen fuel is electrolyzed from a natural-gas-fired powerplant, a hydrogen car will produce higher NOx and slightly higher hydrocarbon emissions than a natural-gas HEV. Note that there is a conflict between the cleanest hydrogen production and delivery pathways in terms of full-fuel-cycle air pollutant emissions and greenhouse gas emissions (see Fig. 12) as long as natural gas (or other fossil energy) is the primary energy source.

In summary, hydrogen vehicles, without catalytic controls, can achieve tailpipe emissions an order of magnitude or more below ULEV levels, and well below fossil-fueled HEVs, but full-fuel-cycle emissions complicate the emissions issue. To achieve full-fuel-cycle emissions comparable to BPEVs (from natural-gas-fired power plants) requires steam-reformed hydrogen, but natural-gas HEVs offer NOx and hydrocarbon emission reductions below any hydrogen vehicle using natural gas as a source of primary energy source.

Taken together, the tailpipe and fuel-cycle emissions estimates in Figs. 12 and 13 indicate that a rationale based on emissions benefits alone is weak, resting chiefly on reducing $\mathrm{CO}$ emissions, or focusing narrowly upon tailpipe emissions. This is not because hydrogen vehicles produce high full-fuel-cycle emissions, but because fossil-fueled vehicle tailpipe emissions can be controlled to very low levels, if necessary (albeit at additional cost). 


\section{Electricity Generation Mix Changes and Impacts on Pathway Emissions}

\section{A. Three Scenarios of Greenhouse Gas Emissions for Hydrogen Pathways in 2030}

The preceding section has shown that, as long as natural gas (or any fossil fuel) is used as the primary energy source for hydrogen pathways, hydrogen cars will have higher greenhouse gas, NOx, and hydrocarbon emissions than natural-gas hybrid cars. The greenhouse-gas-emission benefits of hydrogen vehicles can be improved significantly with pathways fueled from a cleaner, more efficient primary energy mix that contains a larger proportion of renewable or nuclear energy. Figure $14(\mathrm{a}-\mathrm{c})$ shows three scenarios of electricity-generation primary energy mix and the corresponding emissions of $\mathrm{CO}_{2}$ and NOx per kWh of electricity generated from 2005 to 2050 . In choosing the scenarios, it was important to encompass the spectrum of possibilities over the time required for full implementation of hydrogen vehicles. Three scenarios were adapted from the "reference," "market," and "climate" electricity-generation mixes constructed in America's Energy Choices: Investing in a Strong Economy and a Clean Environment (1992). 37 Full-fuelcycle emission factors were adapted from a study for the Gas Research Institute examining full-fuel-cycle emissions of alternative-fuel vehicles, including BPEVs. ${ }^{36}$ The "reference" scenario results in a clean-coal-based (75\%) mix in 2035 . The "market" scenario embodies an electricity mix using efficient advanced technologies, pollution abatement, and renewable energy when it is economically competitive, with $40 \%$ of electricity coming from non-fossil sources by 2035 . The "climate" case uses all available supply and efficiency options to replace coal-generated electricity, resulting in only $5 \%$ of electricity coming from coal in 2035.

Figure 15(a-d) shows the improvements in full-fuel-cycle greenhouse emissions of hydrogen vehicles achievable under these scenarios for the pathways in Fig. 11. Full-fuel-cycle emissions of hydrogen vehicles are compared with emissions from gasoline and natural-gas cars, and from BPEVs. Figure 15(a) shows the situation under the "reference" electricity mix in 2005. Hydrogen cars produce $150-550$ grams of $\mathrm{CO}_{2}$-equivalent greenhouse gases per mile, depending upon pathway. This is in some cases less than a 30mpg gasoline car (340 grams/mile), but gasoline and natural-gas HEVs produce only 150 grams/mile and 110 grams/mile respectively, while a BPEV produces only 130 grams/mile. By 2035, however, cars using hydrogen from steam electrolysis can achieve lower greenhouse-gas-emissions (100 grams/mile) than steam-formed hydrogen and fossil-fueled vehicles except BPEVs under the "climate" scenario, in which electricity is produced from mostly non-fossil sources (70\%) and natural gas. In the other two scenarios, the heavy reliance on coal to produce electricity prevents electrolytic 
hydrogen vehicles from achieving greenhouse-gas-emissions lower than fossil-fuel HEVs. The major conclusion to be drawn from Fig. 15(a-c) is that a transition to a largely non-fossil electricity mix (or other hydrogen source) is absolutely necessary for hydrogen vehicles to reduce full-fuel-cycle greenhouse-gas emissions below those of fossil-fuel HEVs. A greenhouse-gas rationale for hydrogen vehicles that are not ultimately fueled renewably or by using nuclear energy does not appear supportable.

\section{B. Three Scenarios of Air Pollutant Emissions for Hydrogen Pathways in 2030}

Another key argument advanced for hydrogen vehicles is urban air pollution. It appears that, like greenhouse-gas emissions, the rationale for hydrogen can be improved if hydrogen vehicles are fueled from a cleaner, more renewable electricity mix, which can be gradually developed over the decades required for a full transition to hydrogen vehicles. Figure 16 shows the potential NOx and hydrocarbon full-fuel-cycle emission improvements achievable with various hydrogen pathways under the three scenarios of a changing electricity mix from 2005 to 2035 (the same scenarios used in Fig. 15). Emissions from hydrogen cars fueled by these pathways are compared to ULEV conventional gasoline cars, fossil hybrids, and BPEVs. Carbon monoxide emissions are negligible for hydrogen production and hydrogen vehicles $(\sim 0.005 \mathrm{~g} / \mathrm{mile})$ and so were not included.

Figure 16(a-d) shows that initially, under the 2005 "reference" scenario, fueling hydrogen cars would produce considerably more NOx than ULEV fossil-fueled cars or BPEVs. These emissions come principally from coal-fired electricity for hydrogen production, compression, or liquefaction. Hydrocarbon emissions from hydrogen vehicles are lower than fossil-fuel vehicles in all pathways except methanol decomposition. It is also clear that the fuel cycle is responsible for the majority of emissions for all vehicles and that NOx emissions will be the most important issue for hydrogen vehicles. Figure 16(b-d) shows that NOx emissions can be reduced dramatically, by 2035, in all three scenarios, through the use of emission controls on combined-cycle plants and/or non-fossil electric generation. In all three scenarios, hydrogen vehicles from a number of electrolytic or thermochemical routes would produce lower NOx than gasoline vehicles. However, the natural-gas HEV (and the BPEV) produce even lower emissions than hydrogen vehicles in almost all cases. Only under the most aggressive electricity-generation mix scenario ("climate") do hydrogen vehicles approach this very low level of emissions.

In summary, hydrogen vehicles can provide comparable or lower air pollutant emissions than ULEV gasoline vehicles but require a mostly nonfossil electricity-generation mix to achieve full-fuel-cycle emissions levels comparable to natural-gas HEVs. The greatest distinction is between 
thermochemical and electrolytic pathways. Thermochemical pathways use relatively little primary energy and electricity, so emissions are initially moderate and decrease little under changes in electricity-generation mix. Electrolytic pathways would produce more NOx early on but can ultimately be much cleaner than thermochemical hydrogen pathways by the time (2035) hydrogen vehicles are a major portion of the light-duty fleet. This is especially true if high-efficiency steam electrolysis is used to generate hydrogen fuel.

Even by 2035, however, the air-pollutant emissions from hydrogen vehicles would be roughly comparable to natural-gas HEVs. A rationale for hydrogen vehicles based on air pollutant emissions, even given a mostly non-fossil electricity mix, is very weak. Hydrogen vehicles and the hydrogen fuel cycle will need to be clean, but that will not be sufficient. A strong rationale will require benefits of hydrogen vehicles not achievable with natural gas HEVs. 


\section{Benefits and Evaluation of a Transition to Hydrogen Vehicles}

\section{A. Charting a Transition to Hydrogen Vehicles}

In the preceding sections the costs, energy use, and full-fuel-cycle emissions for hydrogen production, storage, and delivery for hydrogen vehicles were estimated for a representative set of hydrogen pathways. These estimates can now be used to explore the benefits of different pathways for a transition to hydrogen vehicles, and to compare these benefits with those of other alternative-vehicle transitions from conventional gasoline vehicles. Transition scenarios were constructed with common transportation demand and market penetration assumptions for the decades from 2005 to 2050 . The oil use and emissions for each case were then calculated and compared to a base case in which the U.S. passenger vehicle fleet meets ULEV emissions standards and achieves an average fuel efficiency of $30 \mathrm{mpg}$.

A relatively simple transportation-demand scenario was adapted from an analysis in America's Energy Choices (1992) ${ }^{37}$ based on growth in U.S. driving-age population, saturation in vehicle ownership, and moderate growth in average annual driving to the distances driven by average male drivers today. These assumptions result in a scenario in which the U.S. passenger car fleet grows slowly from 169 million vehicles in 2005 to saturate at 200 million in 2050. Growth in vehicle miles traveled is moderate also: rising $30 \%$ from 1.83 trillion miles/year to 2.4 trillion miles/year over the same period.

Alternative vehicles fueled by hydrogen, electricity, or natural gas are introduced using an aggressive schedule to replace gasoline cars by 2040, as shown in Table 4. A 10-year vehicle life is assumed for all vehicles.

For clarity, constant vehicle fuel efficiencies are assumed of $30 \mathrm{mpg}$ for conventional internal-combustion-gasoline-powered fleet, $65 \mathrm{mpg}$ for

Table 4. Production schedule for alternative vehicles.

\begin{tabular}{lcll}
\hline Year & $\begin{array}{l}\text { Production rate } \\
\text { (106 vehicles/yr) }\end{array}$ & $\begin{array}{l}\text { Total alternative } \\
\text { vehicles in fleet } \\
\text { (millions) }\end{array}$ & $\begin{array}{l}\text { Vehicle miles traveled } \\
\text { (trillion miles) }\end{array}$ \\
\hline 2005 & 0.1 & 0 & 1.832 \\
2015 & 3 & 1 & 2.074 \\
2025 & 13 & 50 & 2.248 \\
2030 & 18 & 110 & 2.328 \\
2050 & 20 & 200 & 2.400 \\
\hline
\end{tabular}


gasoline HEVs, $70 \mathrm{mpg}$ for natural-gas HEVs, and $80 \mathrm{mpg}$ for hydrogen HEVs. BPEVs are assumed to perform as well as hydrogen HEVs, requiring 0.16 $\mathrm{kWh} /$ mile. It is optimistically assumed that ULEV tailpipe emission standards are met nationally by the gasoline automobile fleet by 2005 .

\section{B. Benefits of Transitions to Hydrogen and Other Advanced Vehicles}

\section{Reduced Oil Use}

The conventionally cited benefits of a transition to alternative-fuel vehicles include reduced oil consumption, reduced urban air-pollutant emissions, and reduced greenhouse-gas emissions. Of these, reducing oil use enjoys the broadest consensus as a worthwhile benefit and also the broadest range of methods to achieve the benefit. Any alternative-fuel vehicle displaces oil use. Oil use reductions achievable by alternative-fuel cars under the market penetration assumptions described previously are shown in Fig. 17. The associated passenger fleet population, average annual mileage, and replacement of gasoline cars with alternative-fuel cars are also shown. The most striking point about oil-use reductions and alternative-fuel vehicles is the very long lead times necessary for large-scale change. Alternative-fuel cars introduced in 2005 do not begin to materially influence aggregate oil use for another decade, and two decades more (2035) are required to replace gasoline vehicles. This points out the need for an assured, single transition to an enduring, and essentially permanent, alternative fuel-arguably a position that hydrogen vehicles alone can claim among the alternatives. It also points out the necessity of a long-term perspective, infrastructure flexibility, and advanced technology in formulating a rationale for hydrogen vehicles.

The second point from Fig. 17 is the sheer amounts of oil and money involved. The transition shown would save an average 2 billion barrels annually over the 20 years from 2030 to 2050 . Assuming an average price of $\$ 30 /$ barrel, that would represent a $\$ 1.2$ trillion savings in imports.

This large benefit is achievable with any alternative fuel, however, and therefore supports moving away from today's gasoline vehicles more than moving towards hydrogen vehicles.

\section{Air-Pollutant and Greenhouse-Gas Emission Reductions}

Air-pollutant and greenhouse-gas emissions argue more specifically for hydrogen vehicles than oil import reductions. A range of vehicle/pathway combinations were chosen to assess the greenhouse-gas and air-pollutant emission benefits of hydrogen and other vehicles. Total emissions reductions for the U.S. passenger car fleet are calculated, combining the electricity-mix assumptions, greenhouse-gas emissions, air-pollutant emissions, and market penetration of Fig. 14-17. Eight transition scenarios were chosen. 
- Conventional (30-mpg) gasoline cars.

- High-efficiency (65-mpg) gasoline HEVs.

- High-efficiency (70-mpg) natural gas HEVs.

- Hydrogen HEVs (80-mpg) fueled by steam reforming.

- Hydrogen HEVs (80-mpg) fueled by steam electrolysis (with "reference" electricity-generation mix).

- Hydrogen HEVs (80-mpg) fueled by steam electrolysis (with "market" electricity- generation mix).

- Hydrogen HEVs (80-mpg) fueled by steam electrolysis (with "climate" electricity-generation mix).

- Advanced (0.16 kWh/mile) BPEVs (with "market" electricity-generation mix).

These options encompass the range of emissions reductions possible from using efficiency, alternative fuels, fossil-fuels, BPEVs, and hydrogen vehicles (for which the hydrogen fuel is made from natural gas and a wide range of electric-generation mixes).

Figure 18(a-d) displays the effect of a transition to each option in terms of U.S. passenger car annual emissions of $\mathrm{CO}_{2}$-equivalent greenhouse gases, NOx, hydrocarbons, and CO. Figure 19(a-d) presents the same options and scenarios in terms of cumulative emissions from U.S. passenger cars.

These figures show that, depending upon the relevant criteria, other advanced/alternative vehicles can deliver a large portion of the benefits of hydrogen vehicles. For example, $65-\mathrm{mpg}$ gasoline vehicles reduce oil consumption by more than half, with greenhouse-gas emissions similar to those of $80-\mathrm{mpg}$ steam-reformed hydrogen vehicles. And 70-mpg natural-gas vehicles can eliminate oil consumption completely, with even lower greenhouse-gas emissions (with the caveat that methane leakage must be eliminated on the vehicle). Natural-gas vehicles would also produce lower hydrocarbon and NOx emissions than steam-reformed hydrogen vehicles. The only criteria on which steam-reformed-based hydrogen vehicles compare favorably to fossil-fueled HEVs are CO tailpipe emissions. BPEVs produce lower pollution and greenhouse-gas emissions than any of the fossil or hydrogen-powered vehicles. Electrolytic hydrogen vehicles can provide lower emissions than most other options only under largely non-fossil electricgeneration mixes (i.e., the "climate" mix). Even though hydrogen vehicles can produce fewer emissions than other alternative-fuel vehicles, the vast majority of emission reductions (from the levels of conventional 30-mpg gasoline vehicles) can be achieved with natural-gas HEVs. 


\section{Maximum Credible Oil Use and Emissions-Reduction Benefits of Hydrogen Vehicles}

An upper estimate of the emissions and oil import reduction benefits of hydrogen vehicles can be made from Fig. 17 and 19, using the transition scenario in which hydrogen vehicles are fueled by steam electrolysis using the most favorable electricity mix (the "climate" scenario).

The value of emission and oil-use reductions can be approximated using control costs for emissions obtained from an Office of Technology Assessment background paper 38 summarizing the Tellus study. The benefits of a transition from $30-\mathrm{mpg}$ gasoline cars to 200 million hydrogen cars can be approximated as shown in Table 5.

Table 5. Emissions benefits from hydrogen vehicles.

\begin{tabular}{|c|c|c|c|}
\hline Externality & Annual savings/benefit & $\begin{array}{l}\begin{array}{l}\text { Price } \\
\text { (billion) }\end{array} \\
\end{array}$ & $\begin{array}{l}\text { Annual value } \\
\text { ( } \$ \text { billion) } \\
\end{array}$ \\
\hline $\begin{array}{l}\text { Carbon monoxide } \\
\text { Nitrogen oxides } \\
\text { Hydrocarbons } \\
\text { Carbon dioxide }\end{array}$ & $\begin{array}{l}4.0 \text { million tons } \\
0.5 \text { million tons } \\
0.4 \text { million tons } \\
600 \text { million tons }\end{array}$ & $\begin{array}{l}\$ 900 / \text { ton } \\
\$ 7500 / \text { ton } \\
\$ 5500 / \text { ton } \\
\$ 24 / \text { ton }\end{array}$ & $\begin{array}{c}3.6 \\
3.8 \\
2.2 \\
14.4\end{array}$ \\
\hline Emissions total & & & 24.0 \\
\hline Oil imports & 2.0 billion barrels & $\$ 30 / \mathrm{bbl}$ & 60 \\
\hline $\begin{array}{l}\text { Total annual value } \\
\text { Total annual benef }\end{array}$ & $\begin{array}{l}\text { of benefit } \\
\text { its per hydrogen vehicle }\end{array}$ & $\begin{aligned} & \$ 84 \\
\sim & \$ 420\end{aligned}$ & \\
\hline
\end{tabular}

This valuation is only approximate, and refinements in the analysis or evaluation process are possible, but two important qualitative results from these calculations are clear:

First, only a tiny fraction, roughly $5 \%$ (in a monetary context), of the emission and oil-use-reduction benefits of hydrogen vehicles are uniquely achievable by hydrogen vehicles ( $\mathrm{CO}$ emission elimination). Even fuel-cell hydrogen vehicles (with zero tailpipe emissions) would only raise the fraction of benefits unique to hydrogen vehicles to $15 \%$ at most.

Second, greenhouse-gas-emissions reductions will be of greater benefit than air-pollution-emission reductions below ULEV gasoline vehicles.

In summary, a strong rationale for hydrogen vehicles requires more than the conventional benefits of air-pollution, greenhouse-gas, and oil-import 
reductions. Hydrogen vehicles need to offer emissions benefits beyond gasoline or natural-gas HEVs and will only do so when the hydrogen is derived from renewable or nuclear energy (because greenhouse-gas emissions from gasoline and natural gas are lower than steam-reformed hydrogen vehicles.

\section{Additional Potential Benefits of Hydrogen Vehicles}

After considering the emissions of vehicles using hydrogen produced from a range of possible electricity-generation mixes and thermochemical production methods, it appears that other benefits are necessary for a robust rationale for hydrogen vehicles, especially in comparison to other vehicle/fuel combinations. Unique benefits are necessary. Three such benefits were advanced in the introduction of this report:

- A smooth, flexible, and enduring transition from gasoline vehicles.

- A flexible, new, value-added market for electricity, improving the economic efficiency of electricity generation and enabling an electricitygeneration mix based in large part on renewables, capturing their environmental and sustainability advantages without the intermittent or fluctuating supply disadvantages of these sources.

- Real and perceived safety advantages of hydrogen vehicles using hydride storage, especially in comparison to compressed storage of alternative fuels.

These advantages are difficult to measure and value precisely, but they can be quite large.

A smooth, flexible, and single transition from today's gasoline vehicles is the strategic goal of every alternative fuel, but hydrogen is superior to other fuels in this regard, because it can be made and used in all of the same ways as other fuels but can also be used and stored more safely (in hydrides) at small scales and is more sustainable. This is the root of both the long-term reliability of a transition to hydrogen vehicles and the short-term low investment risk of starting the transition. To crudely estimate the potential value of this benefit, consider that 2-10 million alternative fuel vehicles (1$5 \%$ market penetration of the 2050 passenger car fleet) are built and that these vehicles later become stranded without a fuel supply (due to any of a number of environmental, economic, or technological changes). This would correspond to a loss of $\$ 40-200$ billion, sufficient perhaps to build the hydrogen-fuel-supply infrastructure for 100 million passenger vehicles.

Electrolytic hydrogen vehicles could dramatically improve the economic efficiency of the nation's utilities and electricity supply system by 2030 . Adding new electricity-generating capacity (and replacing retired capacity) requires a large investment. Forty gigawatts of new capacity is projected to be added by 2010, by which time U.S. generating capacity will reach $722 \mathrm{GW}$. More than $\$ 400-700$ billion will probably be required between 2010 and 2050 to replace this capacity as it ages. Projected electricity production of 3.2 trillion kWh in 
2010 represents only a $50 \%$ capacity utilization of this investment. Electrolytic hydrogen vehicles can make fuller use of this underutilized investment by creating a very large market tolerant of intermittent or off-peak service. Thirty billion kilograms of electrolytic hydrogen would be needed annually to fuel 200 million vehicles traveling 2.4 trillion miles/yr in 2050. The additional 1.6 trillion $\mathrm{kWh} / \mathrm{yr}$ electricity demand would increase utilization of the giant investment in generating capacity to $70 \%$. Estimating the total capital investment of U.S. electric generation in 2035 at $\$ 1$ trillion, and discounting at $10 \%$ over 30 years, the extra benefit of efficiently utilizing generating capacity would be perhaps $\$ 20$ billion annually or $\$ 100 /$ vehicle. For reference, the electricity cost (at $\$ 0.05 / \mathrm{kWh}$ ) for hydrogen fuel would be roughly $\$ 75$ billion annually.

In addition to possible fuel and energy-infrastructure benefits of hydrogen, vehicle characteristics can benefit from hydrogen fuel. Hydrogen's most unique characteristic in this respect is a diversity of storage technologies. The potential safety benefit of hydrogen vehicles with hydride storage is not easily quantified, but there are inherently lower risks than with vehicles using cryogenic and/or high-pressure compressed gas storage, and these lower risks can be readily understood, perceived, and valued by consumers. 


\section{Conclusions}

Examining and estimating the costs, emissions, and benefits of a transition to hydrogen vehicles has led to a number of conclusions.

\section{A. Efficiency and Economics}

High-efficiency $(\sim 80 \mathrm{mpg})$ vehicles are crucial to the competitiveness of hydrogen fuel. An efficient vehicle reduces sensitivity to fuel and onboard storage cost, allowing the full range of possible onboard storage, production, and delivery infrastructures, while reducing the fuel-cycle energy requirements and associated emissions. Internal-combustion-engine HEVs can achieve the necessary fuel efficiency and lead to development of the infrastructure and market for hydrogen fuel cells without requiring automotive fuel cells.

Given 80-mpg-equivalent hydrogen vehicles, all of the options we examined were economically feasible in terms of fuel cost, with conservative economic assumptions ( $\$ 4.00 / \mathrm{GJ}$ natural gas, $\$ 0.05 / \mathrm{kWh}$ off-peak electricity, $\$ 250 /$ ton ammonia, $\$ 11 / \mathrm{GJ}$ methanol, and $20 \%$ discount rates). Cost differences among hydrogen production methods at similar delivery scales were almost negligible (1-2 cents/mile) in comparison to vehicle lifecycle costs (45 cents $/$ mile).

Hydrogen fuel costs were \$35-75/GJ (4.5-11 cents/mile), depending principally upon scale. At stations, hydrogen will cost $\$ 30-50 / G J$, with roughly $\$ 15 / \mathrm{GJ}$ for overhead and compressed gas storage. Production costs are dominated by energy costs except in the case of steam-reforming. Liquid hydrogen delivery was generally cheaper than other options because of onsite storage costs. Among on-site production technologies at the station scale, steam electrolysis and steam reforming could have comparable hydrogen production costs. At smaller production/delivery scales (60 cars/day), the capital costs of storage increase, raising hydrogen costs to $\$ 35-65 / \mathrm{GJ}$. Small fleets that refuel approximately 10 vehicles/day would have hydrogen costs of $\$ 65-75 /$ GJ. Residential electrolysis for a single vehicle is estimated to cost $\$ 60$ 70/GJ.

The greatest potential for cost savings is probably in storage technologies (perhaps hydrides or glass microspheres) to replace compressed gas, especially at small scales. Off-peak electricity rates lower than $\$ 0.05 / \mathrm{kWh}$ would also be significant. 


\section{B. Urban Air Pollution}

Hydrogen vehicles have much lower tailpipe emissions and total $\mathrm{CO}$ emissions than ULEV fossil-fueled HEVs, but full-fuel-cycle emissions estimates (with natural gas as the primary energy source of hydrogen and electricity) indicate that a rationale based on NOx and hydrocarbon emission reductions below ULEV vehicles is weak. To support a rationale for hydrogen vehicles based on full-fuel-cycle emissions requires sustainable sources as a necessary part of the primary energy used to produce hydrogen.

Vehicles using steam-reformed hydrogen (from natural gas) and with hydride storage can achieve emissions levels comparable to BPEVs using natural-gasfired power plants.

Based upon the control costs used in the Tellus study, the benefits from automotive emission reductions below ULEV levels are relatively small for hydrogen vehicles, given the already low air pollutant emission levels of ULEV vehicles in the near future. Other benefits of hydrogen vehicles-such as reducing oil consumption and greenhouse gases or increasing the use of electric generation capacity-are much larger.

\section{Greenhouse Gas Emissions}

High-efficiency gasoline and natural-gas vehicles can achieve lower greenhouse-gas emissions ( $\mathrm{CO}_{2}$ equivalent) than hydrogen vehicles using natural gas as a primary energy source by thermochemical or electrolytic methods. Therefore a rationale based on greenhouse-gas emissions will require significant renewable or nuclear sources of hydrogen before hydrogen vehicles become a major portion of the passenger car fleet (e.g., 2015-2020).

If natural gas is the primary energy source, and if electricity-intensive hydrogen storage (i.e., liquefaction, high-pressure compression) is used, steam-reformed hydrogen vehicles produce $50-100 \%$ more greenhouse-gas emissions than do BPEVs.

\section{Other Benefits of Hydrogen Vehicles}

Overall consideration of the costs and full-fuel-cycle emissions of hydrogen and other alternative-fuel vehicles indicates that additional benefits of hydrogen vehicles beyond emission reductions below ULEV standards are necessary for a robust rationale for hydrogen vehicles. These benefits could potentially be:

- Hydrogen enables a plausible transition from gasoline vehicles that is smoother, more flexible, and more enduring than other alternative-fuel options. This benefit is large but strategic, and therefore hard to quantify. 
- Hydride storage is inherently lower-risk in terms of safety when compared to other alternative fuels. Hydride storage also allows greater flexibility in the hydrogen production and delivery infrastructure, especially when enabling cost-effective production at small scales early in the transition.

- Hydrogen vehicles fueled by off-peak electrolysis can enhance economic efficiency by combining the transportation energy and utility sectors. Fueling 200 million vehicles with electrolytic hydrogen could increase the utility sector's profitability by approximately $\$ 20$ billion annually by raising the use of generating capacity from $50 \%$ to $70 \%$.

- The increased-but flexible-electricity demand $(\sim 30 \%$ of electricity production to fuel 200 million vehicles with electrolytic hydrogen) will permit intermittent or fluctuating renewable energy resources to become a major part of the electricity generating mix.

\section{E. General Conclusions}

\section{Hydrogen Is Affordable}

Vehicle issues (e.g., efficiency, consumer acceptance, safety, range, vehicle life), strategic infrastructure issues, (reliable fuel supply, flexibility, complementary role with existing energy infrastructure), and public policy issues (sustainability and secure domestic hydrogen production) are more important than the costs of producing and delivering hydrogen by different pathways. Many pathways are affordable, given high-efficiency vehicles.

\section{Renewable Electricity Makes the Case Stronger}

Onboard vehicle storage, infrastructure, and public benefit arguments are sufficient to distinguish the desirability of various production/delivery pathways in the overall context of creating a robust rationale for hydrogen vehicles as the best choice among advanced gasoline or alternative-fuel vehicles. The case for hydrogen vehicles is strongest when they enable renewable electricity to significantly penetrate the utility sector (with the attendant environmental benefits).

The three traditionally cited benefits of hydrogen fuel can be largely met by vehicles with fuels that are cheaper and more compactly stored onboard vehicles.

- Gasoline or natural-gas ULEV vehicles will make the urban air pollution emission advantages of hydrogen minimal, especially on a fuel-cycle basis.

- Natural-gas HEVs can displace oil imports at lower cost and with better vehicle range than hydrogen hybrids. 
- Renewable methanol HEVs achieve the $\mathrm{CO}_{2}$ and oil import advantages of hydrogen HEVs at lower cost and with better vehicle range than hydrogen HEVs.

Electrolytic hydrogen pathways, however, can provide major additional benefits beyond these alternatives, given a renewable-intensive electricitygeneration mix.

\section{Onboard Storage Benefits}

Storage technologies can also provide benefits over other fuels. Onboard storage choices can make or break the rationale for hydrogen fuel and vehicles, because they deeply influence both the production and delivery infrastructure and vehicle differentiation, especially in comparison to other cheap, and nearly as clean, alternative fuels (e.g., natural gas). Compressed hydrogen and $\mathrm{LH}_{2}$ storage onboard vehicles are inferior to compressed natural gas or liquefied natural gas in capital cost, vehicle range, and energy requirements. In addition, these storage technologies limit the minimum feasible delivery scale of hydrogen vehicles.

Fortunately, hydrogen storage has more innovative possibilities. Hydride storage provides safety advantages over other fuels, which may ease consumer acceptance and speed the transition. A 300-mile range is feasible with iron-titanium (Fe-Ti) based systems in an $\mathrm{HEV}$ with regenerative braking. (The weight of the hydrides exacts a mileage penalty of about $10 \%$ ). Longer range is achievable without the full energy, cost, and emission penalties of other storage technologies; a combination hydrogen storage system is possible. For example, 100-150 miles of Fe-Ti-based hydride storage coupled with lighter-weight, higher-density, and lower-cost hydrogen storage $\left(\mathrm{LH}_{2}, \mathrm{NH}_{3}, \mathrm{Mg}\right.$-based hydrides) for additional (300-500 mile) range could provide long range without energy, cost, and emission penalties for short urban trips (which comprise the vast majority of total vehicle miles), if the hydrides were refueled separately.

In addition to hydrogen storage, the choice of onboard electricity storage could dramatically change the rationale for hydrogen-powered electric vehicles. Moderate increases in onboard electricity storage (to 2-5 kWh) would allow a significant range (10-30 miles) using electricity largely by recharging at home or work, or by an onboard photovoltaic panel. Supplementing hydrogen fuel with electricity stored in flywheels or batteries could dramatically improve overall drivetrain life, energy efficiency, emissions, and fuel cost for hydrogen vehicles driven moderate distances. 


\section{Recommendations and a Transition Scenario}

\section{A. Need for Technology Development}

A smooth, flexible, ultimate transition, enabling a renewable-intensive electricity mix, is the most valuable benefit that is unique to hydrogen vehicles. Consequently, renewable (or nuclear) electricity and efficient electrolysis technologies will need to be pursued and developed before the hydrogen transition will progress beyond a fraction of the light-duty fleet.

This study has shown that hydrogen offers few benefits that natural gas, a strong candidate for alternative-fuel vehicles, cannot provide. One distinct advantage of hydrogen, however, is hydride storage. A hydride storage system could arguably be declared safer than gasoline and thus lead to public acceptance of hydrogen. Onboard hydride storage needs to be developed sufficient for $3.75 \mathrm{~kg}$ of hydrogen. Fe-Ti- based hydrides are probably suitable.

Another major benefit of hydrogen is the possibility of on-site production, particularly at small scales. Small-scale electrolysis technology should be developed at the station $(1000 \mathrm{~kg} /$ day), fleet $(200 \mathrm{~kg} /$ day), small fleet (30 $\mathrm{kg} /$ day), and individual vehicle $(0.4 \mathrm{~kg} /$ day) levels. The principal need is for new technologies amenable to mass production, or for developing new massproduction techniques for electrolyzers. At small scales, compressor costs can be high; storage media that are filled directly from hydrogen production equipment (e.g., low-pressure gas, glass microspheres, or hydride storage) are needed.

If range requirements beyond hydride storage ( 300 miles) are desired, onboard storage using hydrides combined with either $\mathrm{LH}_{2}$ or cryogenic compressed hydrogen would allow greater range and refueling flexibility, without the full emissions and energy penalties of compressed gas or $\mathrm{LH}_{2}$. A combination vehicular storage system should be thoroughly analyzed for possible development.

\section{B. Need for System Studies}

Vehicle issues, providing fuel supply reliability, and providing benefits from hydrogen fuel that other alternative vehicles cannot supply, should drive the fueling infrastructure-NOT fuel cost. System studies should focus on strategic issues, rather than on fuel cost. These issues need to be addressed to develop a robust rationale for hydrogen fuel and vehicles.

One candidate for study is the feasibility of a hydrogen vehicle with supplementary electricity storage, onboard photovoltaic panels, and 
recharging capability from the grid at home or work. There are potentially dramatic implications for vehicle drivetrain life, hydrogen demand, and infrastructure development, as well as for the utility sector, depending upon driving patterns.

Another issue is to ascertain the degree to which the size and flexibility of demand for electrolytic hydrogen enable the large-scale use of intermittent and renewable resources in the utility sector. Electrolyzing hydrogen for vehicles should be examined and compared with other approaches to enable large-scale renewable implementation and for utility load-leveling using hydrogen.

\section{A Proposed Transition Scenario}

The proposed transition scenario described here would capture the fullest possible benefits of hydrogen at reasonable cost, and thereby support a robust rationale for hydrogen vehicles as the best advanced or alternative-fuel vehicle choice.

1995-2005-Prototype and technology evaluation projects develop (1) a spectrum of production/delivery options and scales beyond $\mathrm{LH}_{2}$ delivery (electrolysis, methanol and ammonia reforming, low-pressure gas, hydrides), (2) hydrogen vehicles for different applications (utility vehicles, buses, cars, trucks), and (3) different onboard storage technologies (cryogenic gas, hydrides, $\mathrm{LH}_{2}$ ).

2001-The transition begins with electrolytically fueled fleet vehicles using hydride storage, providing the first mass market for vehicle technologies and real-world testing. Alternatively, a cheaper and more readily available fueling pathway would be to fuel the fleet via $\mathrm{LH}_{2}$. Such demonstration fleets are necessary to gain favorable actuarial data for insurance purposes.

2003-Electrolytic home refueling for pilot-production quantities of hydrogen vehicles provides the first mass market for electrolyzers and later meets ZEVequivalent mandates without range disadvantages and without the possible further delays of BPEVs.

2005-Mass-production of hydrogen-powered electric vehicles provides a large market for automotive photovoltaic panels to charge onboard electricity storage, enabling the photovoltaic industry to mature in preparation for entering utility markets. Solar electricity complementing hydrogen fuel onboard vehicles dramatically decreases overall emissions, improves drivetrain life, increases energy efficiency, and reduces fuel cost for drivers who make many short trips. 
2010-Having more than 1-5 million hydrogen vehicles in fleet applications stimulates improvements and developments in onboard storage and vehicle efficiency, before the majority of the hydrogen fueling infrastructure is constructed, so that vehicle/infrastructure compatibility is maintained and the maximum vehicle value accelerates market penetration.

-Filling stations or large fleets develop as warranted by market forces, depending upon utility, natural-gas, and/or ammonia industry willingness to participate. Filling stations are of sufficient scale and represent aggregate hydrogen demand large enough to develop and commercialize steam electrolysis.

2015-Electrolytic hydrogen vehicles are numerous enough to create a large, flexible electricity demand, enabling utilities to contemplate major contributions from renewable sources, with attendant environmental advantages. Vehicles can be refueled at stations, fleets, or homes.

2025-Widespread renewable electricity and a full transition to hydrogen vehicles enables a largely clean, low-emission, utility sector, with high economic efficiency, making $\mathrm{LH}_{2}$ and renewable ammonia production feasible on environmental grounds. Liquid hydrogen and/or renewable ammonia now allow the penetration of hydrogen fuel into higher-energydensity applications such as trucks, aircraft, and boats without major performance disadvantages. 


\section{Acknowledgments}

I am grateful to the following for their helpful suggestions in an earlier stage of this work: J.M. Ogden, M. DeLuchi, P.K. Takahashi, and W. Van Vorst. I have benefited greatly from discussions with J. Birk, K. Davis, M. Fairlie, W. Kincaide, D. Sperling, V. Raman, P. Campos, and M. Schalef on infrastructure issues dealing with the introduction of hydrogen into the marketplace. I thank J.R. Smith, R.N. Schock, and G.V. Kaiper for reviewing a draft of this report. This work performed under the auspices of the U.S. Department of Energy by the Lawrence Livermore National Laboratory under Contract No. W-7405-ENG-48. 


\section{References}

1. Joan Ogden, E. Dennis, and Kristalee Montemayor, "Developing a Hydrogen Infrastructure," in Proceedings of the National Hydrogen Association's 6th Annual U.S. Hydrogen Meeting (Alexandria, VA, Mar. 7-9, 1995) pp. 237-260.

2. "Ballard develops fuel cell with power density high enough for automobiles," Clean Fuels Report 7 (Nov. 1995).

3. Christopher Borroni-Bird, Chrysler Corporation. "Light Duty Vehicle Requirements for Fuel Cells and Fuel Processors." Presentation for PNGV Workshop on Fuel Processing for Proton Exchange Membrane Fuel Cells at the Annual Automotive Technology Development Contractor's Coordination Meeting (Dearborn, MI, Oct. 23-27, 1995).

4. Ron Sims, Ford Motor Company, Dearborn, MI, private communication, March 1995.

5. S. M. Aceves and J. R. Smith, "A Hybrid Vehicle Evaluation Code and Its Application to Vehicle Design," SAE paper 950491. SAE International Congress and Exposition (Detroit, MI, Feb. 27-Mar. 2, 1995); Lawrence Livermore National Laboratory Report UCRL-JC-117918.

6. Synergy 2010 Concept Car as described at Ford Motor Company's World Wide Web site (http://www.ford.com) on Jan. 6, 1996.

7. The Hydrogen Letfer, (July 1994), citing SRI International's "Hydrogen" report, published as part of SRI's Chemical Economics Handbook Program (Menlo Park, CA, 1994). The Hydrogen Letter is available from Peter Hoffman, ed., 4104 Jefferson St. Hyattsville, MD.

8. Joan M. Ogden, E. Dennis, M Steinbugler, and J. Strohbehn, "Hydrogen Energy Systems Studies," Final Report to NREL for Contract No. XR11265-2, Center for Energy and Environmental Studies, Princeton University, Princeton, NJ (Jan. 18, 1995).

9. Hydride trailer costs are based on an Fe-Ti hydride trailer design in Kenneth E. Cox and K.D. Williamson, Jr., ed., Hydrogen: Its Technology and Implications, Vol. 5, "Implications of Hydrogen Energy," (CRC Press, Boca Raton, FL, 1979). Magnesium-based hydride alloys were estimated to cost $\$ 10 / \mathrm{kg}$ of alloy.

10. Energy Information Administration, Annual Energy Outlook 1995 with Projections to 2010. DOE/EIA-0383(95) Distribution Category UC-950, Office of Integrated Analysis and Forecasting, U.S. Department of Energy, Washington DC (Jan. 1995).

11. Dana V. O'Hara, Program Manager, Electric and Hybrid Propulsion Division, "DOE EV Implementation Plan." U.S. DOE Presentation for Advanced Energy Storage at the Annual Automotive Technology Development Contractor's Coordination Meeting (Dearborn, MI, Oct. 2327, 1995).

12. "California is Backing Off Mandate for Electric Car: Board Finds Shortcomings in Technology," New York Times, (Dec. 26, 1995). 
13. FY96 Hydrogen Program Annual Operating Plan, Prepared for the U.S. Department of Energy, Office of Utility Technologies, Advanced Utility Concepts Division, by Energetics Incorporated, Columbia, MD (Nov. 1995).

14. Neal Richter, Research Fellow, Texaco Montebello Research Center, Montebello, CA, private communication, 1995.

15. T. A. Czuppon, S.A. Knez, and D.S. Newsome of the M.W. Kellogg Company, Houston, Texas, "Hydrogen," in Encyclopedia of Energy Technology and the Environment, Vol. 3. (John Wiley \& Sons, Inc., New York, 1995) pp. 1752-1782.

16. Christofer Palasinski of Gardner Cryogenics, private communication, June 24, 1994.

17. Glenn D. Rambach, Hydrogen Transport and Storage in Engineered Glass Microspheres, Rev. 1. Presented at the DOE Hydrogen Program Contractor's Review Meeting, Coral Gables, FL, Apr. 18-21, 1995; Lawrence Livermore National Laboratory report UCRL-JC-120054 Rev. 1.

18. Mark DeLuchi, Fuel-Cell Vehicles, Research report UCD-ITS-RR-92-14. Institute of Transportation Studies, University of California at Davis, Davis, CA. (1992)

19. H. M. Sachs, J. Decicco, M. Ledbetter, and U. Mengelberg, "Heavy Truck Fuel-Economy: A Review of Advanced Technologies and Potential for Improvement." TRB Paper No. 920619, 71st Annual Meeting of the Transportation Research Board, American Council for an EnergyEfficient Economy, Washington, DC (1992).

20. AAMA Motor Vehicle Facts \& Figures 1995, (American Automobile Manufacturers Association, Washington, DC, 1995).

21. Russell Burton Scott, W.H. Denton, and C.M. Nicholls, Technology and Uses of Liquid Hydrogen (The Macmillan Company, New York, 1964) p. 54 .

22. M. Bracha, G. Lorenz, A Patzelt, and M. Wanner, "Large-Scale Hydrogen Liquefaction in Germany," International Journal of Hydrogen Energy 19 (Jan. 1994), pp. 53-59.

23. David L. Block, Subhash Dutta, and Ali T-Raissi, "Hydrogen for Power Applications: Task 2, Storage of Hydrogen in Solid, Liquid, and Gaseous Forms," FSEC-CR-204-88. Subcontract No. XK-7-07158. Florida Solar Energy Center (1988) p. 37.

24. Bob Moore, Air Products and Chemicals, "A Summary and Analysis of the Codes and Standards for Hydrogen Energy Workshop," in Proceedings of the National Hydrogen Association's 6th Annual U.S. Hydrogen Meeting (Alexandria, VA, Mar. 7-9, 1995) p. 148.

25. G. Eklund and O. Von Krusenstierna, "Storage and Transportation of Merchant Hydrogen," International Journal of Hydrogen Energy 8 (June 1983) pp. 463-470.

26. Charles L. Davis, "Nitrogen (Ammonia)," in Mineral Facts and Problems, 1985 Ed., U.S. Department of the Interior, Bureau of Mines, Bulletin 675, p. 559. 
27. J. R. Jennings, Catalytic Ammonia Synthesis: Fundamentals and Practice, (Plenum Press, New York, 1991) pp. 263-265.

28. T. Molter, "SPE Water Electrolyzers for Commercial Hydrogen Production," Hamilton Standard Division of United Technologies, Space and Sea Systems, Windsor Locks, CT (1994).

29. K.H. Quandt and R. Streicher, "Concept and Design of a 3.5 MW Pilot Plant for High Temperature Electrolysis of Water Vapor," International Journal of Hydrogen Energy 11, No. 5 (1986) pp. 309-315.

30. W.C. Kincaide, Teledyne Brown Engineering, Energy Systems, Hunt Valley, MD, private communication, June 1995.

31. G. D. Berry, J. Ray Smith, and Robert N. Schock, A Smooth Transition to Hydrogen Transportation Fuel, presented at the DOE Hydrogen Program Review Coral Gables, FL, Apr. 19-21, 1995; Lawrence Livermore National Laboratory Report UCRL-JC-120152.

32. Scott Hynek and W. Fuller, A. D. Little, Inc., "Hydrogen Storage Within the Infrastructure," Presented at Hydrogen '94; the 10th World Hydrogen Energy Conference (Cocoa Beach, FL, June 20-24, 1994) Vol. 2, pp. 13411353.

33. "Behind the Wheel in Honda's New Gasoline-Powered ULEV Accord EX," Green Car Journal 4 (Apr. 1995) pp. 37-39.

34. J. Ray Smith, Salvador Aceves, and Peter Van Blarigan, Series Hybrid Vehicles and Optimized Hydrogen Engine Design. Presented at SAE Future Transportation Technology Conference and Exposition, Costa Mesa, CA (Aug. 7-10, 1995), SAE paper 951955; Lawrence Livermore National Laboratory report UCRL-JC-121174.

35. J. Ray Smith, Lawrence Livermore National Laboratory, private communication, Jan. 1996.

36. Kenneth G. Darrow, "Light-Duty Vehicle Full Fuel Cycle Emissions Analysis," Energy International Report No. 9333R440, prepared for Gas Research Institute under Contract No. 5093-294-2573. Energy International Inc., Bellevue, WA.

37. America's Energy Choices: Investing in a Strong Economy and a Clean Environment, (Union of Concerned Scientists, Cambridge, MA, 1992).

38. Office of Technology Assessment, U.S. Congress, "Studies of the Environmental Costs of Electricity," OTA-ETI-134 (U.S. Government Printing Office, Washington DC, Sept. 1994). 


\section{Appendix A}

\section{Meeting National Energy Policy Goals with Hydrogen Energy}

Renewable hydrogen fuel can best meet the goals of the Nation's energy policy. The most recent consensus reached on energy policy by the U.S. Congress was the Energy Policy Act of 1992. Title XX, Section 2001, of the Act established eight goals for Federal energy research and development. These goals were reiterated in 1995 by the current Administration in Sustainable Energy Strategy: Clean and Secure Energy for a Competitive Economy (U.S. Government Printing Office, Superintendent of Documents, Washington, DC, ISBN 0-16-048183-x, page 55). The goals are quoted below in bold type, followed by comments to show that hydrogen fuel, vehicles, and production technology can best achieve these goals, far more comprehensively and with greater flexibility and consistency than other options.

It is the goal of the United States in carrying out energy supply and energy conservation research and development-

(1) to strengthen national energy security by reducing dependence on imported oil;

Many fuel/vehicle combinations can displace imported oil, but hydrogen fuel can be made from cleaner, more diverse, and more sustainable primary energy sources than other fuels, with vehicle range that battery-powered electric vehicles cannot match.

(2) to increase the efficiency of the economy by meeting future needs for energy services at the lowest total cost to the Nation, including environmental costs, giving comparable consideration to technologies that enhance energy supply and technologies that improve the efficiency of energy end uses;

Hydrogen fuel has higher direct costs, but these are offset by unparalleled enduse efficiency capabilities and by much lower environmental costs than any other energy carrier. Hydrogen fuel can uniquely integrate transportation fuel supply with the existing and future electricity supply system, increasing the overall economic efficiency of the nation's energy supply infrastructure.

(3) to reduce the air, water, and other environmental impacts (including emissions of greenhouse gases) of energy production, distribution, transportation, and utilization, through the development of an environmentally sustainable energy system; 
Hydrogen fuel is the obvious choice for an environmentally sustainable energy system. It can be made locally or at the point of use from renewable electricity, with minimal land and water requirements, producing zero emissions throughout the fuel cycle. Hydrogen can extend the reach of renewable electricity to include uses where electric battery storage is too costly, heavy, bulky, material intensive, or environmentally undesirable.

(4) to maintain the technological competitiveness of the United States and stimulate economic growth through the development of advanced materials and technologies;

Hydrogen fuel provides much greater opportunity for advanced materials and technology markets than any other fuel. The advanced materials and technology associated with hydrogen have been explored and developed for onboard power systems in spacecraft since the 1960s. Advanced materials and technology are used throughout hydrogen production, storage, and end use. Advances in technology that can develop while implementing hydrogen energy include cryogenics, high-pressure gas storage, solid-state compressors, energy storage using metal hydrides, magnetic refrigeration, electrochemical production, and the use of plastics, molten salts, and solid oxide materials. The higher incentives for fuel efficiency in hydrogen vehicles will demand greater improvements in vehicle technology than conventional fuels. Lowcost thin-film materials and manufacturing techniques can develop through the commercialization of photovoltaics and high-density fuel cells to produce and use hydrogen. Hydrogen fuel would be used on an unprecedented scale in economic sectors crucial to maintaining U.S. competitiveness, such as automobiles, aircraft, and the metallurgical and chemical industries.

(5) to foster international cooperation by developing international markets for domestically produced sustainable energy technologies, and by transferring environmentally sound, advanced, energy systems and technologies to developing countries to promote sustainable development;

Hydrogen is uniquely suited to promote sustainable development in developing countries. Hydrogen technologies enable renewables to reach beyond the constraints of battery storage. Hydrogen has excellent small-scale and distributed production potential, especially in concert with renewable energy. Such systems would be unsurpassed in their environmental soundness and advanced technical character.

(6) to consider the comparative environmental and public health impacts of the energy to be produced or saved by the specific activities;

Hydrogen fuel from renewable sources has the greatest ability to prevent environmental and public health impacts from urban air pollution, land and water use, and waste generation due to fuel production. Hydrogen is nontoxic and has no environmental impacts when spilled or released. It produces no 
carbon monoxide or hydrocarbons when burned, and NOx can be eliminated if lean combustion or fuel cells are used to produce electricity.

(7) to consider the obstacles inherent in private industry's development of new energy technologies and steps necessary for establishing or maintaining technological leadership in the area of energy and energy efficiency resource technologies; and

Hydrogen fuel can overcome some market obstacles to new energy technologies better than other options through decentralized small-scale production and through storage at or near the point of use. The Department of Energy's national laboratories can reduce the technical and economic risk of advanced hydrogen technologies, encouraging U.S. industry to bring these technologies to market. Advanced renewable energy technologies to produce hydrogen and advanced technologies to store and use hydrogen efficiently are being pursued vigorously in Europe and Japan. Hydrogen technology development and commercialization is a necessary step in establishing U.S. technological leadership in energy supply and energy-efficient end-use technologies, especially vehicles, in the 21 st century.

(8) to consider the contribution of a given activity to fundamental scientific knowledge.

Hydrogen has a variety of unique properties and advantages, as the simplest, smallest, and lightest element. Hydrogen production, storage, and use methods span thermochemistry, electrochemistry, biology, cryogenics, solid state physics, and advanced materials science. Developing these technologies will create considerably more new scientific knowledge than conventional, mature, energy technologies for fossil fuels. 


\section{Appendix B}

\section{Technical and Economic Summaries}

This appendix provides the technical and economic assumptions of (1) liquid hydrogen and compressed gas storage at stations of various sizes, and (2) each of the eight hydrogen pathways examined in this study, highlighting salient technical and economic parameters. Costs are given in 1996 dollars using the Producer Price Index (PPI) for capital equipment up to 1991. Costs were escalated an additional 10\% to convert from 1991 to 1996 dollars (an average of $1.9 \% / \mathrm{yr}$ ).

\section{Liquid Hydrogen Station Parameters}

Cars served

Vehicle tank size

Average fillup

Hydrogen throughput

Compressed $\mathrm{H}_{2}$ dispensers (4 hoses @ $1 \mathrm{~kg} / \mathrm{min}$ each)

15,000 gallon $\mathrm{LH}_{2}$ storage tank $(4000 \mathrm{~kg} \mathrm{H})$

$\mathrm{LH}_{2}$ pumps and vaporizers ( $2000 \mathrm{~kg} \mathrm{H} /$ day capacity)

Total capital investment

Operating and maintenance (tanks, pumps, dispensers)

$\mathrm{LH}_{2}$ pump electricity @ $\$ 0.05 / \mathrm{kWh}$

Overhead (including labor)

Total operating costs

\section{Liquid Hydrogen Small Station Parameters}

Cars served

Vehicle tank size

Average fillup

Hydrogen throughput

Compressed $\mathrm{H}_{2}$ dispensers ( 2 hoses @ $1 \mathrm{~kg} / \mathrm{min}$ each)

6,000 gallon $\mathrm{LH}_{2}$ storage tank $\left(1600 \mathrm{~kg} \mathrm{H}_{2}\right)$

$\mathrm{LH}_{2}$ pumps and vaporizers ( $1000 \mathrm{~kg} \mathrm{H}_{2}$ /day capacity)

Total capital investment

Operating and maintenance (tanks, pumps, dispensers)

$\mathrm{LH}_{2}$ pump electricity @ $\$ 0.05 / \mathrm{kWh}$

Overhead (including labor)

Total operating costs
300 cars/day

$3.75 \mathrm{~kg} \mathrm{H} 2$

$3.0 \mathrm{~kg} \mathrm{H}$

$900 \mathrm{~kg} \mathrm{H}_{2}$ /day

$\$ 100,000$

$\$ 180,000$

$\$ 72,000$

$\$ 352,000$

$\$ 9000 / \mathrm{yr}$

$\$ 4,500 / \mathrm{yr}$

$\$ 265,000 / \mathrm{yr}$

$\$ 279,000 / \mathrm{yr}$
60 cars / day

$3.75 \mathrm{~kg} \mathrm{H}$

$3.0 \mathrm{~kg} \mathrm{H} 2$

$180 \mathrm{~kg} \mathrm{H}_{2}$ /day

$\$ 50,000$

$\$ 120,000$

$\$ 36,000$

$\$ 206,000$

$\$ 5000 / \mathrm{yr}$

$\$ 1000 / \mathrm{yr}$

$\$ 53,000 / \mathrm{yr}$

$\$ 59,000 / \mathrm{yr}$ 
Liquid Hydrogen Fleet Refueling Parameters

Cars served

Vehicle tank size

10 cars/day

Average fillup

Hydrogen throughput

Compressed $\mathrm{H}_{2}$ dispenser ( 1 hose @ $1 \mathrm{~kg} / \mathrm{min}$ )

1650 -gallon $\mathrm{LH}_{2}$ storage tank $(400 \mathrm{~kg} \mathrm{H})$

$3.75 \mathrm{~kg} \mathrm{H}_{2}$

$3.0 \mathrm{~kg} \mathrm{H}_{2}$

$\mathrm{LH}_{2}$ pumps and vaporizers ( $1000 \mathrm{~kg} \mathrm{H} /$ day capacity)

$30 \mathrm{~kg} \mathrm{H}_{2}$ / day

Total capital investment

$\$ 30,000$

$\$ 92,000$

$\$ 36,000$

Operating and maintenance (tanks, pumps, dispensers)

LH 2 pump electricity @ $\$ 0.05 / \mathrm{kWh}$

$\$ 158,000$

Overhead (part-time labor)

$\$ 5000 / \mathrm{yr}$

$\$ 160 / \mathrm{yr}$

$\$ 8,830 / \mathrm{yr}$

Total operating costs

$\$ 14,000 / \mathrm{yr}$

\section{Compressed Gas Station Parameters}

Cars served

Vehicle tank size

300 cars/day

Average fillup

$3.75 \mathrm{~kg} \mathrm{H} 2$

Hydrogen throughput

$3.0 \mathrm{~kg} \mathrm{H}$

Hydrogen output pressure

Electricity requirements ( $8400 \mathrm{psi}$ )

Cascade $\mathrm{H}_{2}$ recovery efficiency

Storage compressor capacity (two $98-\mathrm{kW}$ compressors)

Usable storage capacity

Compressed $\mathrm{H}_{2}$ dispensers (4 hoses @ $1 \mathrm{~kg} / \mathrm{min}$ each)

Storage compressors (multi-stage 200 up to $8400 \mathrm{psi}$ )

Storage tanks (63 vessels 8400 psi cascade)

$900 \mathrm{~kg} \mathrm{H}_{2} /$ day

Total capital investment

$8400 \mathrm{psi}$

$2.75 \mathrm{kWh} / \mathrm{kg} \mathrm{H}$

$60 \%$

$1700 \mathrm{~kg} \mathrm{H}_{2}$ /day

$540 \mathrm{~kg} \mathrm{H}_{2}$

$\$ 100,000$

$\$ 380,000$

$\$ 660,000$

Operating and maintenance

Compression electricity @ \$0.05/kWh

Overhead (including labor)

$\$ 1.14$ million

Total operating costs

$\$ 15,000 / y r$

$\$ 45,000 / \mathrm{yr}$

$\$ 265,000 / \mathrm{yr}$

$\$ 325,000 / \mathrm{yr}$ 
Compressed Gas Small Station Parameters

Cars served

Vehicle tank size

Average fillup

Hydrogen throughput

Hydrogen output pressure

Electricity requirements ( $8400 \mathrm{psi})$

Cascade $\mathrm{H}_{2}$ recovery efficiency

Storage compressor capacity ( $98 \mathrm{~kW})$

Usable storage capacity

Compressed $\mathrm{H}_{2}$ dispensers (2 hoses @ $1 \mathrm{~kg} / \mathrm{min}$ each )

Storage compressor (multi-stage $200 \mathrm{psi}$ to $8400 \mathrm{psi}$ ) ( $850 \mathrm{~kg} \mathrm{H}_{2}$ /day)

60 cars/day

$3.75 \mathrm{~kg} \mathrm{H}_{2}$

$3.0 \mathrm{~kg} \mathrm{H}_{2}$

$180 \mathrm{~kg} \mathrm{H}_{2} /$ day

8400 psi

$2.75 \mathrm{kWh} / \mathrm{kg} \mathrm{H}$

$60 \%$

$850 \mathrm{~kg} \mathrm{H}_{2} /$ day

$100 \mathrm{~kg} \mathrm{H}_{2}$

$\$ 50,000$

$\$ 190,000$

Storage tanks (13 vessels 8400 psi cascade)

$\$ 140,000$

Total capital investment

$\$ 380,000$

Operating and maintenance

Compression electricity @ $\$ 0.05 / \mathrm{kWh}$

Overhead (including labor)

$\$ 5300 / \mathrm{yr}$

$\$ 9,000 / \mathrm{yr}$

$\$ 53,000 / \mathrm{yr}$

Total operating costs

$\$ 67,300 / \mathrm{yr}$

\section{Compressed Gas Fleet Refueling Parameters}

Cars served

Vehicle tank size

Average fillup

Hydrogen throughput

10/day

$3.75 \mathrm{~kg} \mathrm{H}_{2}$

$3.0 \mathrm{~kg} \mathrm{H}$

Output pressure

Electricity requirements ( $8400 \mathrm{psi})$

Cascade $\mathrm{H}_{2}$ recovery efficiency

$30 \mathrm{~kg} \mathrm{H}_{2} /$ day

Storage compressor capacity (17 scfm)

Usable storage capacity

8400 psi

$2.75 \mathrm{kWh} / \mathrm{kg} \mathrm{H}_{2}$

$42 \%$

$60 \mathrm{~kg} \mathrm{H}_{2} /$ day

$30 \mathrm{~kg} \mathrm{H}_{2}$

Compressed $\mathrm{H}_{2}$ dispensers (1 hose @ $1 \mathrm{~kg} / \mathrm{min}$ )

$\$ 30,000$

Storage compressor (estimated @ $\$ 2000 / \mathrm{scfm})(60 \mathrm{~kg} \mathrm{H} / 2 /$ day)

$\$ 35,000$

Storage tanks (6 vessels 8400 psi cascade)

$\$ 60,000$

Total capital investment

$\$ 125,000$

Operating and maintenance

Compression electricity @ \$0.05/kWh

Overhead (including labor)

Total operating costs

$\$ 14,000 / \mathrm{yr}$ 


\section{Hydrogen Pathways}

\section{Central Steam-reforming/LH 2 Delivery}

Of the pathways examined, central reforming with truck delivery is the closest to today's gasoline infrastructure. Hydrogen fuel is produced from $\$ 2.50 / \mathrm{GJ}$ natural gas at a large 100 -million-scf $\mathrm{H}_{2}(237,000 \mathrm{~kg})$ per day steam methane reforming plant, with $68 \%$ LHV efficiency. The hydrogen is liquefied in a $100+$ ton/day liquefaction plant using $\$ 0.05 / \mathrm{kWh}$ electricity equal to $40 \%$ of the LHV of the hydrogen. The hydrogen is then transported by truck (13,000- to 18,000-gallon capacity) an average of 250 miles (using 84 gallons of diesel fuel round trip) to a refueling station. Up to four day's worth of $\mathrm{LH}_{2}(4000 \mathrm{~kg}$ ) can be stored on site, pumped to high pressure (up to 6000 psi), and evaporated to refuel an 80-mpg hydrogen car with an average of 3.0 $\mathrm{kg} \mathrm{H}_{2}$ in a $5000-6000$ psi pressure tank.

\section{Technical parameters}

$\mathrm{H}_{2}$ production efficiency

Storage $\left(\mathrm{LH}_{2}\right)$ energy requirements

Truck transport

Delivery distance

Annual delivery-truck mileage

NOx emissions (steam methane reformer)

\section{Economic parameters}

Capital costs

Central reforming facility ( 237 tonnes $\mathrm{H}_{2} /$ day)

Liquefaction plant (237 tonnes $\mathrm{H}_{2}$ day)

$\mathrm{LH}_{2}$ truck trailer ( $3500 \mathrm{~kg} \mathrm{H}_{2}$ capacity)

Semi-tractor trailer truck

Operating costs

Fuel (natural gas @ \$2.50/GJ)

Labor, maintenance, etc.

Steam reformer

Liquefier

$\mathrm{LH}_{2}$ truck delivery costs

Personnel (to support 1 truck)

Fuel (\$1.25/gallon @ 6 mpg)

Maintenance
$68 \%$ LHV (natural gas)

$13.3 \mathrm{kWh} / \mathrm{kg}$ (electricity)

$1 \mathrm{kWh} / \mathrm{kg}$ (diesel fuel)

250 miles

$100,000 \mathrm{miles} / \mathrm{yr}$

$0.3 \mathrm{lb}$. $\mathrm{NOx} /$ per $10,000 \operatorname{scf} \mathrm{H}_{2}$
$\$ 200$ million

$\$ 140$ million

$\$ 400,000$

$\$ 60,000$

$\$ 105,000 /$ day

$\$ 50,000 /$ day

$\$ 20,000 /$ day

$\$ 1.50 /$ mile

$\$ 0.21 / \mathrm{mile}$

$\$ 0.35 /$ mile 


\section{On-site Station Steam-Reforming/Compressed $\mathrm{H}_{2}$}

Station steam-reforming eliminates the energy and cost penalties of $\mathrm{LH}_{2}$ distribution but increases the capital cost of production and on-site storage, because of the relatively small scale of the reformer. Hydrogen is produced at 200 psi from a small ( 1 ton $\mathrm{H}_{2}$ /day) steam methane reformer and compressed up to $8400 \mathrm{psi}$ and stored on-site in a pressure vessel cascade at the refueling station.

\section{Technical summary}

$\mathrm{H}_{2}$ production efficiency

Reformer electricity

Emissions

$68 \%$ LHV (from natural gas)

Compressor efficiency

$0.3 \mathrm{lb}$. NOx/per $10,000 \mathrm{scf} \mathrm{H}_{2}$

Compression from 200 to $6000 \mathrm{psi}$

$85 \%$

$2.75 \mathrm{kWh} / \mathrm{kg}(8.25 \% \mathrm{LHV})$

Economic summary

Capital costs

Small steam methane reformer ( $900 \mathrm{~kg} \mathrm{H}_{2}$ /day)

$\$ 2.2$ million

Operating costs

Reformer operating costs

Reformer electricity

Feedstock and fuel ( $\$ 4.00 / \mathrm{GJ}$ natural gas)

Total operating costs

$\$ 350 /$ day

$\$ 18 /$ day

$\$ 635 /$ day

$\$ 1000 /$ day 


\section{On-site Station Methanol Decomposition/Compressed $\mathrm{H}_{2}$}

Station methanol reforming offers the possibility of on-site hydrogen production from a widely available, and potentially renewable source, which is more easily distributed than $\mathrm{LH}_{2}$. It also appears feasible at smaller scales than steam methane reforming. Methanol decomposition is characterized by lower capital costs and temperatures than steam methane reforming, but with higher embodied energy requirements and emissions (considering the energy to manufacture the methanol). Emissions from methanol combustion are primarily hydrocarbons (estimated to be 0.36 grams $/ \mathrm{kWh}$ of methanol by mass). Because of lower process temperatures, NOx emissions from methanol reforming were assumed to be $1 / 3$ of emissions from steam-reforming. Hydrogen is produced at $200 \mathrm{psi}$ and compressed up to 8400 psi in on-site compressed gas storage at a refueling station.

Technical summary

$\mathrm{H}_{2}$ production efficiency

Reformer electricity

Emissions (estimated)

Compressor efficiency

Compression from 200 to $8400 \mathrm{psi}$

\section{Economic summary}

Station scale (300 cars/day)

Capital costs

Small methanol reformer ( $900 \mathrm{~kg} \mathrm{H}_{2}$ /day)

Operating costs

Reformer operation and maintenance

Reformer electricity

Feedstock and fuel ( $\$ 11.00 / G$ J methanol)

Total operating costs

Small station scale ( 60 cars/day)

Fleet methanol reformer $\left(180 \mathrm{~kg} \mathrm{H}_{2}\right.$ /day)

Methanol storage tank (10,000 gallons)

Total capital costs

Operation and maintenance

Fuel (\$11.00/GJ methanol)
$80 \%$ LHV (from methanol)

$0.34 \mathrm{kWh} / \mathrm{kg}$

$0.12 \mathrm{lb}$. NOx $/ 10,000$ scf $\mathrm{H}_{2}$

$0.9 \mathrm{lb}$. $\mathrm{HC} / 10,000 \mathrm{scf} \mathrm{H}_{2}$

$85 \%$

$2.75 \mathrm{kWh} / \mathrm{kg}$ (8.25\% LHV)
$\$ 1.6$ million

$\$ 260 /$ day

$\$ 36 /$ day

$\$ 1500 /$ day

$\$ 1800 /$ day

$\$ 345,000$

$\$ 15,000$

$\$ 360,000$

$\$ 140 /$ day

$\$ 300 /$ day 


\section{On-site Station Ammonia Decomposition/Compressed $\mathbf{H}_{2}$}

Ammonia decomposition offers on-site hydrogen production from a highdensity hydrogen carrier, more easily stored and distributed than $\mathrm{LH}_{2}$ which can be manufactured using only air, water, and electricity. Ammonia decomposition has higher capital costs and decomposition temperatures than methanol reforming, but lower capital costs and temperatures than steam methane reforming. Hydrogen is produced at 200 psi from a small (200-1000 $\mathrm{kg} \mathrm{H}_{2}$ /day) unit and compressed up to 8400 psi in on-site compressed gas storage at a refueling station. NOx emissions from ammonia combustion as low as $100 \mathrm{ppm}$ have been measured (approximately 1 gram NOx per $\mathrm{kg}$ of $\mathrm{NH}_{3}$ burned). This would result in NOx emissions comparable to steamreforming, but slightly higher values were used in this analysis to be conservative.

\section{Technical summary}

$\mathrm{H}_{2}$ production efficiency

Reformer electricity

Emissions (estimated)

$66 \%$ LHV (from ammonia)

Compressor efficiency

$0.17 \mathrm{kWh} / \mathrm{kg} \mathrm{H}_{2}$

Compression from 200 to $8400 \mathrm{psi}$

$0.6 \mathrm{lb} . \mathrm{NOx} / 10,000 \mathrm{scf} \mathrm{H}_{2}$

$85 \%$

$2.75 \mathrm{kWh} / \mathrm{kg}(8.25 \% \mathrm{LHV})$

\section{Economic summary}

Station scale ( 300 cars/day)

Capital costs

Ammonia cracker $\left(900 \mathrm{~kg} \mathrm{H}_{2} /\right.$ day)

$\$ 1.9$ million

Operating costs

Operation and maintenance

Reformer electricity

Feedstock and fuel (\$13.00/GJ ammonia)

Total operating costs

\section{Small station scale (60 cars/day)}

Fleet ammonia reformer ( $180 \mathrm{~kg} \mathrm{H}_{2}$ /day)

Ammonia storage tank $(10,000$ gallons $)$

Total capital costs

$$
\$ 335 / \text { day }
$$

$\$ 18 /$ day

$\$ 2125 /$ day

$\$ 2500 /$ day

Operating costs

Fuel costs ( $\$ 13.00 / \mathrm{GJ}$ ammonia)

$\$ 405,000$

$\$ 75,000$

$\$ 480,000$

$\$ 180 /$ day

$\$ 425 /$ day

Total operating costs

$\$ 600 /$ day 


\section{On-site Station Alkaline Electrolysis/Compressed $\mathbf{H}_{\mathbf{2}}$}

Alkaline electrolysis offers on-site hydrogen production from a clean, flexible, available, easily transportable, and potentially renewable energy source: electricity. In contrast to thermochemical production methods, electrolysis has lower capital costs at small scales, although the advantage is reduced by exclusive off-peak use. Hydrogen is produced at 200 psi from a small (200$1000 \mathrm{~kg} \mathrm{H}_{2}$ /day) unit and compressed up to $8400 \mathrm{psi}$ in on-site compressed gas storage at a refueling station.

\section{Technical summary}

$\mathrm{H}_{2}$ production efficiency

Off-peak availability

Compressor efficiency

$68 \%$ LHV (from electricity)

Compression from 200 to $8400 \mathrm{psi}$

$128 \mathrm{hr} /$ week $(76 \%)$

$85 \%$

$2.75 \mathrm{kWh} / \mathrm{kg}(8.25 \% \mathrm{LHV})$

Economic summary

Station scale ( 300 cars/day)

Capital costs

Electrolysis unit (1170 $\mathrm{kg} \mathrm{H}_{2} /$ day capacity) $\$ 2.1$ million

Operation and maintenance

Electrolysis water

Electricity ( $\$ 0.05 / \mathrm{kWh}$ off-peak)

$\$ 90 /$ day

$\$ 225 /$ day

Small station electrolyzer ( $234 \mathrm{~kg} \mathrm{H}_{2}$ /day capacity)

Electrolysis water and maintenance

$\$ 2200 /$ day

Small fleet electrolyzer ( $39 \mathrm{~kg} \mathrm{H} / 2$ day capacity)

Electrolysis water and maintenance

$\$ 650,000$

$\$ 50 /$ day

$\$ 110,000$

$\$ 10 /$ day 


\section{On-site Station Polymer Membrane Electrolysis/Compressed $\mathbf{H}_{2}$}

Polymer electrolysis possesses the advantages of alkaline electrolysis with, in principle, even lower cost and greater safety. Polymer electrolytes also provide the possibility of generating hydrogen on-site at high pressure (>2000 psi), eliminating or reducing compression costs and requirements. This is particularly important at small scales. For this examination, however, hydrogen is considered to be produced at 200 psi from a small $(200-1000 \mathrm{~kg}$ $\mathrm{H}_{2}$ /day) unit and compressed up to $8400 \mathrm{psi}$ in on-site compressed gas storage at a refueling station.

\section{Technical summary}

$\mathrm{H}_{2}$ production efficiency

Off-peak availability

Compressor efficiency

$68 \%$ LHV (from electricity)

Compression from 200 to 8400 psi

$128 \mathrm{hr} /$ week (76\%)

$85 \%$

$2.75 \mathrm{kWh} / \mathrm{kg}(8.25 \% \mathrm{LHV})$

Economic summary

Station scale ( 300 cars/day)

Capital costs

Electrolysis unit ( $1170 \mathrm{~kg} \mathrm{H}_{2} /$ day capacity)

$\$ 1.3$ million

Operation and maintenance

Electrolysis water

Electricity ( $\$ 0.05 / \mathrm{kWh}$ off-peak)

$\$ 90 /$ day

$\$ 225 /$ day

$\$ 2200 /$ day

Fleet-scale electrolyzer ( $234 \mathrm{~kg} \mathrm{H}_{2} /$ day capacity) $\quad \$ 390,000$

Electrolysis water and maintenance

$\$ 50 /$ day

Small-fleet electrolyzer ( $39 \mathrm{~kg} \mathrm{H}$ /day capacity) $\quad \$ 85,000$

Electrolysis water and maintenance

$\$ 10 /$ day 


\section{On-site Station Solid Oxide Steam Electrolysis/Compressed $\mathbf{H}_{2}$}

Steam electrolysis, based on solid oxide electrolytes, is an advanced electrolysis concept that offers very high efficiency, low maintenance, and perhaps long operating life. Steam electrolysis takes advantage of the thermodynamic advantage of electrolyzing steam instead of water. Efficiency of $93 \%$ is possible, as compared to $68 \%$ for water electrolysis. Steam electrolysis should also be feasible at relatively small scales. Hydrogen would be generated at $200 \mathrm{psi}$ from a small (200-1000 $\mathrm{kg} \mathrm{H}_{2} /$ day) unit and compressed up to $8400 \mathrm{psi}$ in on-site compressed gas storage at a refueling station.

\section{Technical summary}

$\mathrm{H}_{2}$ production efficiency

Off-peak availability

Compressor efficiency

$93 \%$ LHV (from electricity)

Compression from 200 to 8400 psi

$128 \mathrm{hr} /$ week (76\%)

$85 \%$

$2.75 \mathrm{kWh} / \mathrm{kg}(8.25 \% \mathrm{LHV})$

\section{Economic summary}

Station scale (300 cars/day)

Capital costs

Electrolysis unit (1170 kg H$/$ /day capacity)

$\$ 910,000$

Operation and maintenance

$\$ 90 /$ day

Electrolysis water

Electricity ( $\$ 0.05 / \mathrm{kWh}$ off-peak)

$\$ 225 /$ day

$\$ 1600 /$ day

Fleet-scale electrolyzer ( $234 \mathrm{~kg} \mathrm{H} /$ day capacity)

$\$ 440,000$

Electrolysis water and maintenance

$\$ 50 /$ day 


\section{Residential Electrolysis/(Hydride Compressor)/Low Pressure}

Residential electrolysis allows hydrogen vehicles to be introduced relatively independent of a hydrogen refueling infrastructure, providing a longer-range alternative to battery-powered electric vehicles. In this pathway scenario, a small electrolyzer would produce $0.4 \mathrm{~kg}$ of hydrogen overnight (12 hours), sufficient for $\sim 30$ miles of daily driving in an $80-\mathrm{mpg}$ vehicle. Buffer storage for $1 \mathrm{~kg} \mathrm{H} \mathrm{H}_{2}$ is provided by a 100 gallon tank (at $500 \mathrm{psi}$ ). This pressure is achievable using polymer electrolysis, and probably alkaline electrolyzers. Another option, perhaps lower cost, is low-pressure electrolysis in combination with a hydride-based compressor. Hydrogen would be transferred to hydride storage onboard the vehicle from the 500-psi buffer storage tank.

\section{Technical summary}

$\mathrm{H}_{2}$ production efficiency

Alkaline

Polymer membrane

Off-peak availability

Production rate

Electrical load (max.)

Buffer storage (500 psi)

$50 \%$ LHV (from electricity) $68 \%$ LHV (from electricity)

$88 \mathrm{hr} /$ week (52\%)

400 grams $\mathrm{H}_{2} / 12$ hours

$2.2 \mathrm{~kW}$

$1 \mathrm{~kg} \mathrm{H}$ ( 100 gallons)

\section{Economic summary}

Alkaline electrolyzer $(0.4 \mathrm{~kg} \mathrm{H} / 2 / 12 \mathrm{hr})$

$\$ 2700$

Polymer membrane electrolyzer $\left(0.4 \mathrm{~kg} \mathrm{H}_{2} / 12 \mathrm{hr}\right) \quad \$ 2600$

500-psi storage system (100 gallon) $\left(1 \mathrm{~kg} \mathrm{H}_{2}\right) \quad \$ 700$

Total capital cost

$\$ 3500$

Electrolysis water and maintenance

Electricity (off-peak @ $\$ 0.05 / \mathrm{kWh}$ ) 


\section{Appendix C}

\section{Figures and Captions}

Figure 1. Elements of a robust rationale for hydrogen vehicles.

Figure 2.

Figure 3.

Conceptual hydrogen powered vehicle.

Figure 4.

Storage systems for $3.75 \mathrm{~kg}$ hydrogen.

Hydrogen from natural gas or off-peak electricity is an affordable fuel in 70-100 mpg vehicles

Figure 5.

Estimated costs of hydrogen delivery 250 miles by truck.

Figure 6.

The effect of delivery distance and storage technology on the cost of hydrogen delivery by truck.

Figure 7. Cost breakdown of 7 hydrogen pathways for stations, fleets, and homes (by pathway step).

Figure 8. Cost breakdown of 7 hydrogen pathways for stations, fleets, and homes (by cost element).

Figure 9. Cost breakdown of 7 hydrogen pathways for stations, fleets, and homes (by pathway step and cost type).

Figure 10. Primary and process energy requirements for hydrogen production, delivery, and storage.

Figure 11. Estimated greenhouse gas emissions in 2005 for passenger cars fueled by hydrogen, batteries, natural gas or gasoline.

Figure 12. Estimated air pollutant emissions in $\mathbf{2 0 0 5}$ for passenger cars fueled by hydrogen, batteries, natural gas, or gasoline

Figure 13. Tailpipe emissions of hybrid electric vehicles using hydrogen, natural gas, and gasoline.

Figure 14(a-c). Electric generating supply mix and average $\mathrm{CO}_{2}$ and NOx emissions ("reference," "market," and "climate" scenarios)

Figure 15(a-d). Estimated greenhouse gas emissions... (four scenarios)

Figure 16(a-d). Estimated air pollutant emissions... (four scenarios)

Figure 17.

U.S. passenger car transportation demand scenario (2005-2050): alternative fuel market penetration and oil import displacement.

Figure 18(a-d). Carbon dioxide/NOx/hydrocarbon/carbon monoxide emissions estimates for U.S. passenger cars (2005-2050

Figure 19(a-d). Cumulative carbon dioxide/NOx/hydrocarbon/carbon monoxide emissions for U.S. passenger cars (2005-2050) 
Figure 1. Elements of a Robust Rationale for Hydrogen-Vehicles. Hydrogen competes with today's gasoline vehicles on a rationale composed of a balance of (1) consumer costs, (2) public benefits, and (3) feasibility of a smooth, flexible transition. Hydrogen has many attractive public policy benefits (secure, domestic, sustainable fuel production; clean air; and new markets that enhance the economic efficiency of utilities) that depend mostly upon the primary energy source. But to achieve these benefits, hydrogen vehicles must be successful in the market. Hydrogen vehicles must deliver greater value (cost, range, vehicle life, refueling time, acceleration, etc.) to consumers than other alternative-fuel vehicles. Technical issues and choices of fuel efficiency, onboard storage, delivery infrastructure, and production scale determine to a large extent the value of hydrogen vehicles to consumers. In addition to a high-value vehicle, consumers want assured fuel availability, which at least initially is a major issue involving both technical and business risk aspects of hydrogen infrastructure. Hydrogen is already produced today in industry, and synergies exist with potential fuel suppliers (utilities, chemical industry) who can invest in delivery infrastructure and capture a new fuel market. The development of a reliable hydrogen fuel supply is helped by the diverse domestic sources of hydrogen production and the wide array of possible production, storage, and delivery scales, which allows market entry and decentralization. These provide hydrogen vehicles a unique flexibility and potential for a smooth transition through changes in the mix of primary energy sources used to produce hydrogen fuel in response to market, economic, or regulatory changes. 


\section{Figure 1. Elements of a Robust Rationale for Hydrogen Vehicles}

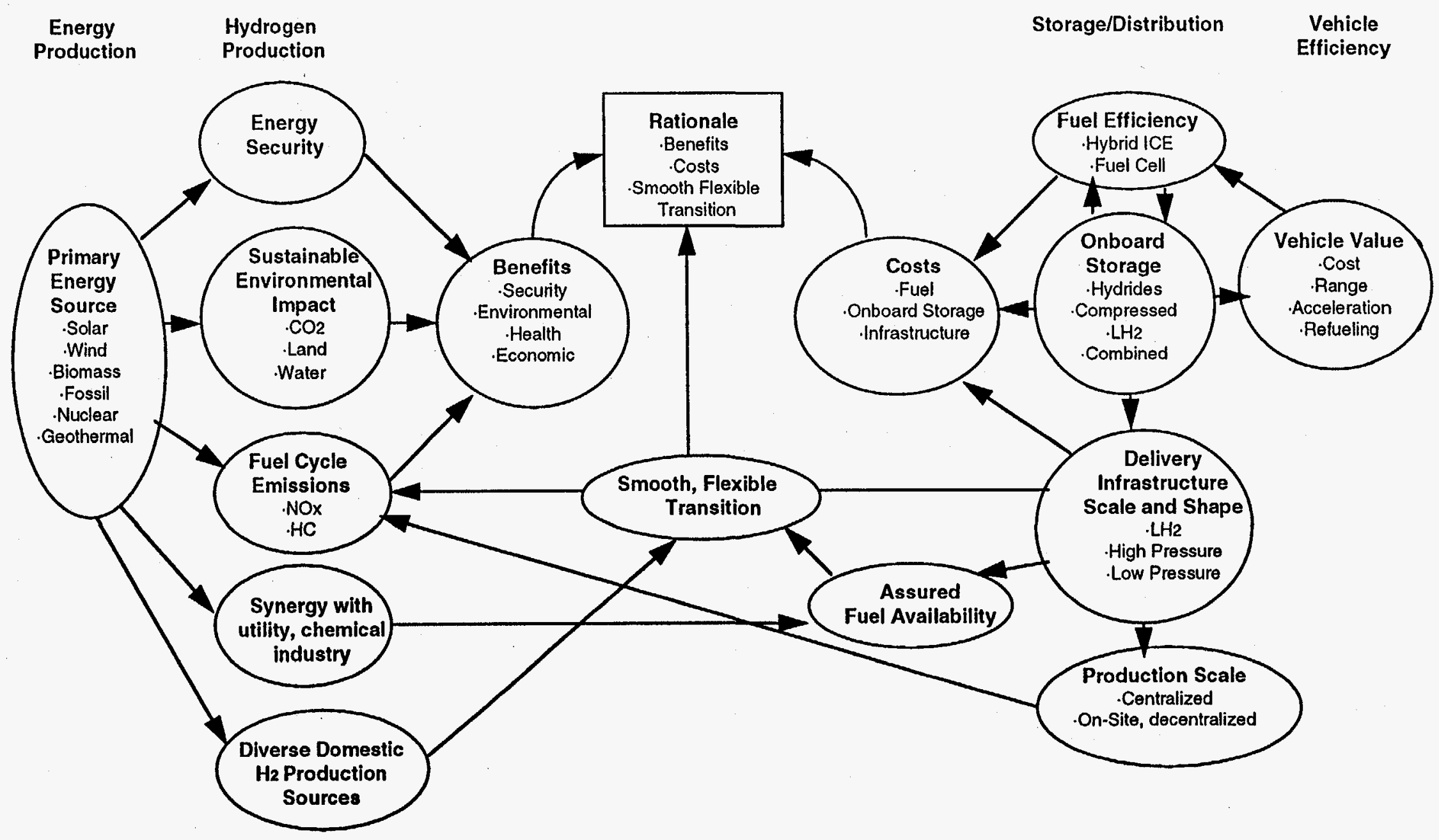


Figure 2. Conceptual design of a hydrogen-powered five-passenger hybridelectric vehicle that can travel 300 miles using only $3.75 \mathrm{~kg}$ of hydrogen fuel, achieving 80-mpg-energy-equivalent mileage. This high fuel efficiency is possible because of a low drag coefficient and high drivetrain efficiency. A small internal combustion engine (or ultimately a fuel cell), optimized for hydrogen, generates electricity at peak efficiency to charge a secondary electrical energy storage device (batteries, a flywheel, or capacitors) that delivers electricity to the electric motor and has sufficient power for peak accelerations and energy recovery from regenerative braking. Hydrogen is stored onboard in a hydride bed, in compressed gas tanks at 5000 psi and room temperature, or cryogenically as a compressed gas $(80 \mathrm{~K}, 3600 \mathrm{psi})$, or as a liquid $(20 \mathrm{~K}, 5 \mathrm{~atm})$. 


\section{Figure 2. Conceptual hydrogen powered vehicle}

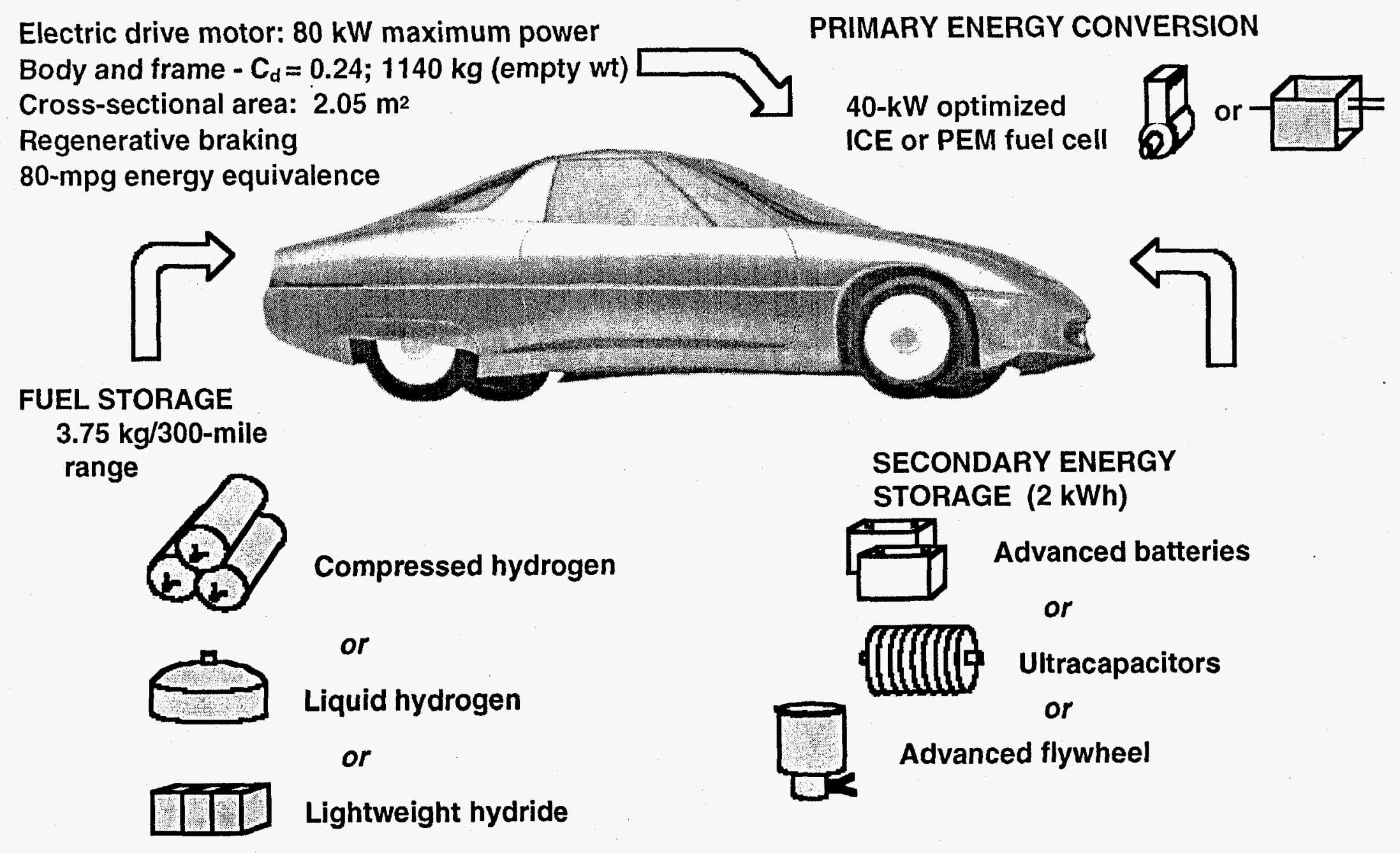


Figure 3. To provide enough fuel for a 300-mile range in an $80-\mathrm{mpg}-$ equivalent hydrogen vehicle, $3.75 \mathrm{~kg}$ of hydrogen must be stored onboard. The weight, volume, and storage energy required to store $3.75 \mathrm{~kg}$ of $\mathrm{H}_{2}$ is shown for (1) an Fe-Ti-based hydride (15\% energy penalty), (2) carbon-fiberwrapped aluminum pressure vessels storing hydrogen between 3600 and 9000 psi with a safety factor of 2.25 (5-10\% energy penalty), (3) a cryogenic pressure tank storing hydrogen at $3600 \mathrm{psi}$ and $80 \mathrm{~K}$ ( $25 \%$ energy penalty), and (4) a lowpressure $(1-5 \mathrm{~atm})$ liquid hydrogen tank $(40 \%$ energy penalty). The system volumes and weights shown are all feasible (although room-temperature compressed gas tanks may require pressures of 5000 psi or above). Compact, lightweight storage technologies require generally large increases in energy requirements. 
Figure 3. Storage systems for $3.75 \mathrm{~kg}$ hydrogen (300 mile range at $80 \mathrm{mpg}$ )

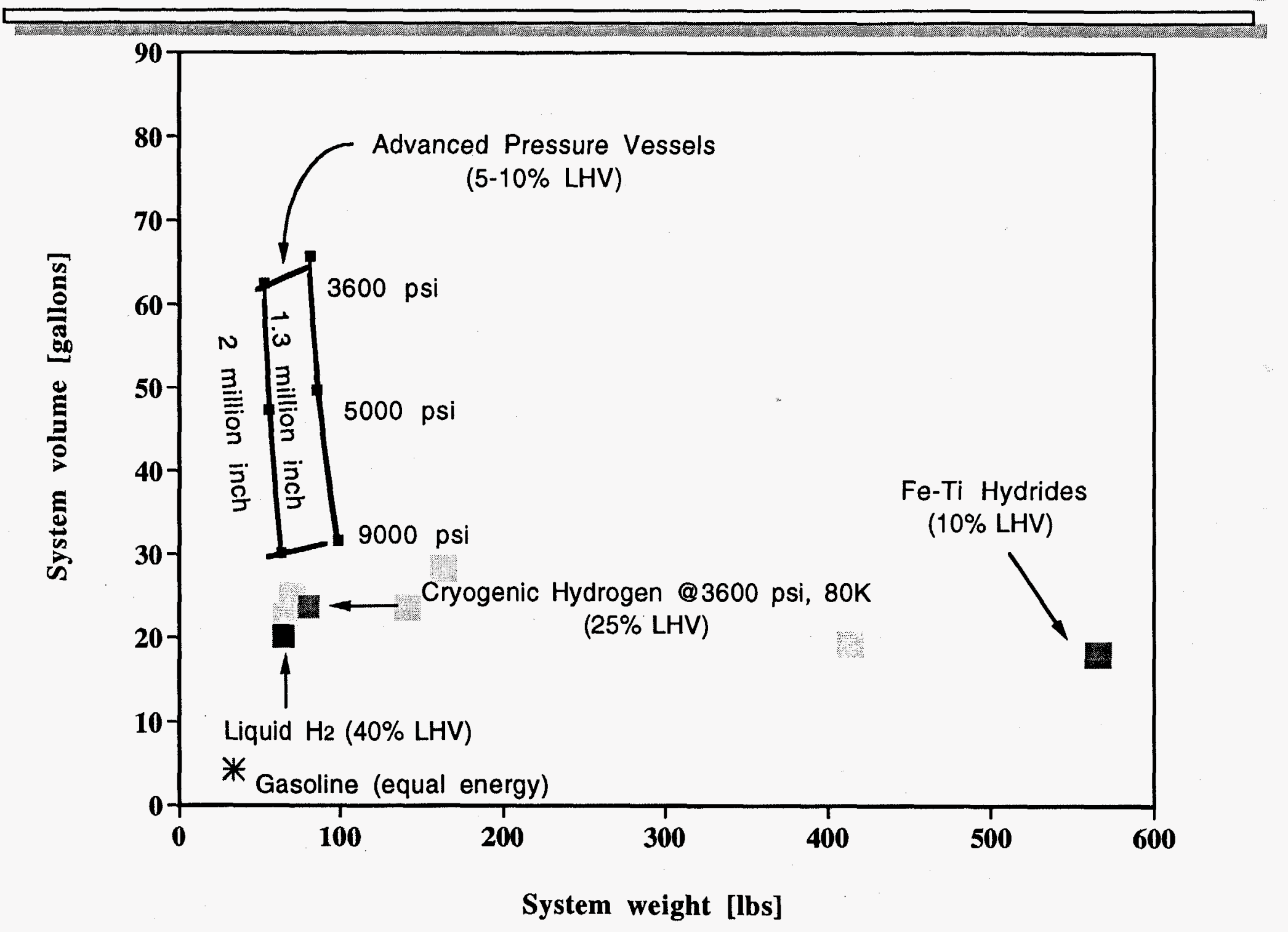


Figure 4. Fuel cost in cents per mile is shown for hydrogen vehicles ranging in fuel efficiency from 70 to $100-\mathrm{mpg}$ gasoline energy equivalent. Hydrogen in filling stations is conservatively estimated to cost at most $\$ 50 / \mathrm{GJ}$ (off-peak electrolysis at $\$ 0.05 / \mathrm{kWh}$ for electricity). Hydrogen costing $\$ 40 / \mathrm{GJ}$ (equivalent to $\$ 5.00 /$ gallon gasoline) corresponds to only $\$ 0.06 /$ mile, comparable to gasoline fueling costs in today's vehicles. 


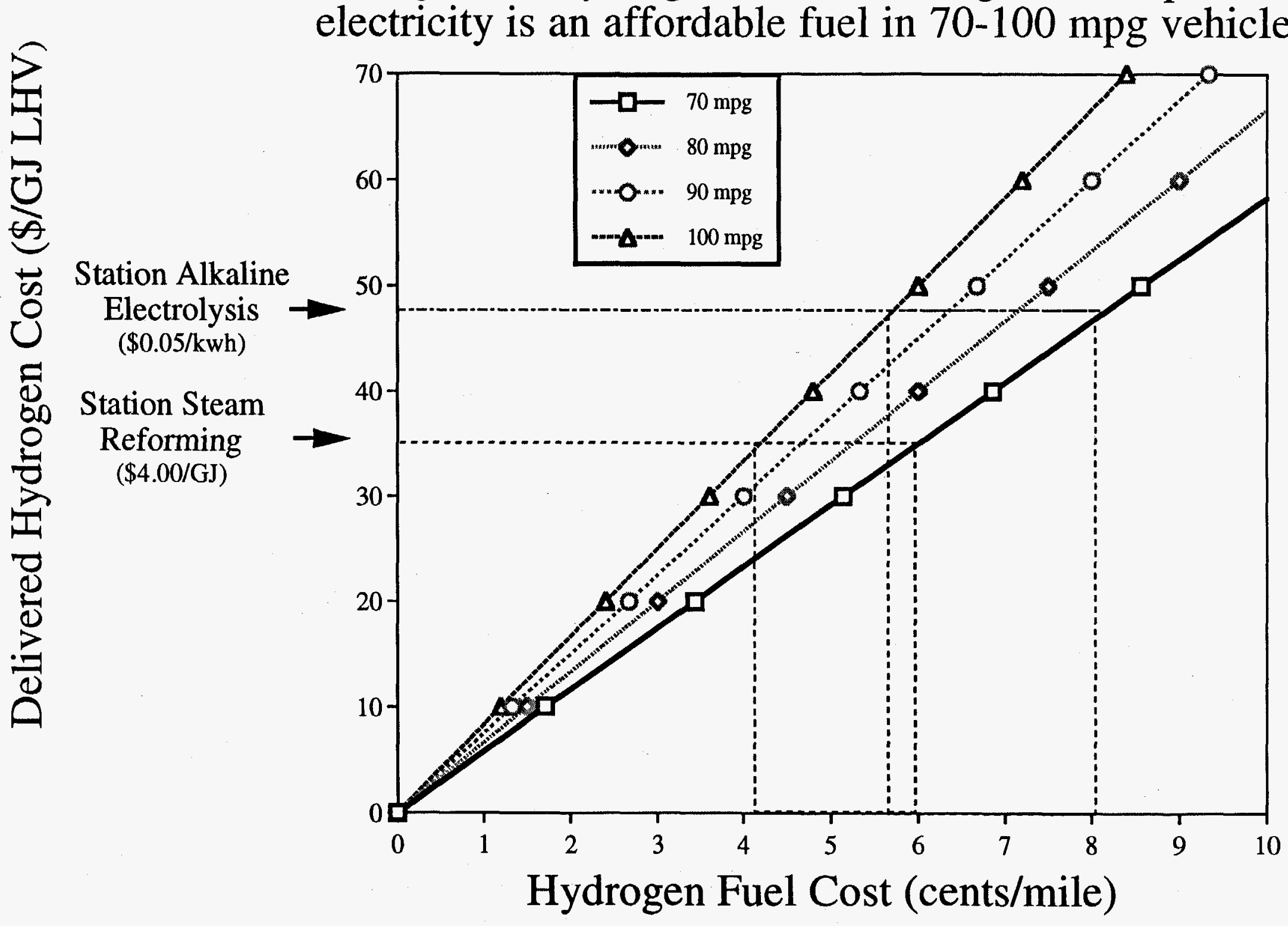


Figure 5. The cost components of hydrogen delivered 250 miles by truck using four different mobile hydrogen storage technologies. Hydrogen is assumed to be produced for $\$ 9.30 / \mathrm{GJ}$ at a large steam methane reforming plant. Electricity for hydrogen storage is assumed to cost $\$ 0.05 / \mathrm{kWh}$. Capital equipment is discounted at $20 \%$ over 10 years. Trucks travel $100,000 \mathrm{miles} / \mathrm{yr}$, and associated personnel costs are assumed to be $\$ 150,000 / y r$. Liquid hydrogen $\left(\mathrm{LH}_{2}\right)$ trucks have low capital investment and low operating costs (lined patterns) but high fixed-storage costs (fill patterns). The alternative technologies each store less hydrogen than $\mathrm{LH}_{2}$ trucks, so variable operating costs are higher. The alternative technologies have lower fixed-storage costs because of lower energy requirements. Each technology could deliver centrally produced hydrogen over a distance of 250 miles for roughly $\$ 20$ 25/GJ. 


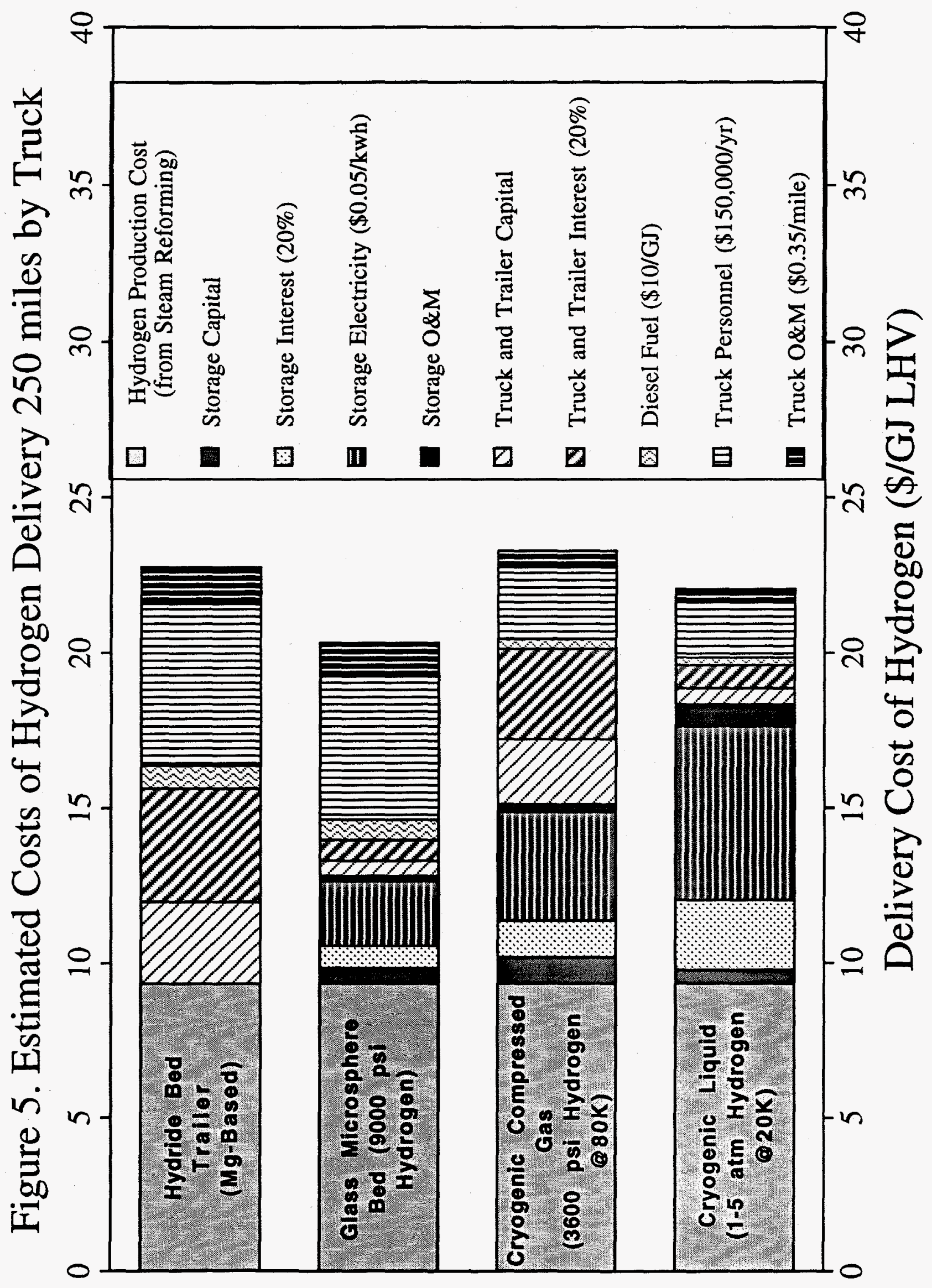


Figure 6. The estimated costs of truck-delivered hydrogen using four different storage technologies-magnesium-based hydride, microspheres, $\mathrm{LH}_{2}$, and cryogenic $(80 \mathrm{~K})$ hydrogen gas $(3600 \mathrm{psi})$-are shown as a function of delivery distance. Economic assumptions are the same as in Fig. 5. Alternatives to $\mathrm{LH}_{2}$ delivery are much more cost-sensitive to delivery distance but could offer some benefit for short deliveries $(<150$ mile). Microspheres appear to be the most promising of the alternatives. 
Figure 6. The Effect of Delivery Distance and Storage Technology on the Cost of Hydrogen Delivery by Truck

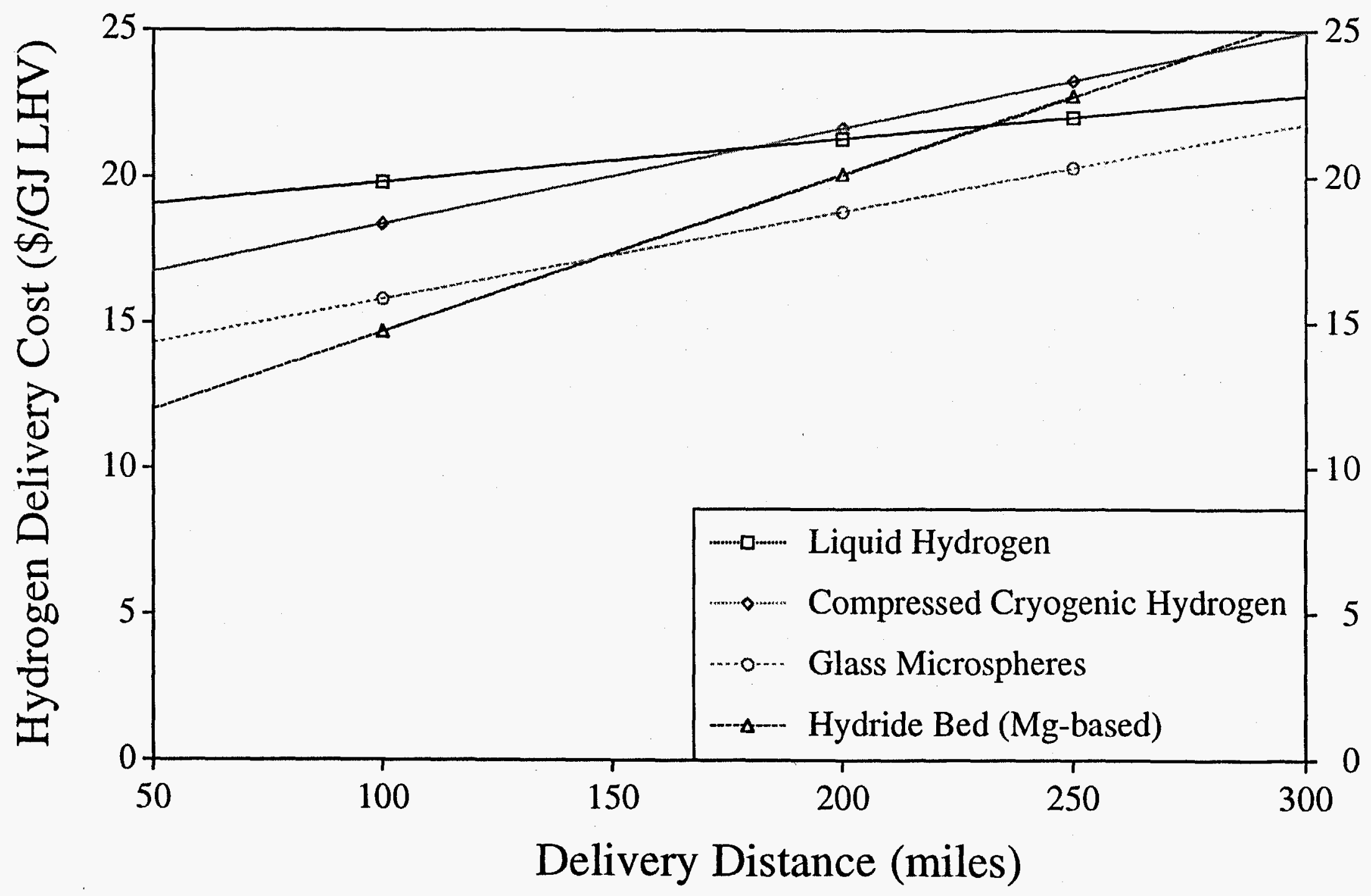


Figure 7. The costs of production, storage, and delivery of hydrogen at four scales, broken down by process steps, are shown for seven hydrogen pathways: (1) $\mathrm{LH}_{2}$ delivery by truck, (2) on-site steam-reforming from $\$ 4.00 / \mathrm{GJ}$ natural gas, (3) on-site methanol reforming from $\$ 0.66 /$ gallon methanol, (4) on-site ammonia cracking from $\$ 250 /$ ton ammonia, (5) conventional alkaline electrolysis, (6) polymer membrane electrolysis, and (7) steam electrolysis. Offpeak electricity costs are $\$ 0.05 / \mathrm{kWh}$. Discount rates are $20 \%$ for stations, $10 \%$ for individual vehicle systems. Note that individual-vehicle refueling using home electrolysis has compressed gas storage for $1 \mathrm{~kg}$ of hydrogen. 
Figure 7. Cost Breakdown of 7 Hydrogen Pathways for Stations, Fleets, and Homes (broken down by pathway step)

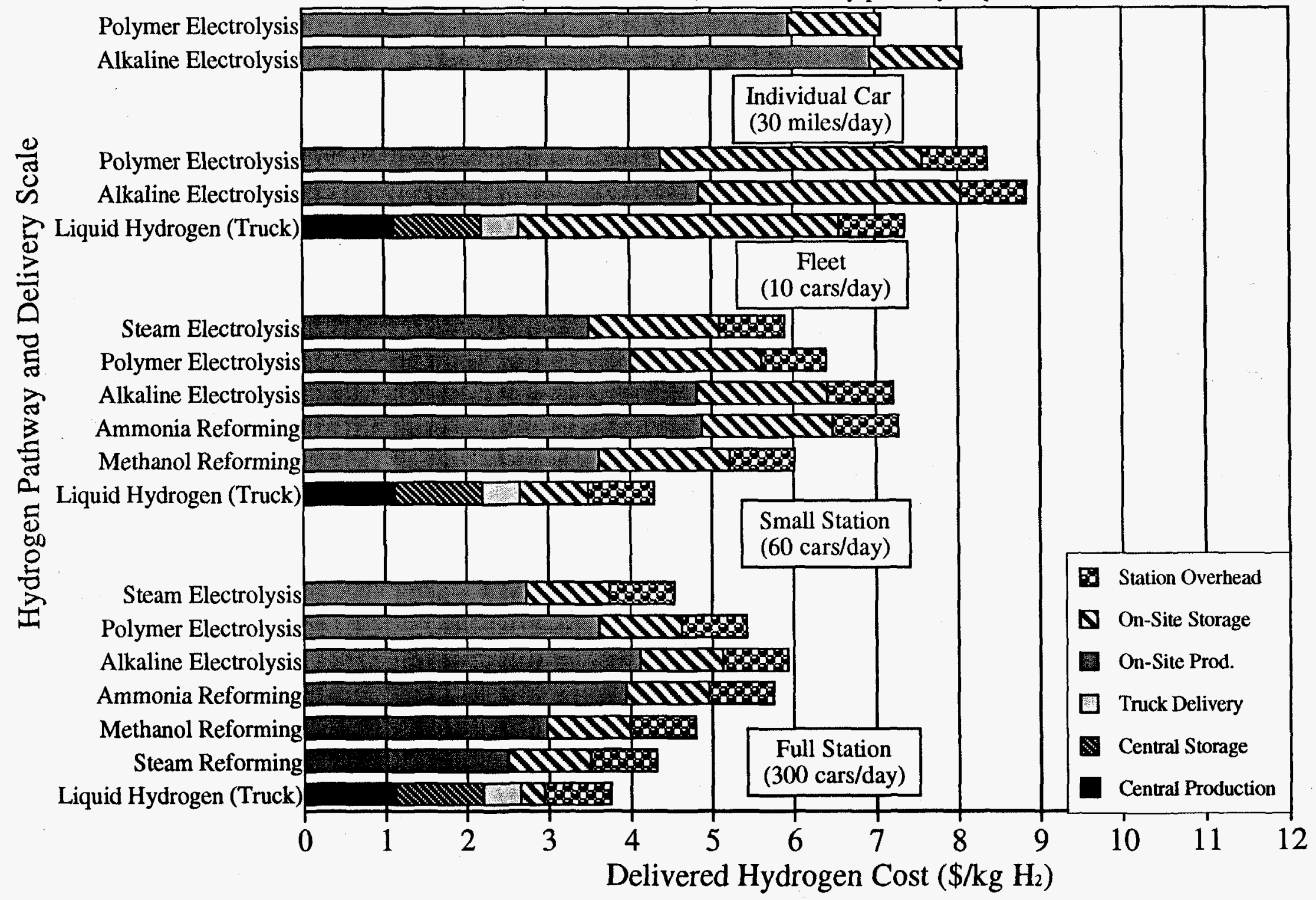


Figure 8. The costs of production, storage, and delivery of hydrogen at four scales-broken down into capital recovery, interest, energy, overhead, and operations and maintenance costs-are shown for seven hydrogen pathways: (1) $\mathrm{LH}_{2}$ delivery by truck, (2) on-site steam reforming from $\$ 4.00 / \mathrm{GJ}$ natural gas, (3) on-site methanol reforming from \$0.66/gallon methanol, (4) on-site ammonia cracking from $\$ 250 /$ ton ammonia, (5) conventional alkaline electrolysis, (6) polymer membrane electrolysis, and (7) steam electrolysis. Offpeak electricity costs are $\$ 0.05 / \mathrm{kWh}$. Discount rates are $20 \%$ for stations, $10 \%$ for individual vehicle systems. Equipment life is 20 years for production and 10 years for storage. 
Figure 8. Cost Breakdown of 7 Hydrogen Pathways for Stations, Fleets, and Homes (broken down by cost element )

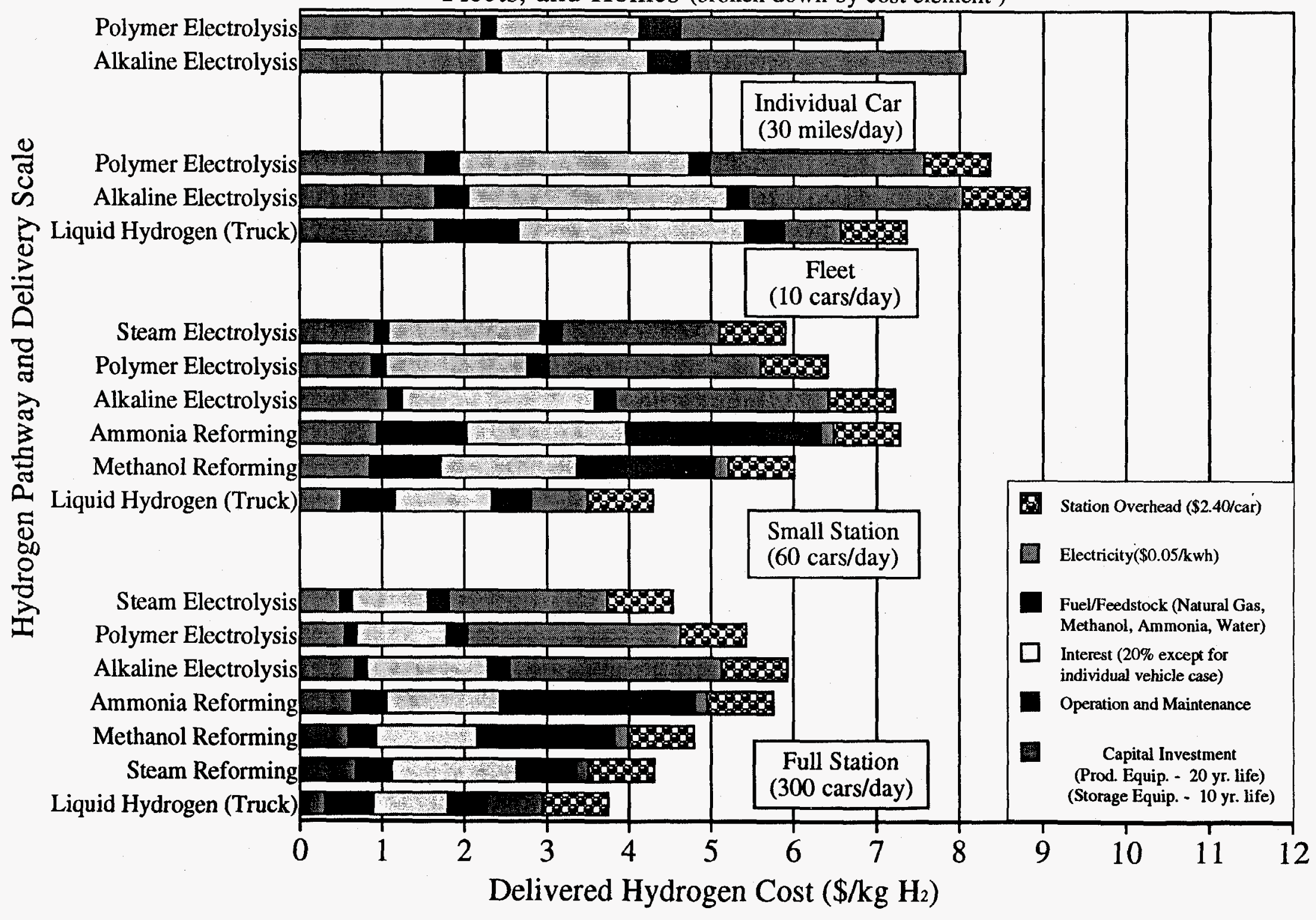


Figure 9. Detailed cost breakdown for production, storage, and delivery of hydrogen at four scales-broken down into capital recovery, interest, energy, overhead, and operations and maintenance costs of each process step-are shown for seven hydrogen pathways: (1) $\mathrm{LH}_{2}$ delivery by truck, (2) on-site steam reforming from $\$ 4.00 / \mathrm{GJ}$ natural gas, (3) on-site methanol reforming from $\$ 0.66 /$ gallon methanol, (4) on-site ammonia cracking from $\$ 250 /$ ton ammonia, (5) conventional alkaline electrolysis, (6) polymer membrane electrolysis, and (7) steam electrolysis. Off-peak electricity costs are $\$ 0.05 / \mathrm{kWh}$. Discount rates are $20 \%$ for stations, $10 \%$ for individual vehicle systems. Equipment life is 20 years for production and 10 years for storage. Note that $\$ / \mathrm{kg}$ of hydrogen can be changed to $\$ / \mathrm{GJ}$ by an 8.33 multiplier. 
Figure 9. Cost Breakdown of 7 Hydrogen Pathways for Stations, Fleets, and Homes (broken down by pathway step and cost type )

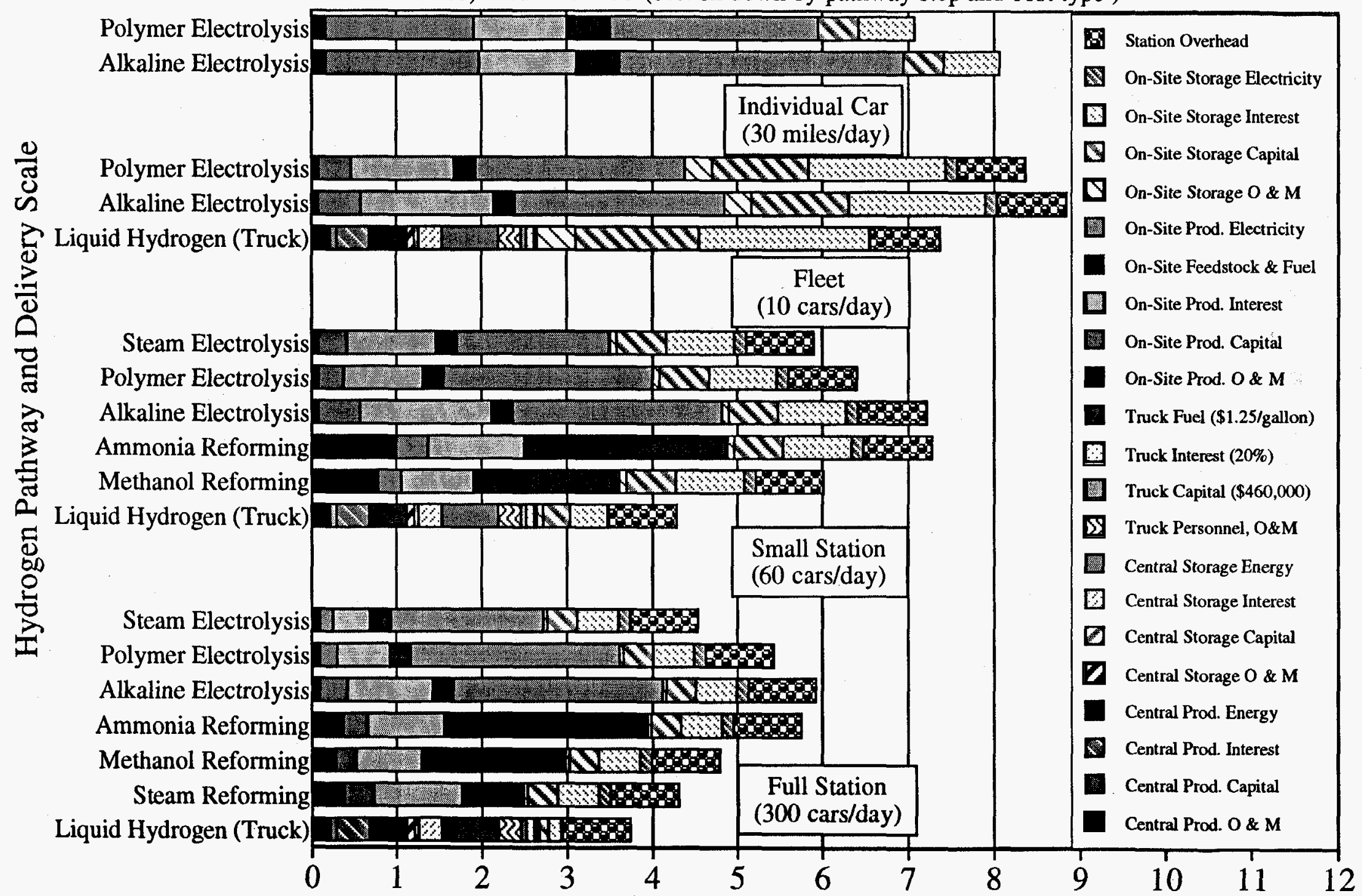

Delivered Hydrogen Cost $\left(\$ / \mathrm{kg} \mathrm{H} \mathrm{H}_{2}\right)$ 
Figure 10. The primary energy and process energy requirements for the stages of seven hydrogen pathways are shown in kilowatt-hours of energy input per $\mathrm{kWh}$ of hydrogen delivered. Process energy requirements to deliver $1 \mathrm{kWh}$ of hydrogen range from $1.2 \mathrm{kWh}$ (steam electrolysis) to $2.5 \mathrm{kWh}$ (ammonia decomposition at a hydrogen filling station.) If the electricity for compression and/or liquefaction steps is generated from fossil energy through a steam cycle, then the primary energy requirements increase sharply for all hydrogen pathways except for on-site steam reforming and hydrogen carrier (ammonia or methanol) decomposition. Primary energy requirements can then range from nearly 2 to $5.5 \mathrm{kWh}$ per $\mathrm{kWh}$ of hydrogen delivered. Process step efficiencies are principally taken or adapted from Ref. 14, 21, and 22. 
Figure 10. Primary \& Process Energy Requirements for Hydrogen Production, Delivery, and Storage

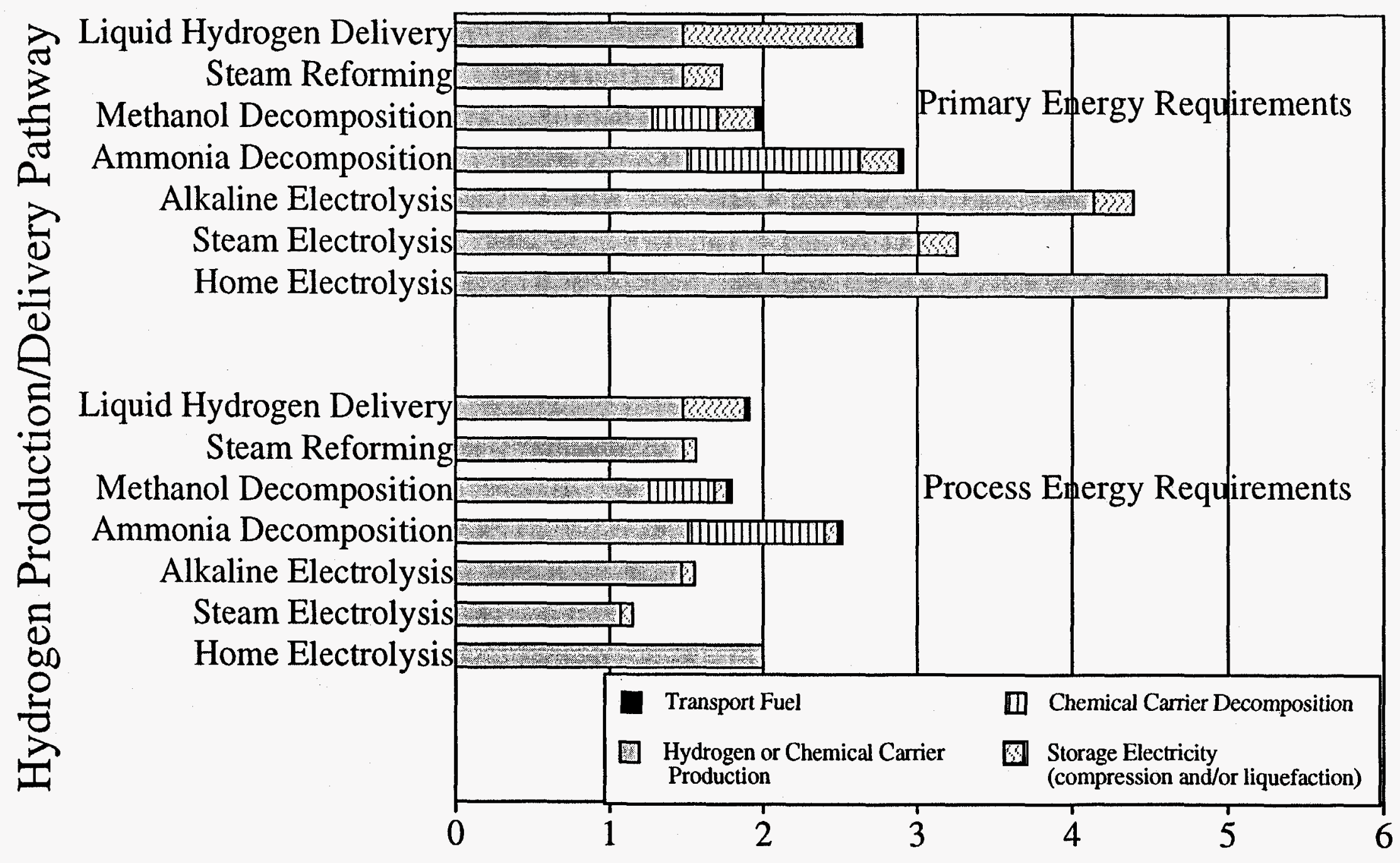

$\mathrm{kWh}$ of energy required to deliver $1 \mathrm{kWh}$ of hydrogen fuel (30 grams) 
Figure 11. Greenhouse $\mathrm{CO}_{2}$-equivalent emissions are shown for five vehicles with equivalent power requirements: a conventional gasoline $30-\mathrm{mpg}$ car, a 65-mpg gasoline HEV, a 70-mpg natural-gas HEV, a BPEV achieving 0.16 $\mathrm{kWh} / \mathrm{mile}$, and an 80-mpg hydrogen HEV. Emissions for the hydrogen car are based on the seven hydrogen pathways and energy requirements shown in Fig. 10 and projected to the year 2000 from Ref. 35. It can be seen that if natural gas is the primary energy source under consideration, $80-\mathrm{mpg}$ hydrogen vehicles can reduce greenhouse gas emissions below today's gasoline cars, but even the most energy-efficient hydrogen pathway (station steam-reforming) produces the same emissions as a 65-mpg gasoline hybrid car. Natural-gas HEVs and BPEVs offer significantly lower greenhouse-gas emissions than gasoline or hydrogen vehicles. 
Figure 11. Estimated Greenhouse Gas Emissions in 2005 for Passenger Cars Fueled by Hydrogen, Batteries, Natural Gas, or Gasoline (using natural gas for primary energy)

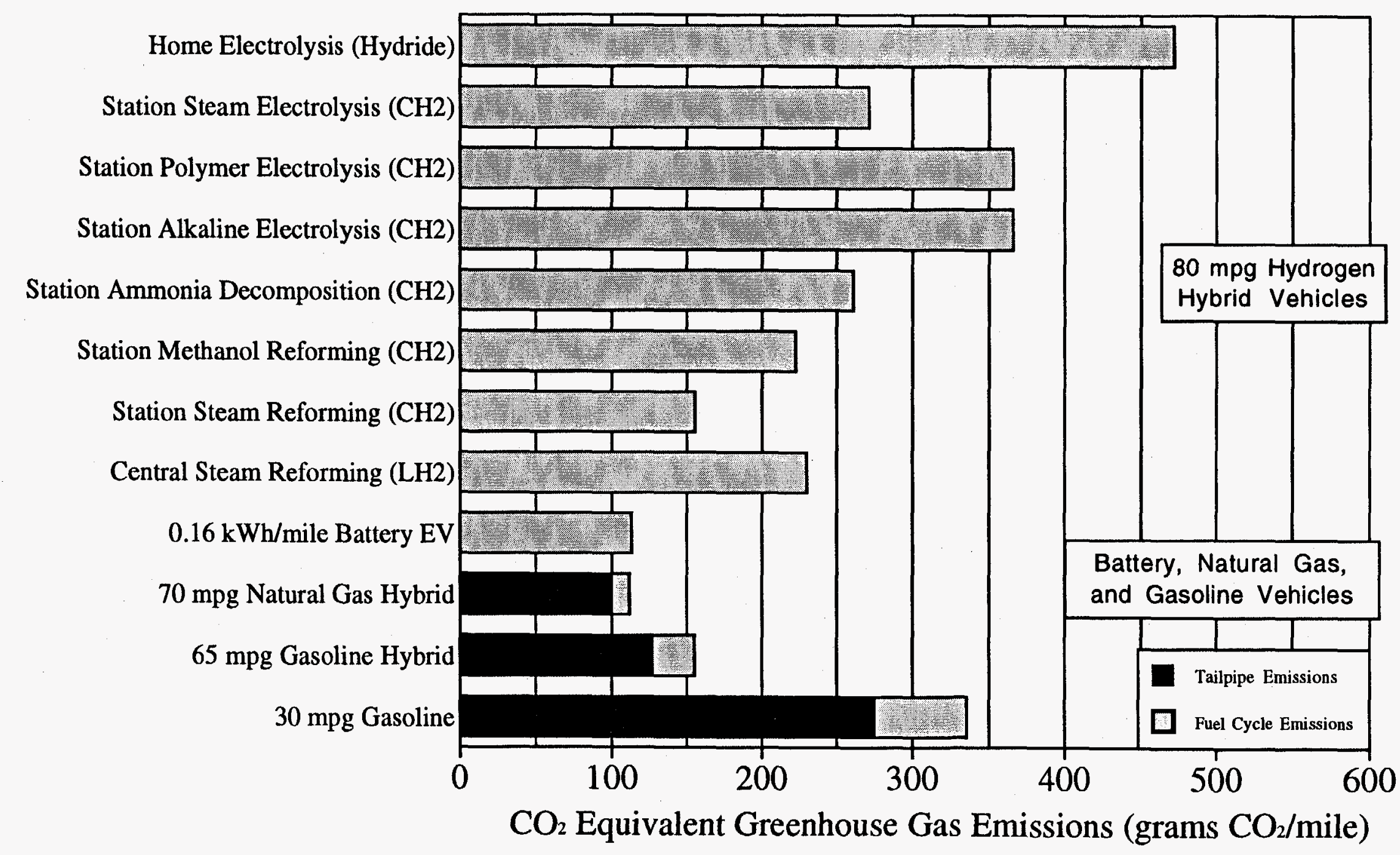


Figure 12. Estimated tailpipe and fuel-cycle emissions of nitrogen oxides (NOx) and hydrocarbons are shown for the five vehicles and seven hydrogen pathways in Fig. 11. Projected 2005 emission factors were taken from Ref. 35. It can be seen that on a full-fuel-cycle basis, hydrogen vehicles using natural gas as a primary energy source provide no NOx emissions benefit over ULEV (or lower) non-hydrogen vehicles. There are some hydrocarbon emission benefits for hydrogen vehicles over gasoline vehicles, but natural-gas HEVs and BPEVs produce lower emissions of both NOx and hydrocarbons than gasoline vehicles. It also appears that NOx full-fuel-cycle emissions is the primary air pollutant issue facing hydrogen vehicles. 
Figure 12. Estimated Air Pollutant Emissions in 2005 for Passenger Cars Fueled by Hydrogen, Batteries, Natural Gas, or Gasoline (using natural gas for primary energy)

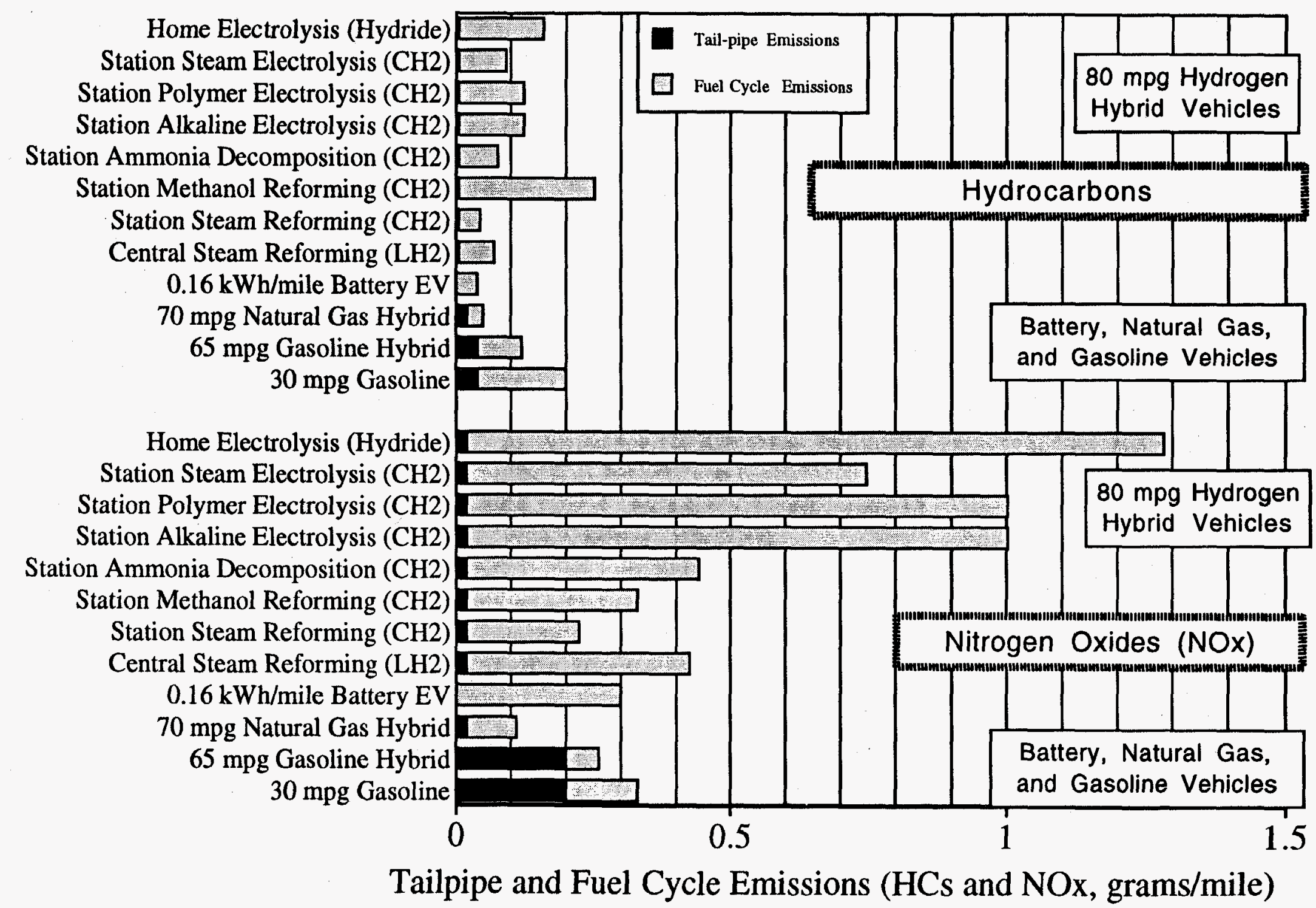


Figure 13. Tailpipe emissions of $\mathrm{CO}$, hydrocarbons, and NOx are shown for hydrogen, natural gas, and gasoline HEVs. Ultra-low emission vehicle (ULEV) standards are used to represent emissions from a gasoline hybrid. Emissions from a natural-gas HEV are based upon recent certification tests of Chrysler's NGV minivan (Ref. 35). Hydrogen vehicle tailpipe emissions are from Ref. 5 and 34. It can be seen that both hydrogen and natural-gas vehicles offer tailpipe emission levels many times lower than ULEV standards, but the only in the case of $\mathrm{CO}$ do hydrogen vehicles provide significant emissions benefits over natural gas. 


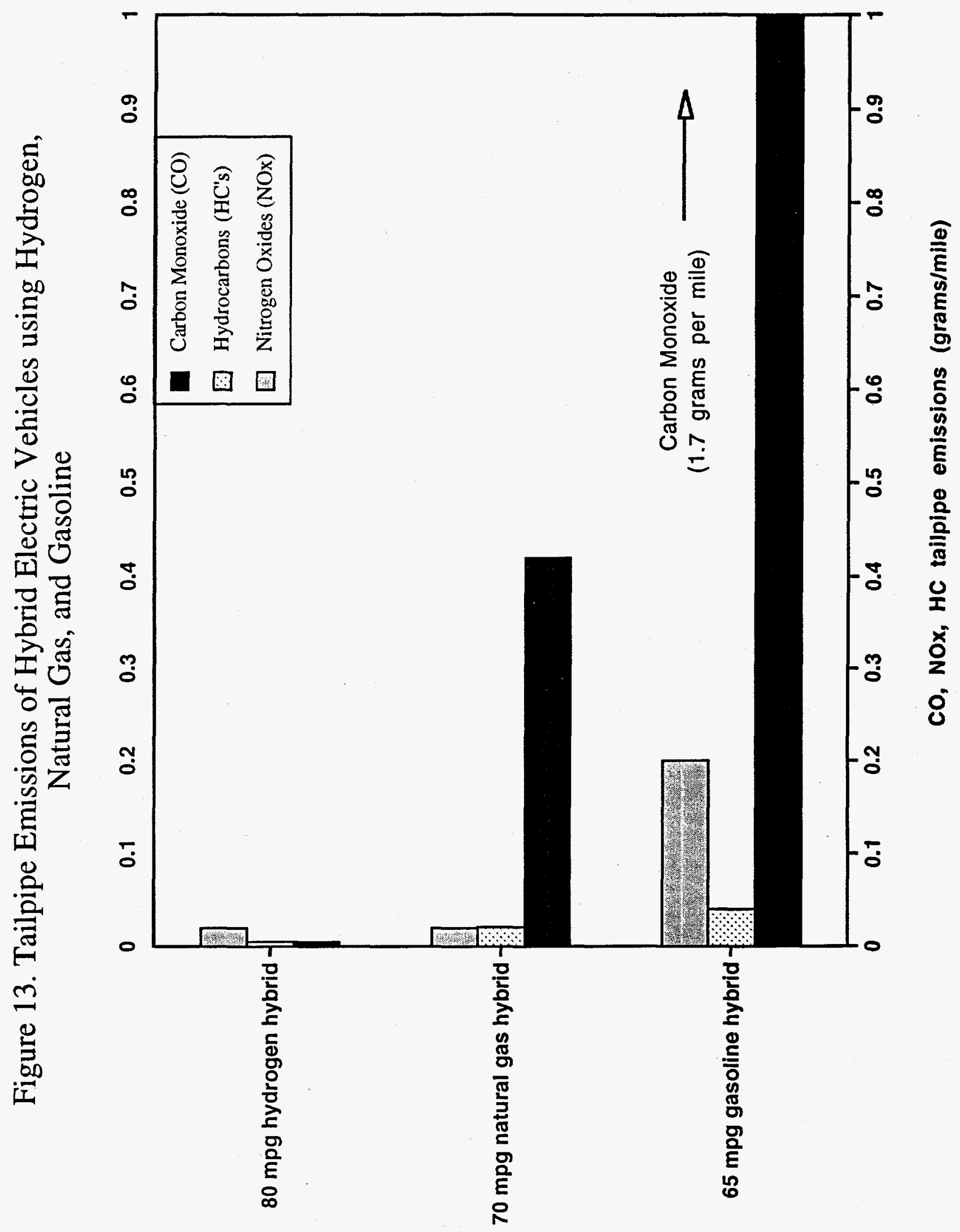


Figure 14(a-c). Electricity-generation primary energy supply mix and associated average full-fuel-cycle emissions of greenhouse gases $\left(\mathrm{kg}\right.$ of $\mathrm{CO}_{2}$ equivalent) and NOx are shown for three electricity-mix scenarios spanning the period 2005 to 2050. The scenarios were adapted from Ref. 36. Figure 14(a) describes a "reference" scenario in which the share of coal-based generation grows from $55 \%$ to $70 \%$ from 2005 to 2030 at the expense of oil-based and nonfossil generation, with natural-gas-based generation retaining a steady share of $15 \%$. Figure 14(b) describes a "market" scenario in which market barriers to non-fossil generation are diminished, increasing the share of non-fossil generation from $30 \%$ to $40 \%$, reducing gas-based generation, and eliminating oil-based generation, while coal remains steady. Figure 14(c) describes a "climate" scenario in which greenhouse-gas emission reductions are a longterm driver. Coal-based generation is eliminated by 2040, initially replaced by retaining oil generation, but ultimately by increasing natural-gas generation from $10 \%$ to $30 \%$ and non-fossil generation from $40 \%$ to $70 \%$ of electricity production.

Emissions for all three scenarios were based chiefly on Ref. 35 and 36 and on the Department of Energy's "Hydrogen Program Plan, FY1993-FY1997" (DOE/CH10093-147 DE92010556, 1992), using conventional steam generation for each fuel type but phasing in cleaner and more efficient combined-cycle plants between 2020 and 2035. NOx and $\mathrm{CO}_{2}$ emissions for non-fossil generation were assumed to be essentially zero. Average NOx emission rates drop from roughly $1 / 3$ to $1 / 10$ of emissions in 2005 by the 2035-2040 timeframe, depending upon scenario. Average $\mathrm{CO}_{2}$ emission rates increase slightly between 2005 and 2050 or drop by up to $75 \%$, depending upon scenario. 

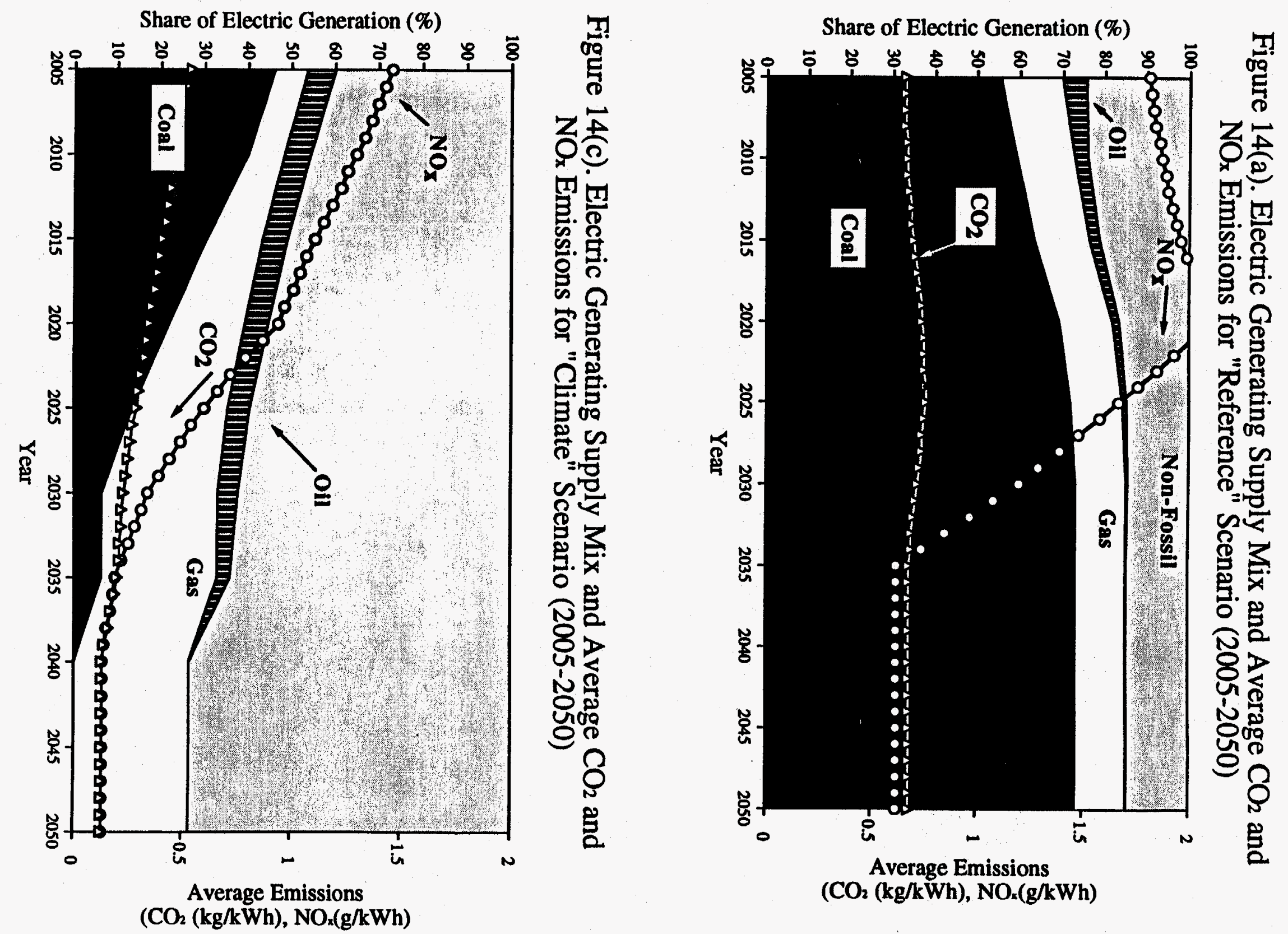
Figure 14(b). Electric Generating Supply Mix and Average $\mathrm{CO}_{2}$ and NOx Emissions for "Market" Scenario (2005-2050)

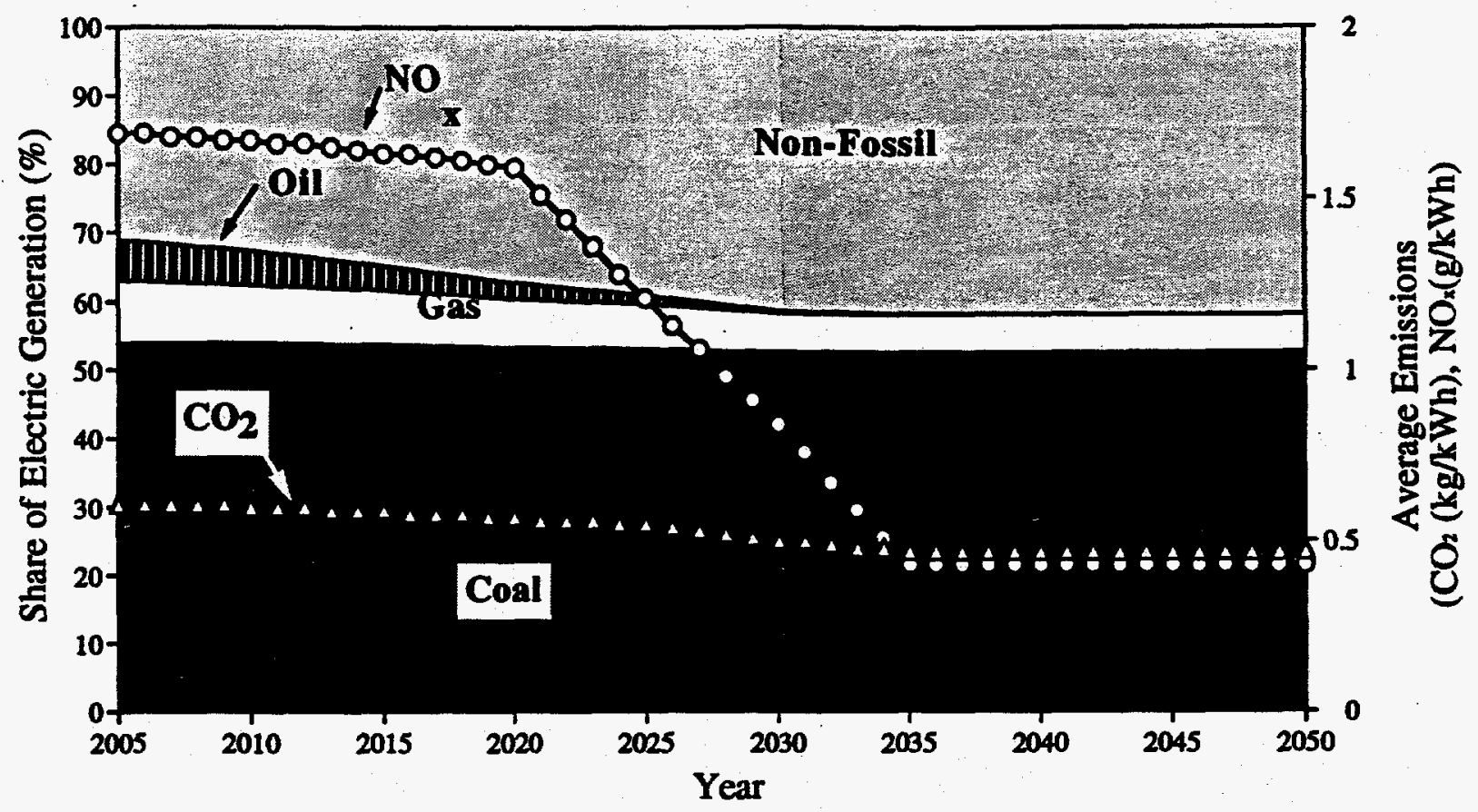


Figure 15(a-d). Four snapshots of full-fuel-cycle greenhouse-gas emissions (in $\mathrm{CO}_{2}$-equivalent grams per mile) are shown for the same five vehicles and seven hydrogen pathways used in Fig. 11 and 13, but using the three electricity mix scenarios of Fig. 14 in 2005 and 2035. Emissions are reduced significantly with changes in electricity-generation mix. Figure 15(a) shows emissions under the "reference" scenario in 2005. Figure 15(b) shows that emissions in 2035 increase slightly under the "reference" scenario. Figure 15(c) shows that emissions decrease roughly $25 \%$ for electricity-intensive pathways in 2035 , under the "market" scenario. Figure 15(d) shows that emissions decrease sharply in 2035 under the "climate" scenario. Figure 15(b-d) also shows that under the "reference" case hydrogen cars are inferior to fossil-fuel hybrid vehicles and battery cars in 2035, while electrolytic hydrogen cars only achieve emission levels comparable to $30-\mathrm{mpg}$ gasoline vehicles. The emissions of hydrogen cars can equal or better 30-mpg gasoline cars under the "market" scenario, but natural-gas hybrids and battery vehicles still offer significantly lower emissions. Under the "climate" scenario, a number of interesting changes occur by 2035. First, electrolytic hydrogen pathways offer lower or comparable emissions than thermochemical hydrogen pathways using natural gas or hydrogen carriers manufactured from natural gas, and even lower emissions than gasoline vehicles, comparable to greenhouse-gas emissions from a natural-gas HEV. If hydrogen is produced from highefficiency steam electrolysis, or similar methods, then hydrogen cars achieve lower emissions than fossil-fuel HEVs, roughly one third of $30-\mathrm{mpg}$ gasoline vehicle emissions. 
Figure 15(a). Estimated Greenhouse Gas Emissions in 2005 for Cars Fueled by Hydrogen, Batteries, Natural Gas, or Gasoline (using "Reference Case" Electric Generation Mix)

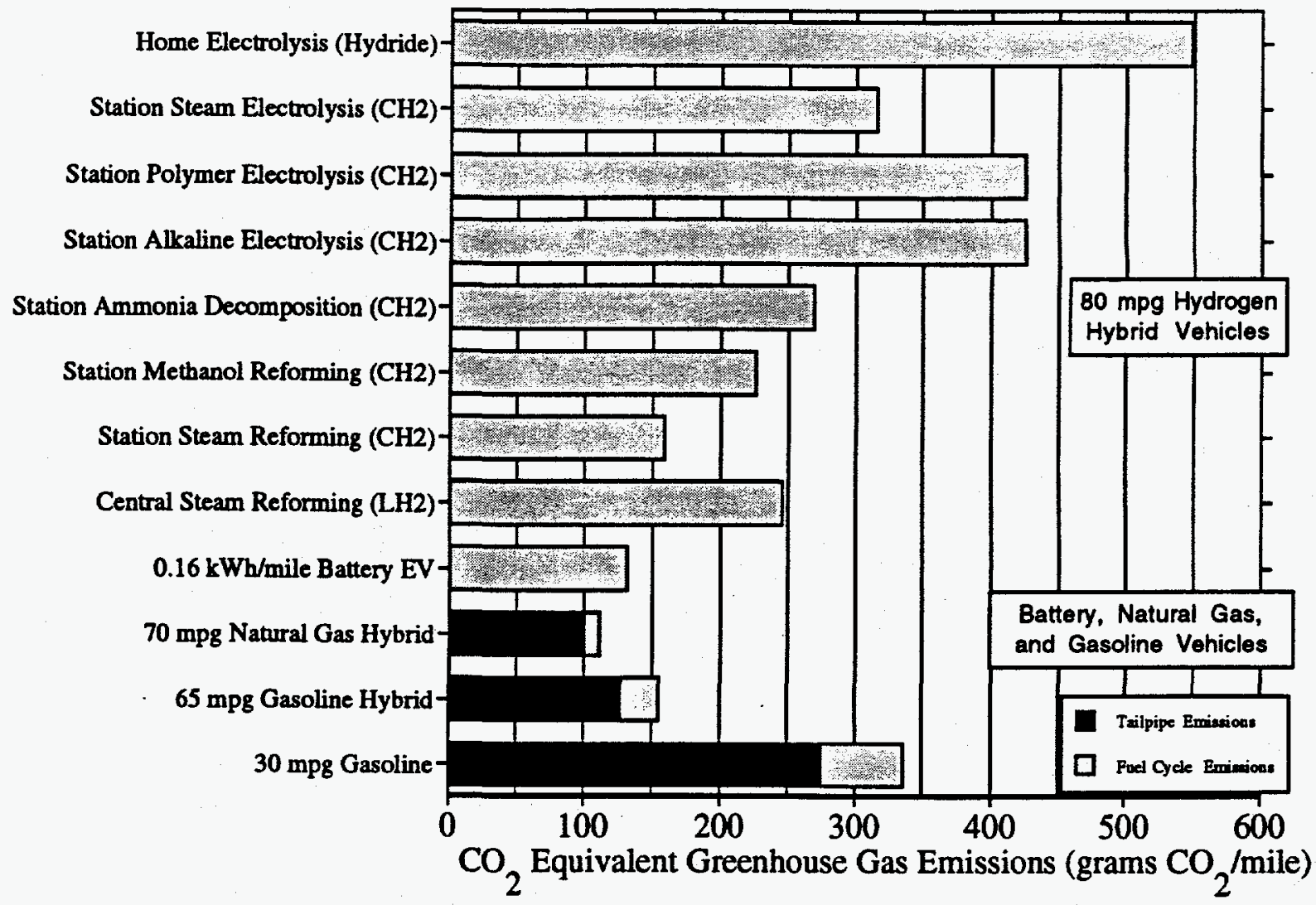

Figure 15(c). Estimated Greenhouse Gas Emissions in 2035 for Cars Fueled by Hydrogen, Batteries, Natural Gas, or Gasoline (using "Market Case" Electric Generation Mix)

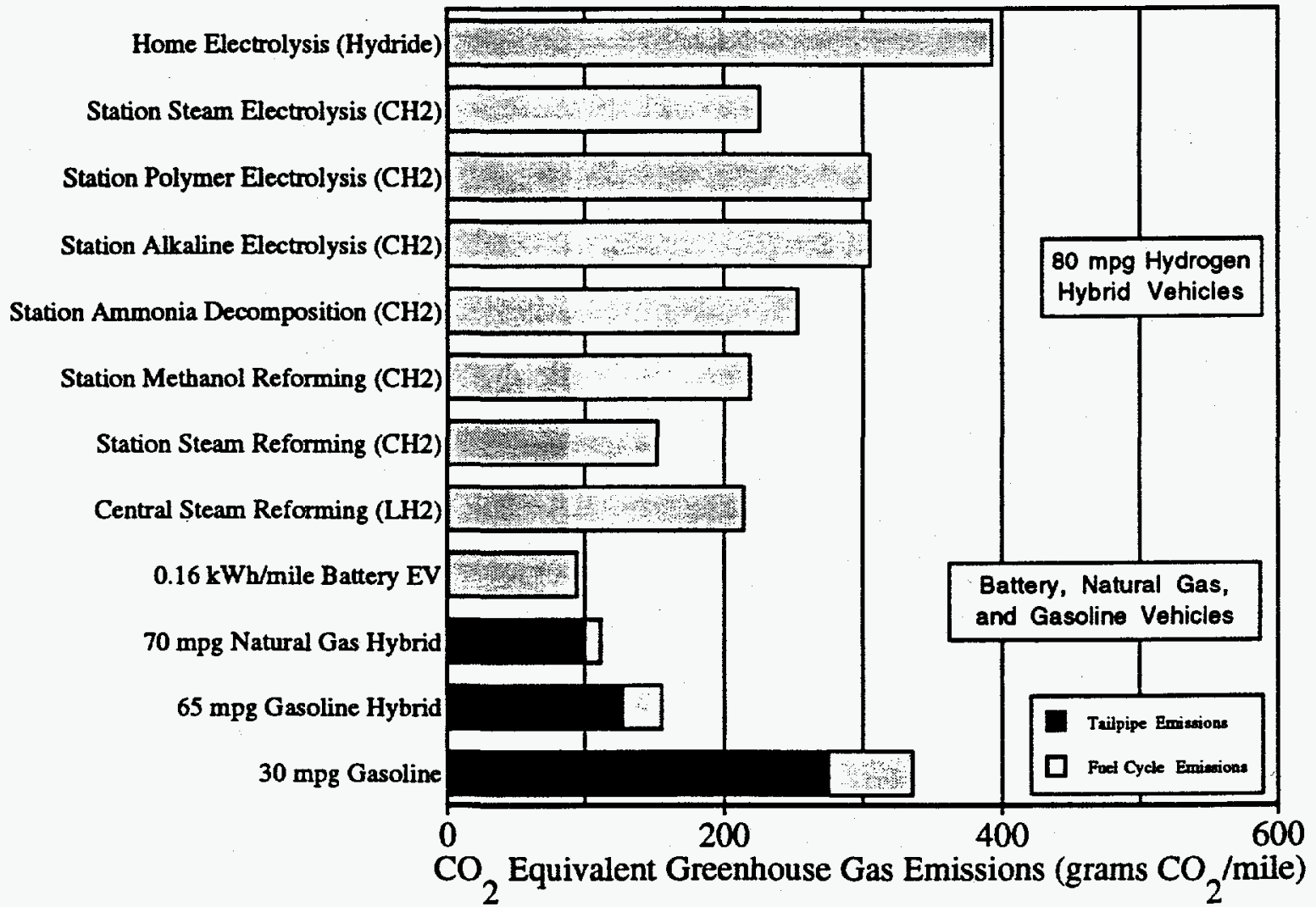


Figure 15(b). Estimated Greenhouse Gas Emissions in 2035 for Cars Fueled by Hydrogen, Batteries, Natural Gas, or Gasoline (using "Reference Case" Electric Generation Mix)

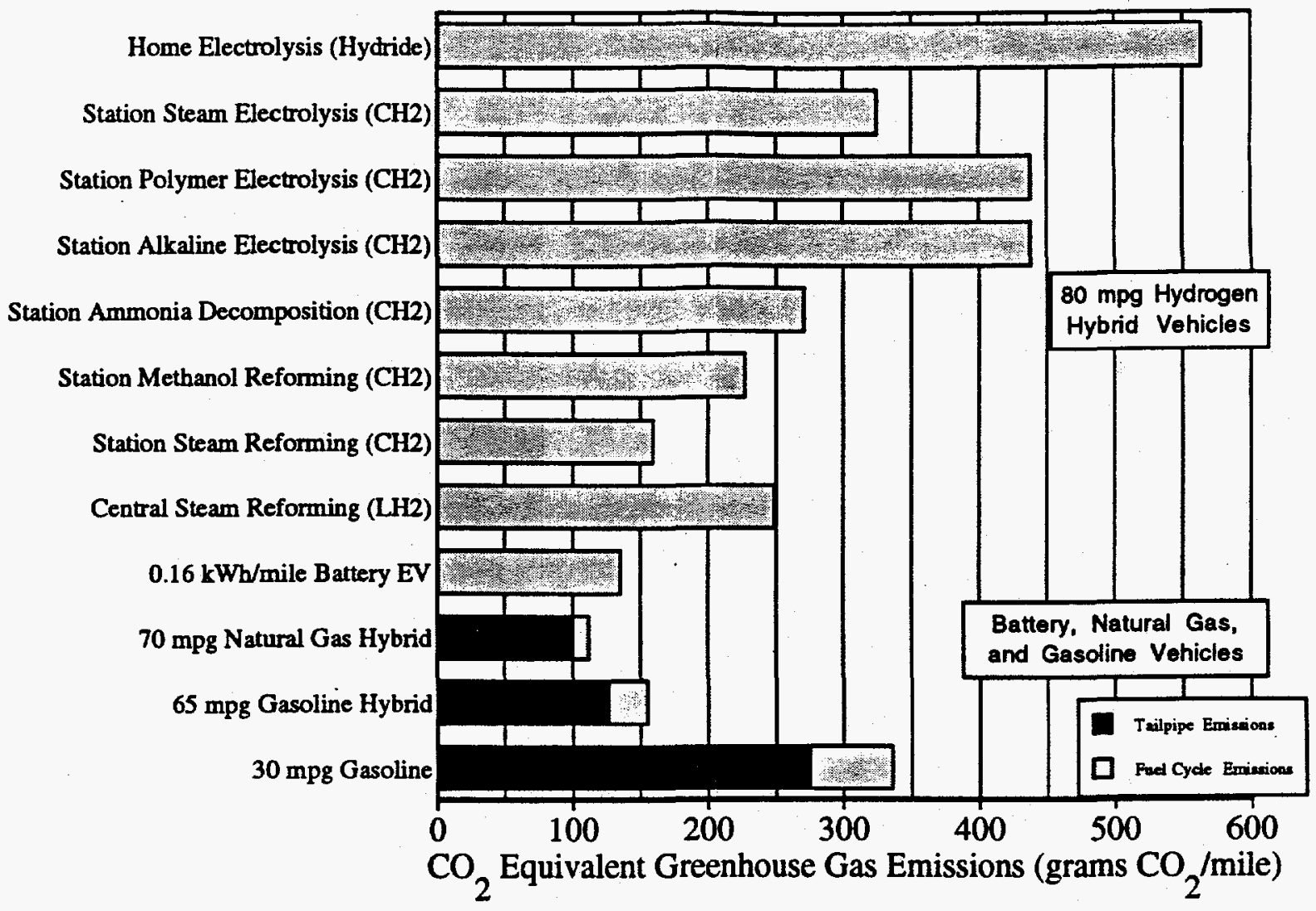

Figure 15(d). Estimated Greenhouse Gas Emissions in 2035 for Cars Fueled by Hydrogen, Batteries, Natural Gas, or Gasoline (using "Climate Case" Electric Generation Mix)

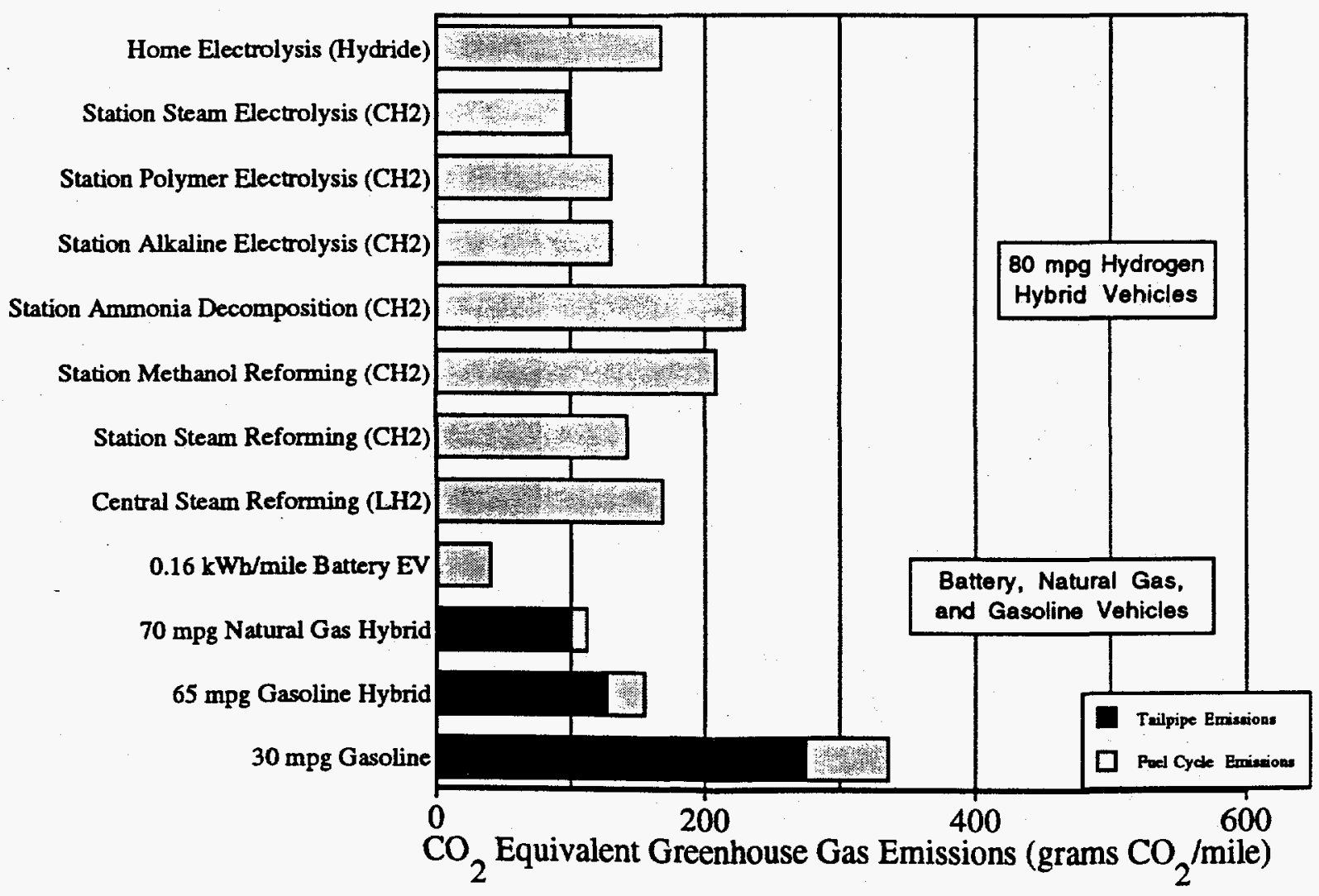


Figure 16(a-d). Fuel-cycle and tailpipe emissions of hydrocarbons and NOx are shown for the five vehicles and seven hydrogen pathways in Fig. 15 under the three electricity-mix scenarios of Fig. 14 in 2005 and 2035. Emissions improve markedly with technical advancements and changes in electricitygeneration mix. Figure 16(a) shows emissions under the "reference" scenario in 2005. Figure 16(b-d) shows emissions under "reference," "market," and "climate" scenarios in 2035. Initially, NOx emissions, mostly from coal-based electricity, are sharply higher for hydrogen HEVs than for gasoline or naturalgas HEVs or for BPEVs. Hydrogen vehicles do have hydrocarbon emission reduction advantages, but overall hydrocarbon emissions are small. By 2035, however, NOx emissions are reduced sharply in all scenarios, and most hydrogen pathways achieve levels comparable to or better than ULEV gasoline vehicles. However, to reach NOx emissions levels as low as a natural-gas HEV, hydrogen vehicles require high-efficiency steam electrolysis and an electricity mix that relies largely $(70 \%)$ on non-fossil generation. 
Figure 16(a). Estimated Air Pollutant Emissions in 2005 for Cars Fueled by Hydrogen, Batteries, Natural Gas, or Gasoline (using "Reference Case" Electric Generation Mix)

Home Electrolysis (Hydride)

Station Steam Electrolysis (CH2)

Station Polymer Electrolysis (CH2)

Station Alkaline Electrolysis (CH2)

Station Ammonia Decomposition (CH2)

Station Methanol Reforming (CH2)

Station Steam Reforming (CH2)

Central Steam Reforming (LH2)

$0.16 \mathrm{kWh} /$ mile Battery EV

70 mpg Natural Gas Hybrid I $65 \mathrm{mpg}$ Gasoline Hybrid $30 \mathrm{mpg}$ Gasoline

Home Electrolysis (Hydride)

Station Steam Electrolysis (CH2)

Station Polymer Electrolysis (CH2)

Station Alkaline Electrolysis (CH2)

Station Ammonia Decomposition ( $\mathrm{CH} 2)$

Station Methanol Reforming (CH2)

Station Steam Reforming ( $\mathrm{CH} 2$ )

Central Steam Reforming (LH2)

$0.16 \mathrm{kWh} / \mathrm{mile}$ Battery EV

70 mpg Natural Gas Hybrid

$65 \mathrm{mpg}$ Gasoline Hybrid $30 \mathrm{mpg}$ Gasoline

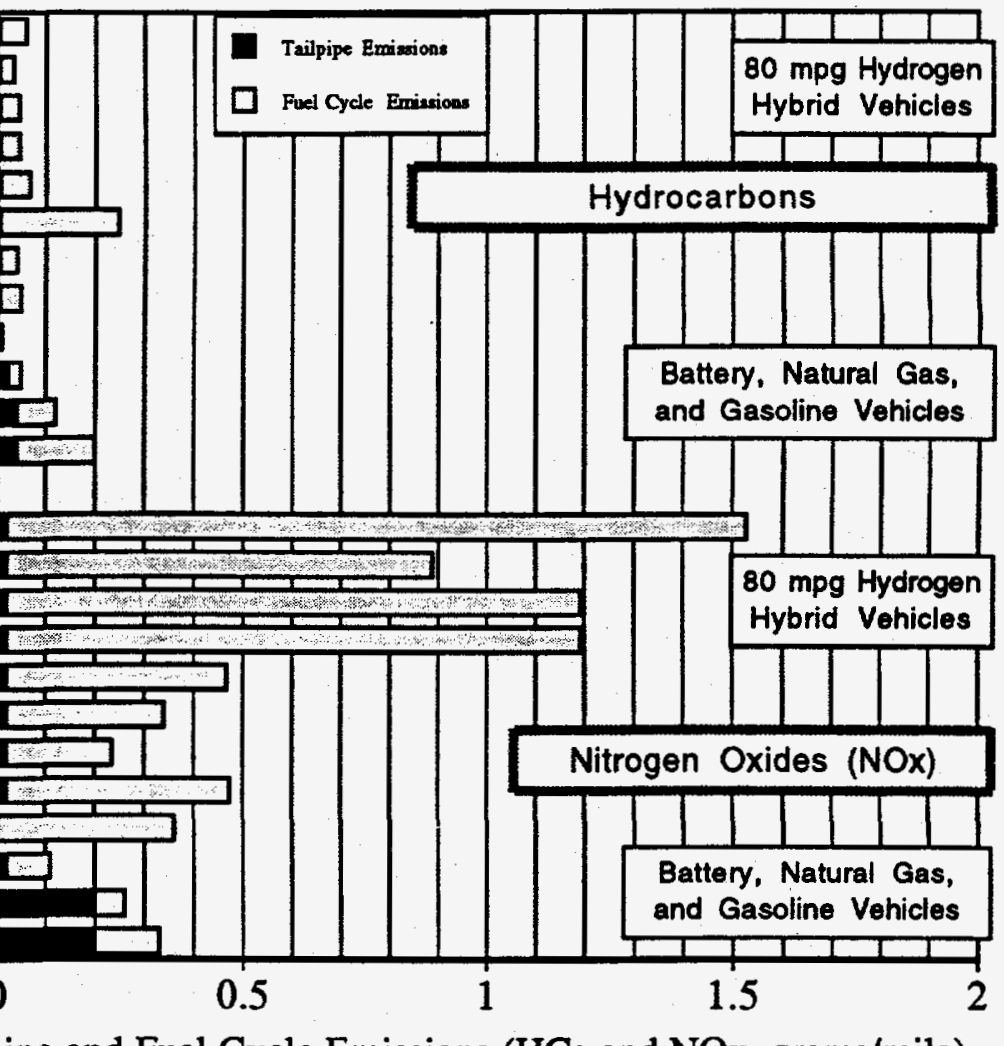

Tailpipe and Fuel Cycle Emissions (HCs and NOx, grams/mile)

Figure 16(c). Estimated Air Pollutant Emissions in 2035 for Cars Fueled by Hydrogen, Batteries, Natural Gas, or Gasoline (using "Market Case" Electric Generation Mix)

Home Electrolysis (Hydride)

Station Steam Electrolysis ( $\mathrm{CH} 2)$

Station Polymer Electrolysis (CH2)

Station Alkaline Electrolysis (CH2)

Station Ammonia Decomposition (CH2)

Station Methanol Reforming ( $\mathrm{CH} 2)$

Station Steam Reforming ( $\mathrm{CH} 2)$

Central Steam Reforming (LH2) $\square$

$0.16 \mathrm{kWh} / \mathrm{mile}$ Battery EV

70 mpg Natural Gas Hybrid 1 65 mpg Gasoline Hybrid $30 \mathrm{mpg}$ Gasoline

Home Electrolysis (Hydride)

Station Steam Electrolysis (CH2)

Station Polymer Electrolysis (CH2)

Station Alkaline Electrolysis (CH2)

Station Ammonia Decomposition ( $\mathrm{CH} 2)$

Station Methanol Reforming (CH2)

Station Steam Reforming (CH2)

Central Steam Reforming (LH2)

$0.16 \mathrm{kWh} / \mathrm{mile}$ Battery EV

$70 \mathrm{mpg}$ Natural Gas Hybrid $65 \mathrm{mpg}$ Gasoline Hybrid $30 \mathrm{mpg}$ Gasoline

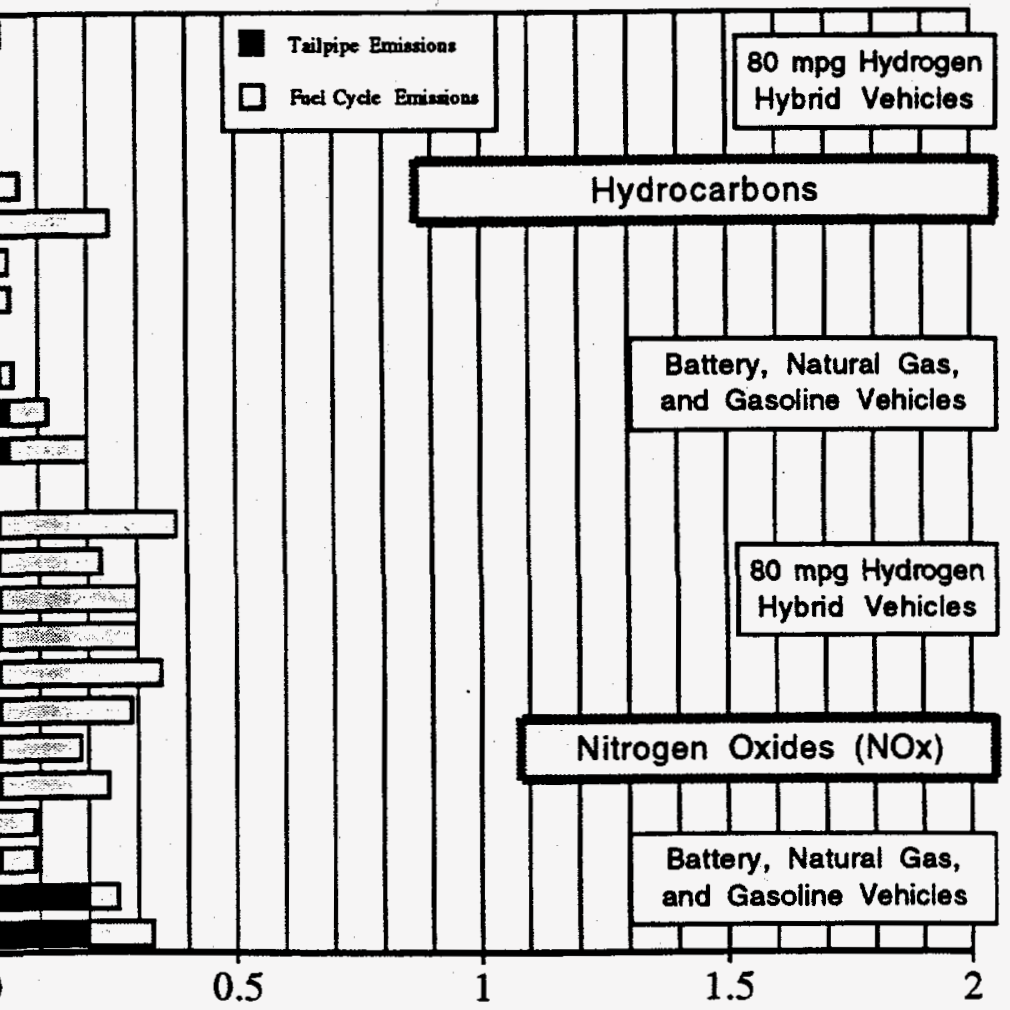

Tailpipe and Fuel Cycle Emissions (HCs and NOx, grams/mile) 
Figure 16(b). Estimated Air Pollutant Emissions in 2035 for Cars Fueled by Hydrogen, Batteries, Natural Gas, or Gasoline (using "Reference Case" Electric Generation Mix)

Home Electrolysis (Hydride) Station Steam Electrolysis (CH2) f Station Polymer Electrolysis (CH2) Station Alkaline Electrolysis (CH2) Station Ammonia Decomposition (CH2)

Station Methanol Reforming (CH2) Station Steam Reforming (CH2) Central Steam Reforming (LH2) $0.16 \mathrm{kWh} /$ mile Battery EV 70 mpg Natural Gas Hybrid 65 mpg Gasoline Hybrid $30 \mathrm{mpg}$ Gasoline

Home Electrolysis (Hydride) Station Steam Electrolysis (CH2) Station Polymer Electrolysis (CH2) Station Alkaline Electrolysis (CH2) Station Ammonia Decomposition (CH2) Station Methanol Reforming (CH2) Station Steam Reforming (CH2) Central Steam Reforming.(LH2) $0.16 \mathrm{kWh} / \mathrm{mile}$ Battery EV $70 \mathrm{mpg}$ Natural Gas Hybrid $65 \mathrm{mpg}$ Gasoline Hybrid $30 \mathrm{mpg}$ Gasoline 0

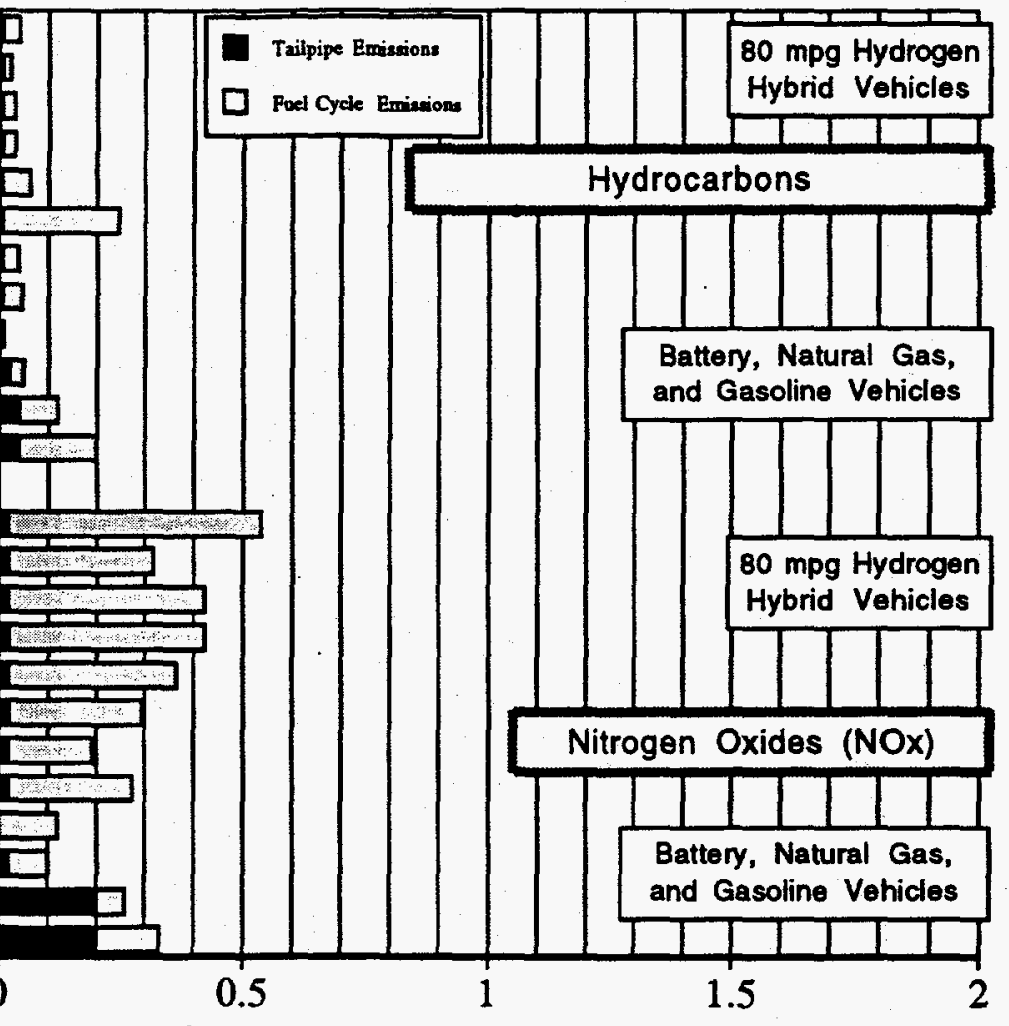

Tailpipe and Fuel Cycle Emissions (HCs and NOx, grams/mile)

Figure 16(d). Estimated Air Pollutant Emissions in 2035 for Cars Fueled by Hydrogen, Batteries, Natural Gas, or Gasoline (using "Climate Case" Electric Generation Mix)

Home Electrolysis (Hydride) Station Steam Electrolysis (CH2) Station Polymer Electrolysis (CH2) Station Alkaline Electrolysis (CH2) Station Ammonia Decomposition (CH2)

Station Methanol Reforming (CH2) Station Steam Reforming (CH2) Central Steam Reforming (LH2) $0.16 \mathrm{kWh} / \mathrm{mile}$ Battery EV $70 \mathrm{mpg}$ Natural Gas Hybrid $]$ 65 mpg Gasoline Hybrid $30 \mathrm{mpg}$ Gasoline

Home Electrolysis (Hydride) Station Steam Electrolysis ( $\mathrm{CH} 2)$ Station Polymer Electrolysis (CH2) Station Alkaline Electrolysis ( $\mathrm{CH} 2)$ Station Ammonia Decomposition (CH2) Station Methanol Reforming (CH2) Station Steam Reforming ( $\mathrm{CH} 2)$ Central Steam Reforming (LH2) $0.16 \mathrm{kWh} / \mathrm{mile}$ Battery EV 70 mpg Natural Gas Hybrid $65 \mathrm{mpg}$ Gasoline Hybrid $30 \mathrm{mpg}$ Gasoline

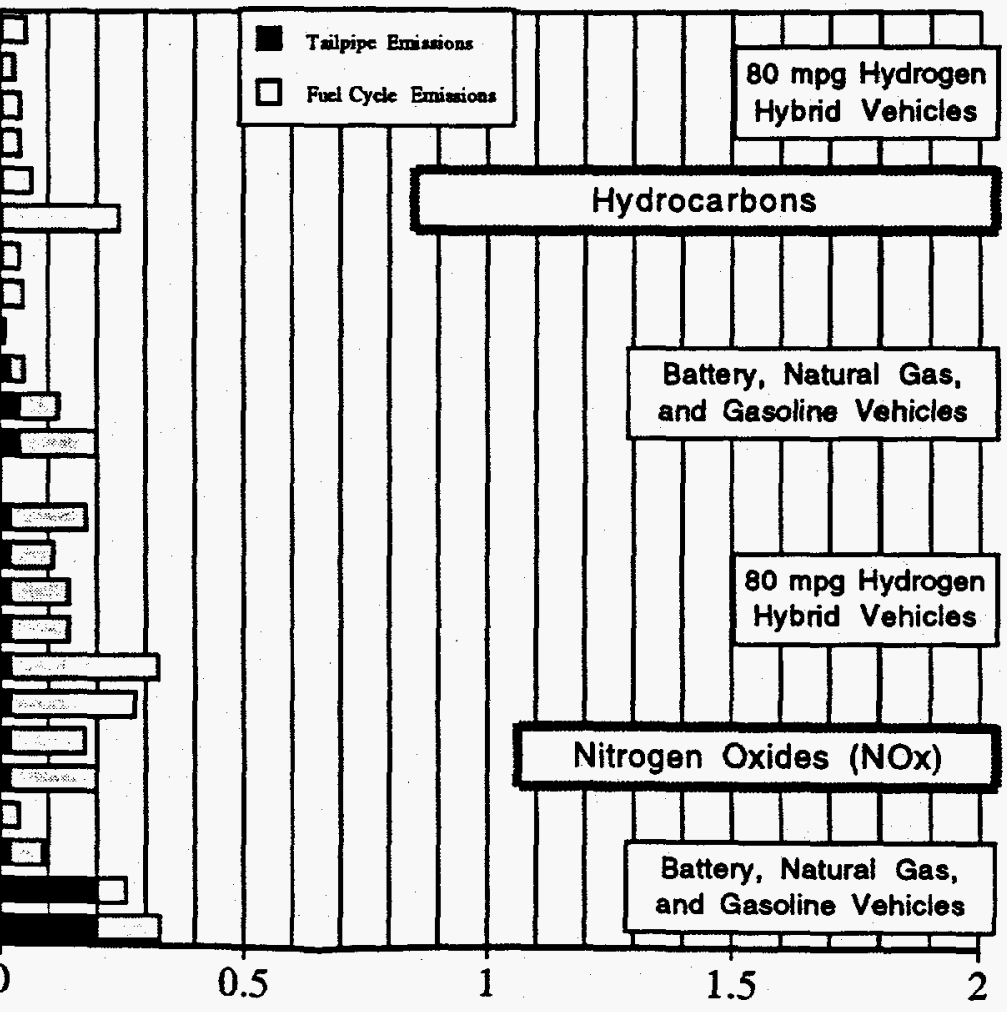

Tailpipe and Fuel Cycle Emissions (HCs and NOx, grams/mile) 
툰

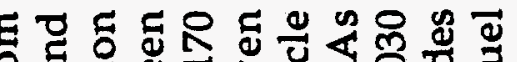

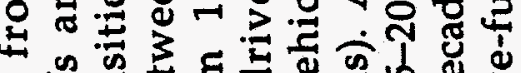

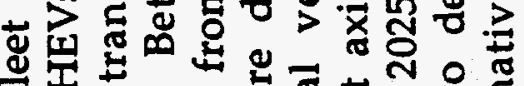

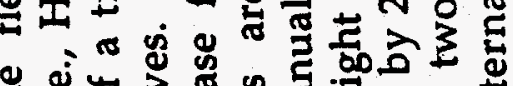

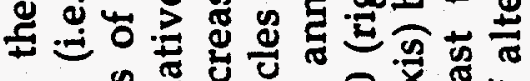

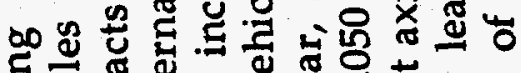

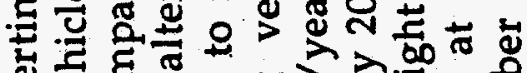

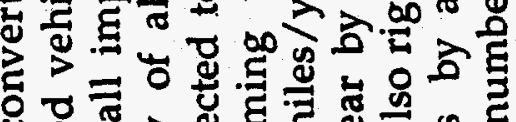

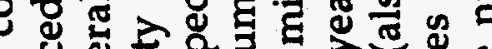

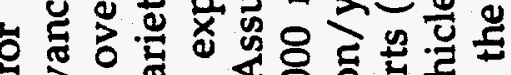
$\geqslant 0$ क

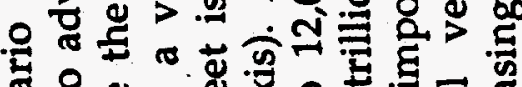

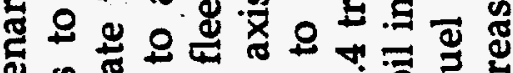

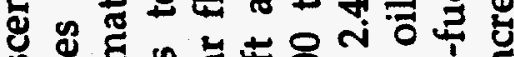

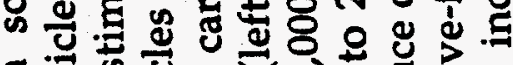

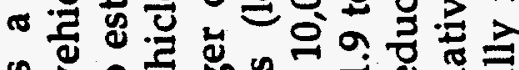

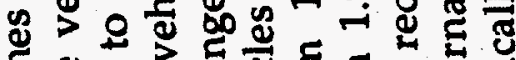

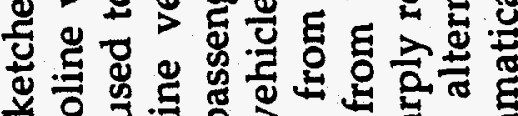
क \% 60 0

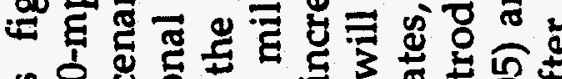
鱼

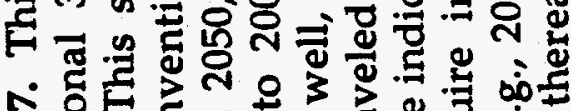

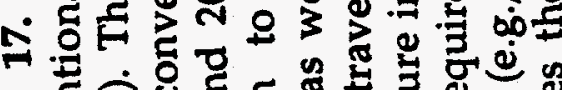

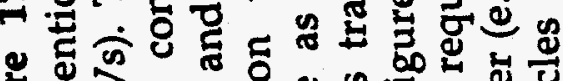

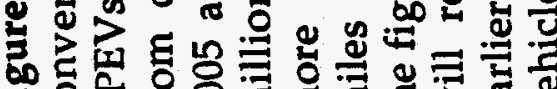
诖 
Figure 17. U.S. Passenger Car Transportation Demand Scenario (2005-2050): Alternative Fuel Market Penetration and Oil Import Displacement

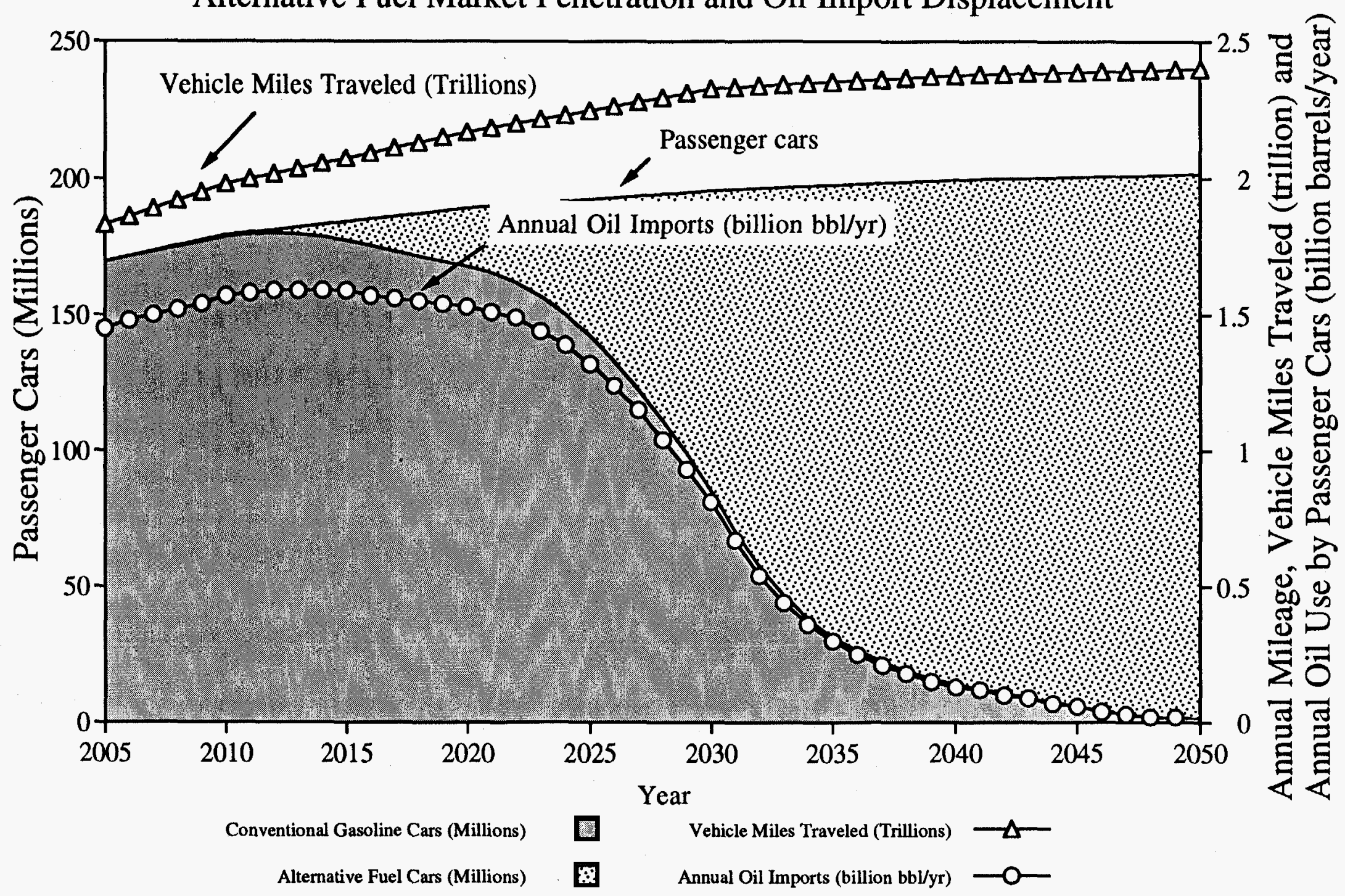


Figure 18(a-d). Annual $\mathrm{CO}_{2}, \mathrm{NOx}, \mathrm{HC}$, and $\mathrm{CO}$ emissions for U.S. Passenger Car Fleet (2005-2050). Using the full-fuel-cycle vehicle emissions in Fig. 15 and 16 and the passenger car fleet size and use assumptions shown in Fig. 17, the total emissions from fueling U.S. passenger cars has been estimated under eight scenarios to demonstrate the emission impacts of continuing to use conventional gasoline vehicles or of a transition to a number of alternative vehicles, fuels, electricity mixes, and hydrogen production pathways. Figure 18(a) shows that hydrogen vehicles will require electrolysis under the "climate" electricity mix to provide the greatest reduction in $\mathrm{CO}_{2}$ emissions. If hydrogen fuel is electrolyzed under more fossil-intensive mixes (on average), then greater emission reduction can be achieved by every other fuel/vehicle combination. If hydrogen is produced at stations by steam-reforming natural gas, then hydrogen vehicles are comparable to gasoline HEVs. Figure 18(b) shows that, in the case of NOx emissions, hydrogen vehicles again require the largely non-fossil "climate" electricity mix to achieve emissions reduction comparable to natural-gas HEVs or BPEVs, although steam-reformed hydrogen can provide emission reductions over gasoline HEVs. Figure 18(c) shows that for hydrocarbon emissions hydrogen vehicles provide large and similar emission reduction benefits whether the fuel is made electrolytically or by steam-reforming. However, natural-gas HEVs approach the emissions levels of steam-reformed hydrogen cars, and BPEVs provide lower emissions than hydrogen vehicles. Figure 18(d) shows that for CO emissions hydrogen vehicles provide large emission reductions over gasoline, but natural gas can achieve $75 \%$ of these emissions reductions as well. Note that, in Fig. 18(d), all of the lines are superimposed on each other, except for the 30-mpg gasoline car and the 70-mpg natural-gas hybrid. 
Figure 19(a). Cumulative Carbon Dioxide $\left(\mathrm{CO}_{2}\right)$ Emissions for U.S. Cars (2005-2050)

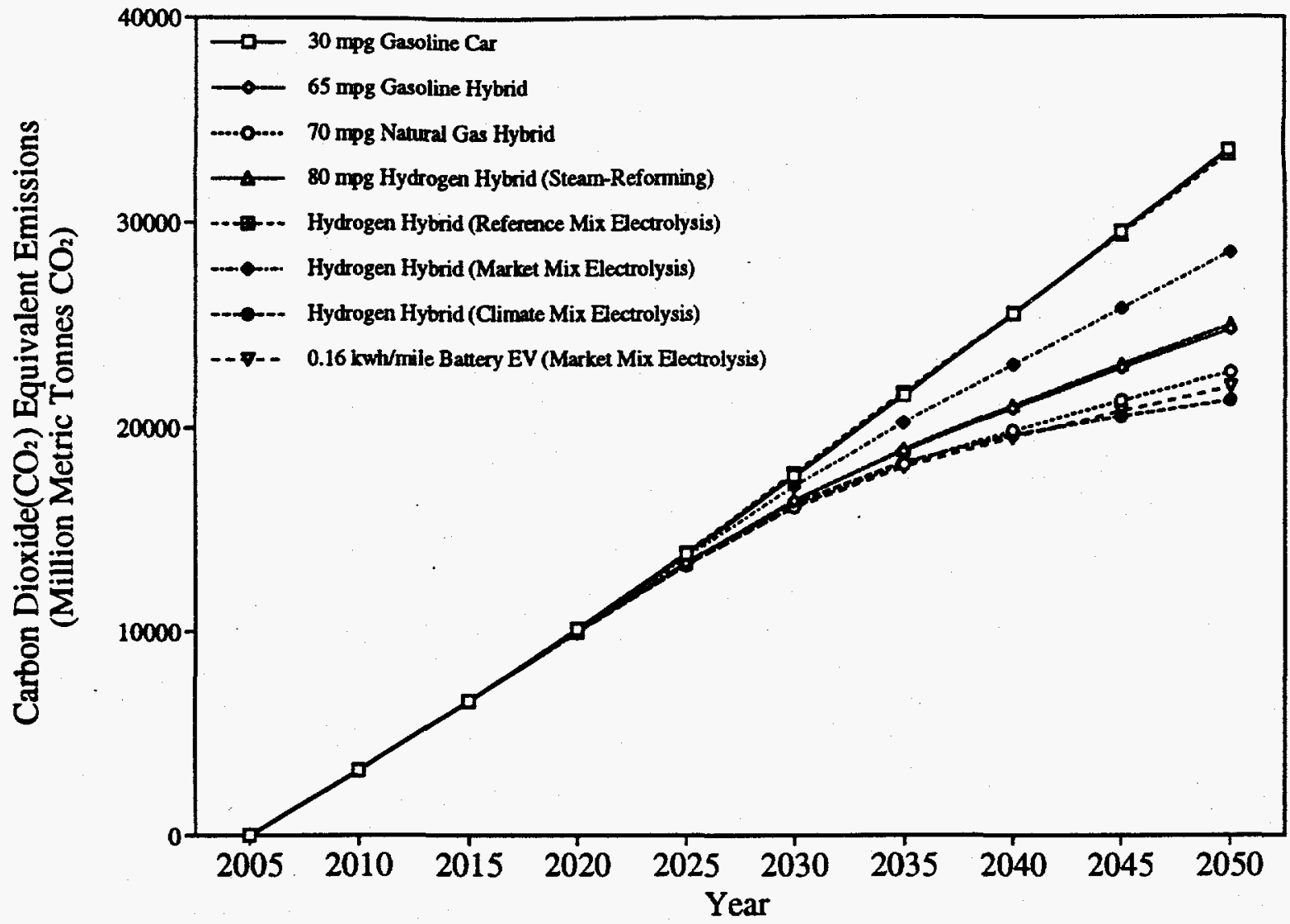

Figure 19(c). Cumulative Hydrocarbon Emissions for U.S. Cars (2005-2050)

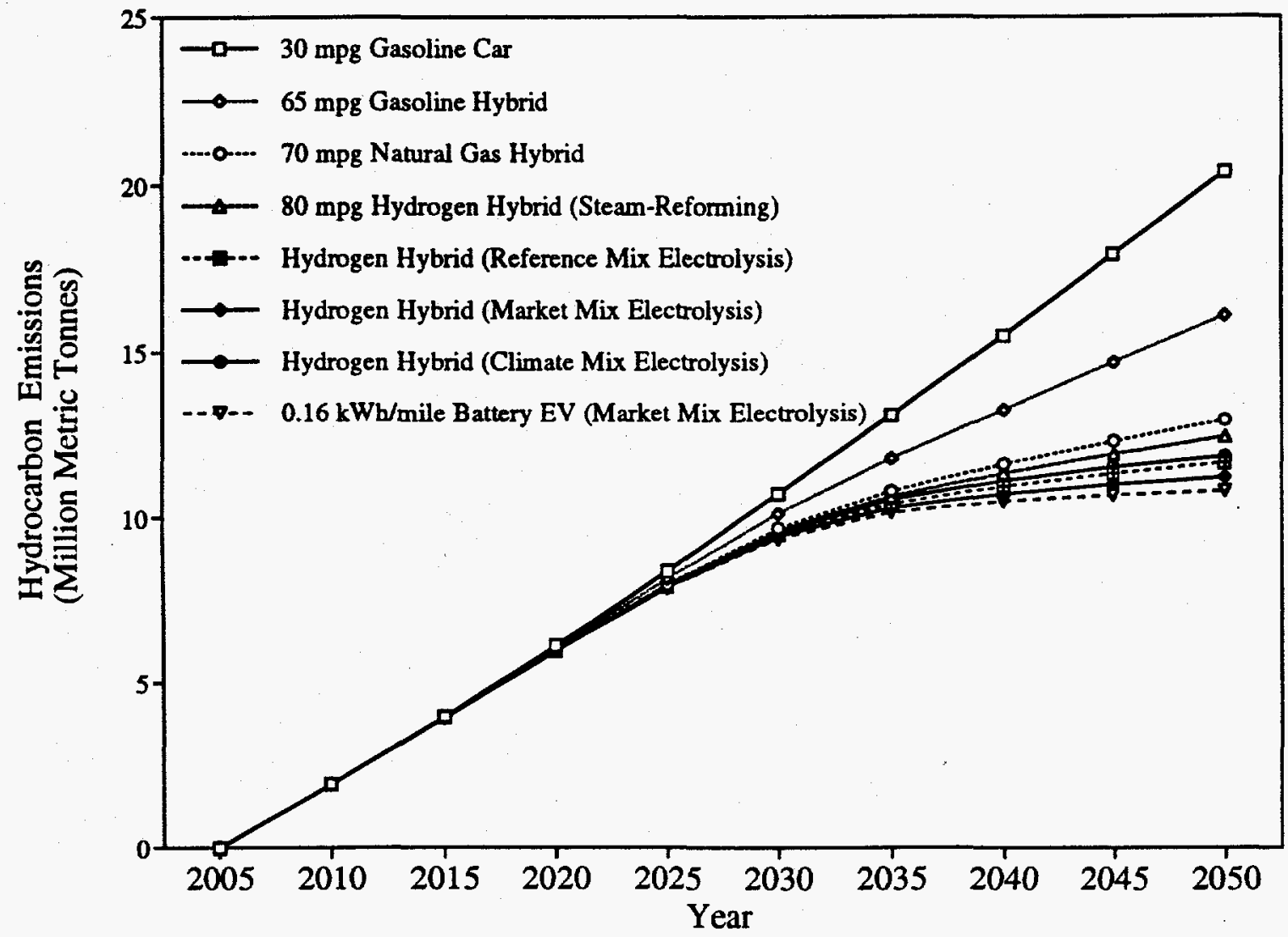


Figure 19(b). Cumulative Nitrogen Oxide (NOx) Emissions for U.S. Cars (2005-2050)

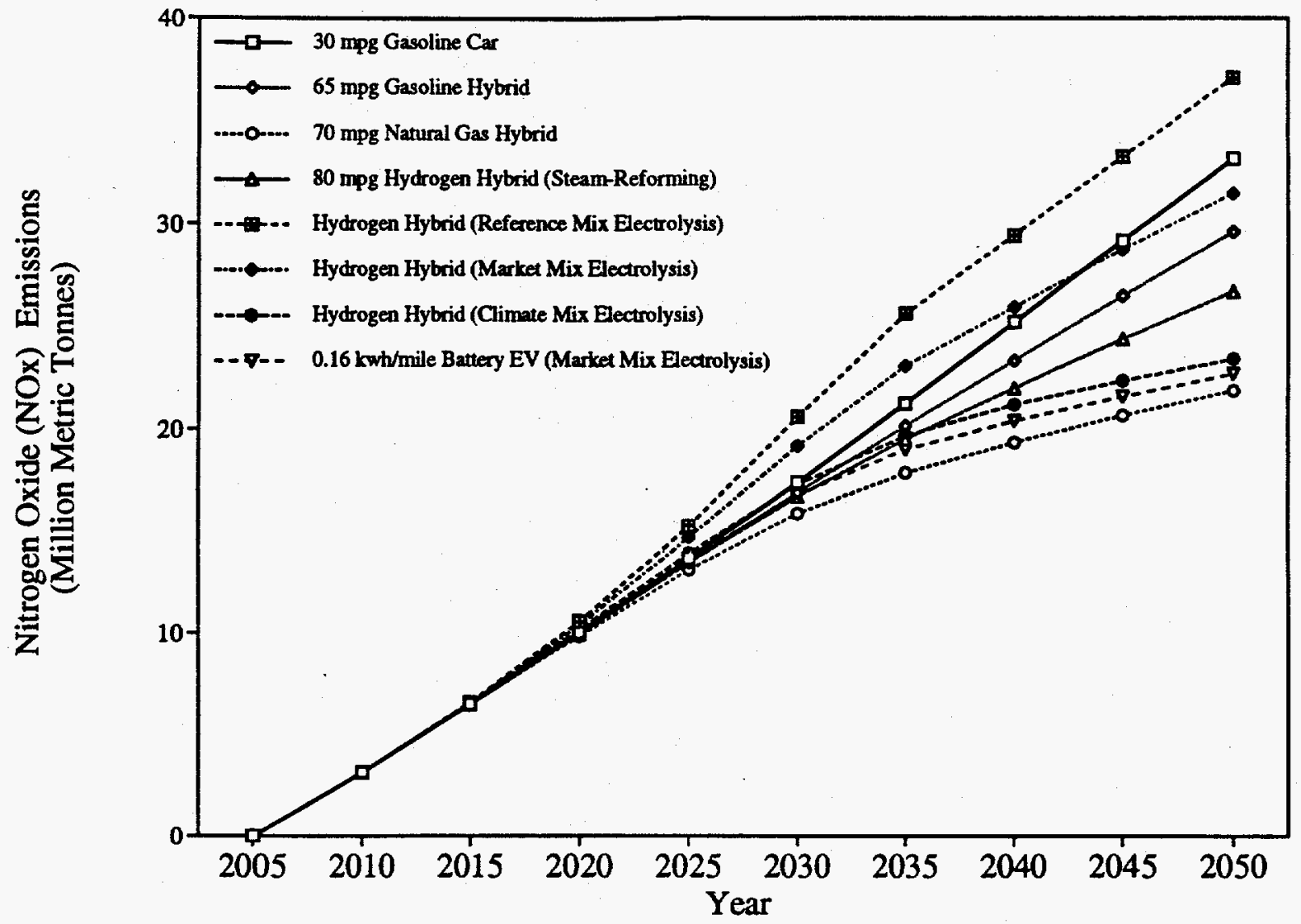

Figure 19(d). Cumulative Carbon Monoxide (CO) Emissions for U.S. Cars (2005-2050)

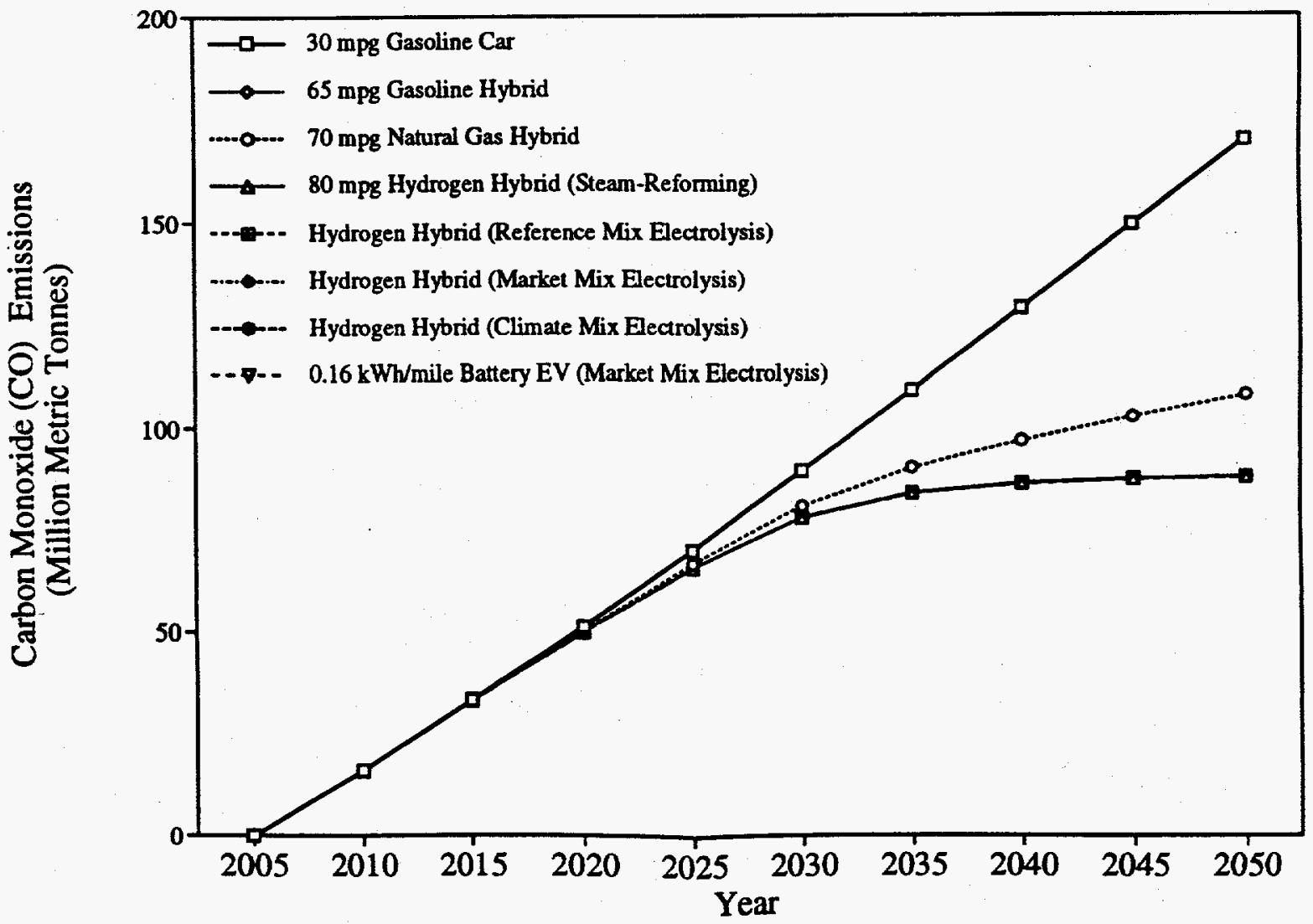


Figure 18(a). Carbon Dioxide Emissions Estimates for U.S. Cars (2005-2050)

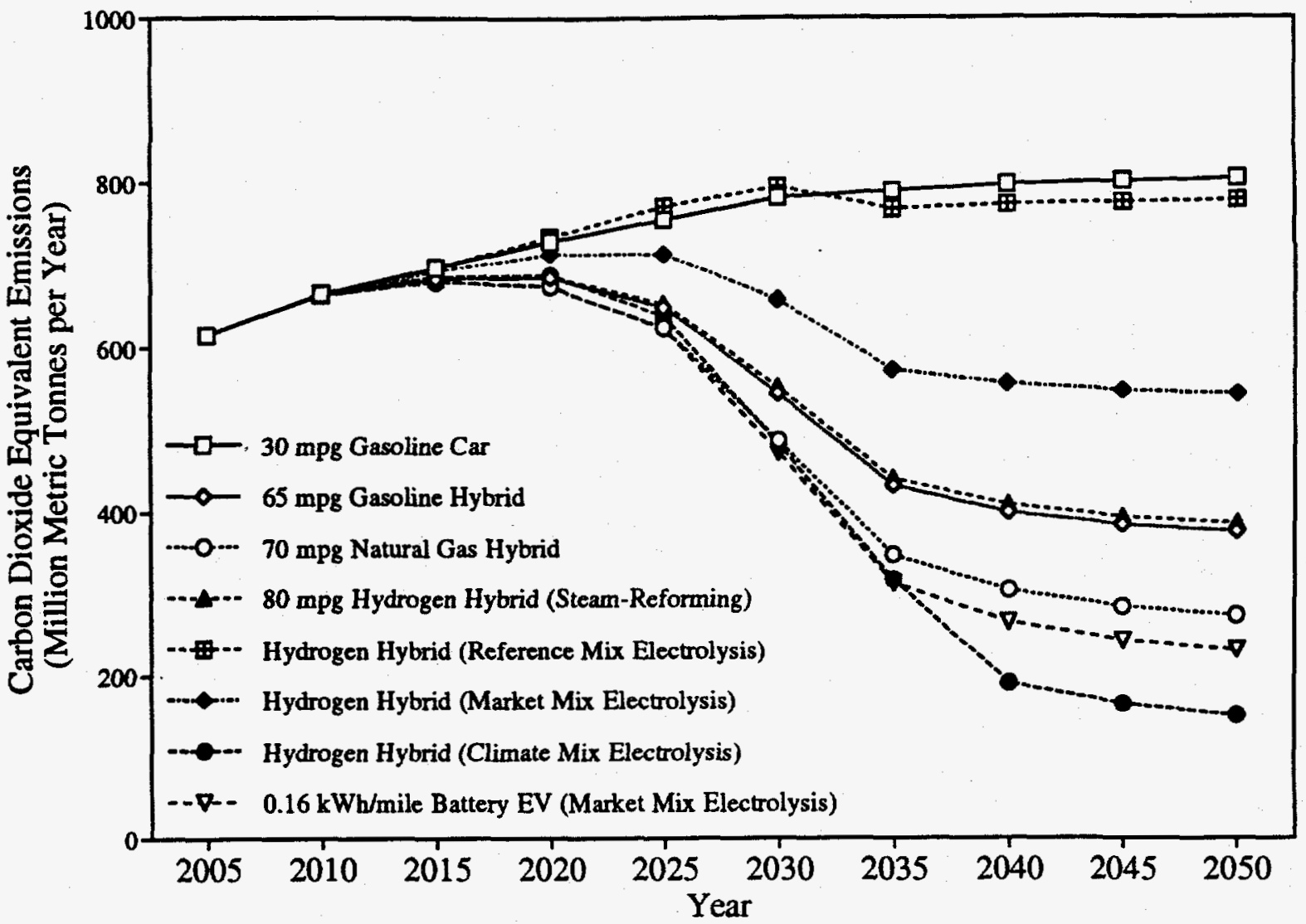

Figure 18(c). Hydrocarbon Emissions Estimates for U.S. Cars (2005-2050)

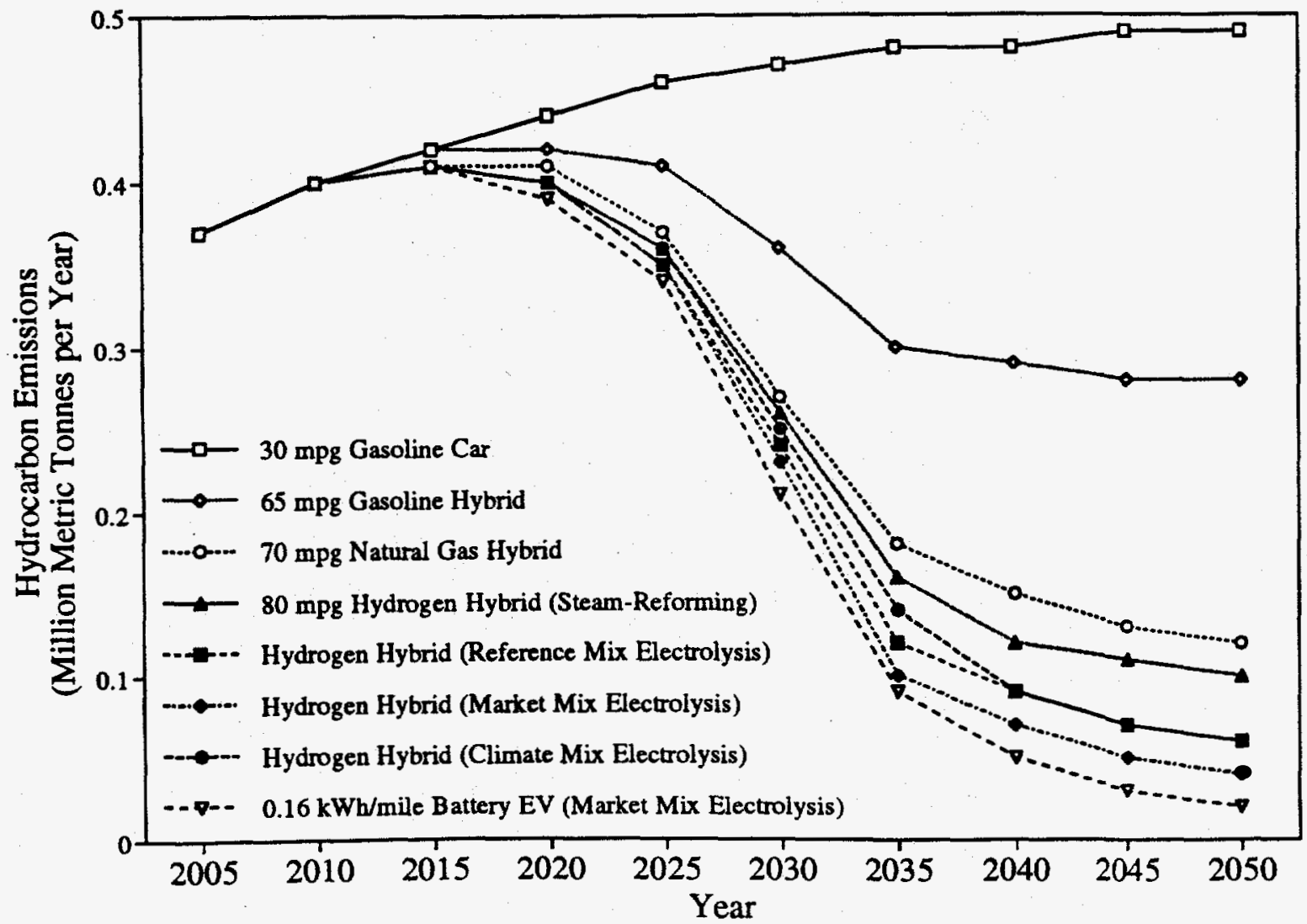


Figure 18(b). Nitrogen Oxide (NOx) Emissions Estimates for U.S. Cars (2005-2050)

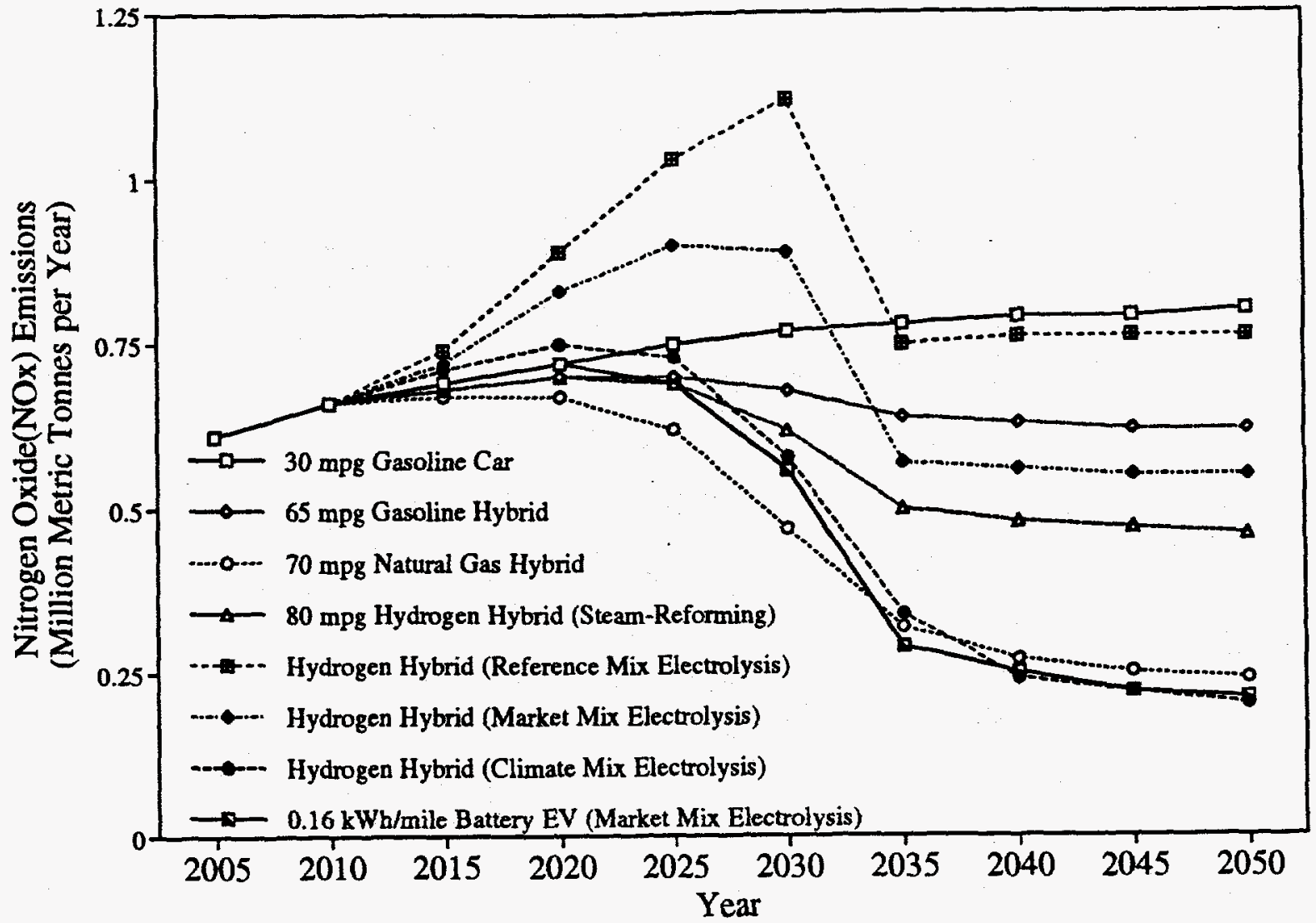

Figure 18(d). Carbon Monoxide (CO) Emissions Estimates for U.S. Cars (2005-2050)

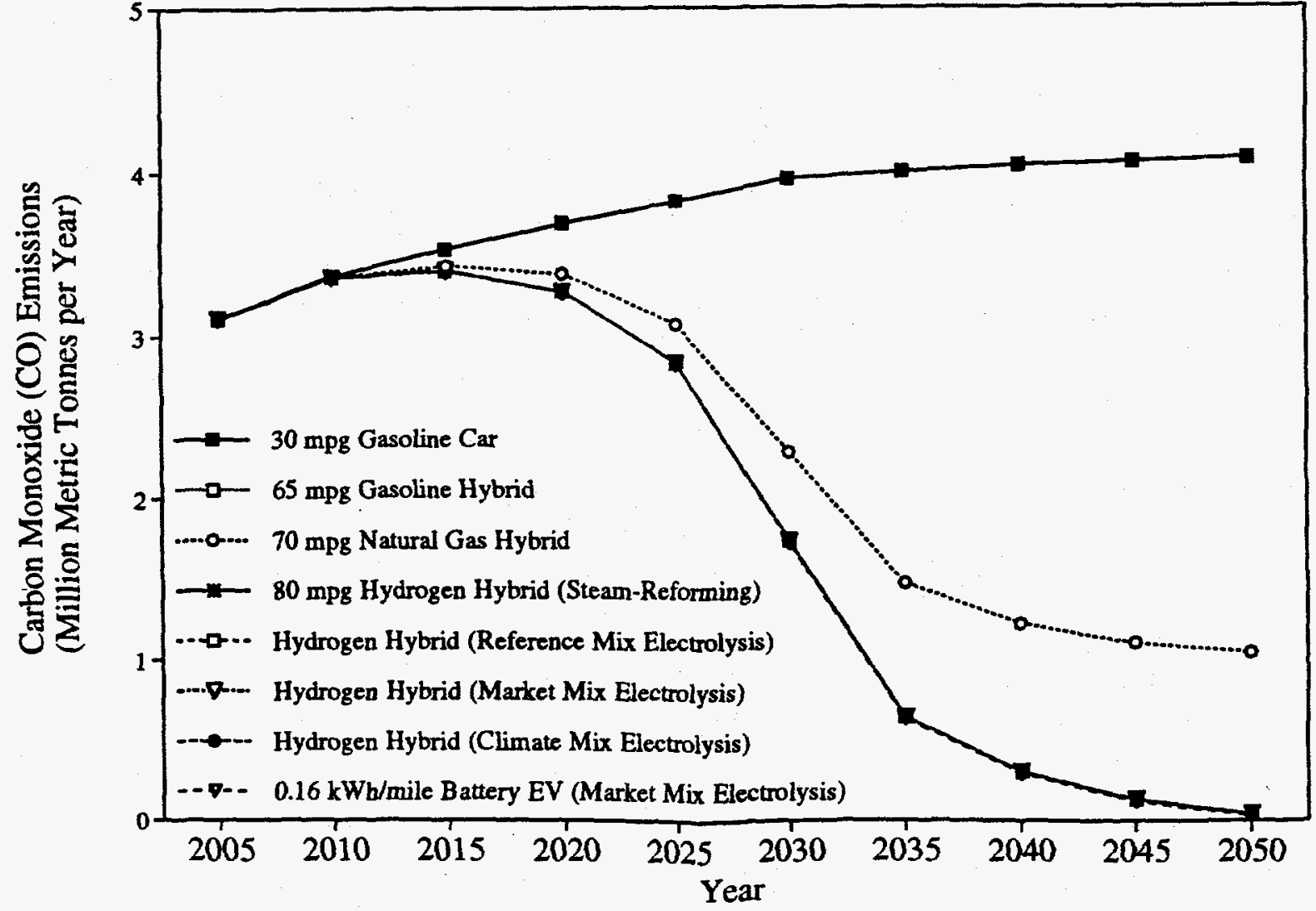


Figure 19 (a-d). Cumulative full-fuel-cycle emissions for U.S. passenger cars over the period 2005-2050 are shown for same eight scenarios presented in Fig. 18, based on the electricity mixes, emissions factors, and passenger car fleet assumptions of Fig. 14, 15-16 and 17, respectively. Figure 19(a) shows that emissions savings of roughly 15 billion tons of $\mathrm{CO}_{2}$-equivalent greenhouse gases through 2050 are achievable by natural-gas HEVs, BPEVs, and electrolytic hydrogen vehicles under a largely non-fossil electric-generating mix (the "climate" mix). Steam-reformed hydrogen vehicles and 65-mpg gasoline HEVs achieve comparable emission reductions. Fossil- intensive electricity mixes limit and possibly eliminate emission reductions with electrolytic hydrogen vehicles over conventional $30-\mathrm{mpg}$ gasoline cars. Figure 19 (b) shows that, in the case of NOx emissions, roughly 12 million metric tons can be saved by 2050 by a transition from $30-\mathrm{mpg}$ gasoline vehicles to naturalgas or hydrogen HEVs, using steam-reformed hydrogen or electrolytic hydrogen under the "climate" electric generation mix. Fossil (particularly coal) electric generation eliminates the potential emission savings of electrolytic hydrogen cars. Figure 19(c) shows that roughly 10 million metric tons of hydrocarbon emissions can be saved by a transition from 30-mpg gasoline vehicles to hydrogen or natural-gas HEVs or to BPEVs, relatively independent of changes in the electricity mix. Figure 19(d) shows that approximately 100 million metric tons of $\mathrm{CO}$ emissions can be eliminated by a transition from gasoline to hydrogen HEVs or BPEVs, but $80 \%$ of these savings can be achieved by natural-gas HEVs. 